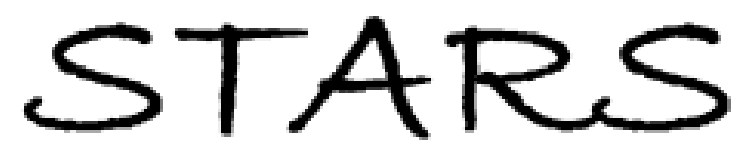

University of Central Florida

STARS

$12-1-2016$

\title{
Energy-Efficient Management Of Mechanical Ventilation And Relative Humidity In Hot-Humid Climates
}

Florida Solar Energy Center

Charles Withers, Jr.

Florida Solar Energy Center, chuck@fsec.ucf.edu

Part of the Energy Systems Commons

Find similar works at: https://stars.library.ucf.edu/fsec

University of Central Florida Libraries http://library.ucf.edu

This Contract Report is brought to you for free and open access by STARS. It has been accepted for inclusion in FSEC Energy Research Center ${ }^{\circledR}$ by an authorized administrator of STARS. For more information, please contact STARS@ucf.edu.

\section{STARS Citation}

Florida Solar Energy Center and Withers, Jr., Charles, "Energy-Efficient Management Of Mechanical Ventilation And Relative Humidity In Hot-Humid Climates" (2016). FSEC Energy Research Center®. 98. https://stars.library.ucf.edu/fsec/98

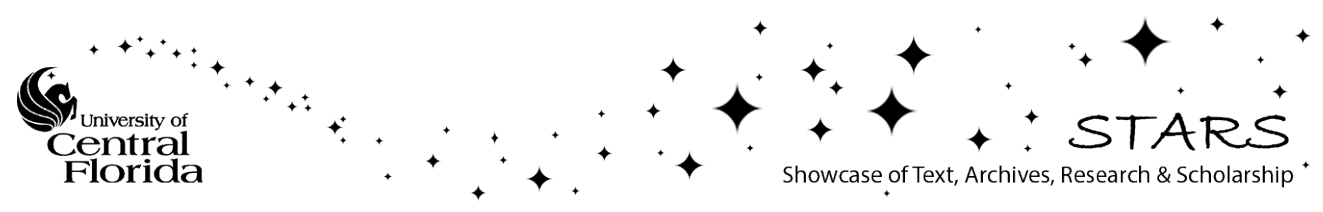




\section{FLORIDA SOLAR ENERGY CENTER \\ Creating Energy Independence}

\section{Energy-Efficient Management of Mechanical Ventilation and Relative Humidity in Hot-Humid Climates}

FSEC-CR-2049-16

December 2016

\section{Authors}

Charles Withers

(C)2016 University of Central Florida. All Rights Reserved.

1679 Clearlake Road

Cocoa, Florida 32922, USA

(321) 638-1000

www.floridaenergycenter.org 


\section{Disclaimer}

The Florida Solar Energy Center/University of Central Florida nor any agency thereof, nor any of their employees, makes any warranty, express or implied, or assumes any legal liability or responsibility for the accuracy, completeness, or usefulness of any information, apparatus, product, or process disclosed, or represents that its use would not infringe privately owned rights. Reference herein to any specific commercial product, process, or service by trade name, trademark, manufacturer, or otherwise does not necessarily constitute or imply its endorsement, recommendation, or favoring by the Florida Solar Energy Center/University of Central Florida or any agency thereof. The views and opinions of authors expressed herein do not necessarily state or reflect those of the Florida Solar Energy Center/University of Central Florida or any agency thereof. 


\section{Energy-Efficient Management of Mechanical Ventilation and Relative Humidity in Hot-Humid Climates}

Charles R. Withers, Jr. Building America Partnership for Improved Residential Construction 


\section{NOTICE}

This report was prepared as an account of work sponsored by an agency of the United States government. Neither the United States government nor any agency thereof, nor any of their employees, subcontractors, or affiliated partners makes any warranty, express or implied, or assumes any legal liability or responsibility for the accuracy, completeness, or usefulness of any information, apparatus, product, or process disclosed, or represents that its use would not infringe privately owned rights. Reference herein to any specific commercial product, process, or service by trade name, trademark, manufacturer, or otherwise does not necessarily constitute or imply its endorsement, recommendation, or favoring by the United States government or any agency thereof. The views and opinions of authors expressed herein do not necessarily state or reflect those of the United States government or any agency thereof.

This report is available at no cost from the National Renewable Energy Laboratory (NREL) at www.nrel.gov/publications.

Available electronically at SciTech Connect http:/www.osti.gov/scitech

Available for a processing fee to U.S. Department of Energy and its contractors, in paper, from:

U.S. Department of Energy

Office of Scientific and Technical Information

P.O. Box 62

Oak Ridge, TN 37831-0062

OSTI http://www.osti.gov

Phone: 865.576.8401

Fax: 865.576.5728

Email: reports@osti.gov

Available for sale to the public, in paper, from:

U.S. Department of Commerce

National Technical Information Service

5301 Shawnee Road

Alexandria, VA 22312

NTIS http://www.ntis.gov

Phone: 800.553 .6847 or 703.605 .6000

Fax: 703.605.6900

Email: orders@ntis.gov 


\section{Energy-Efficient Management of Mechanical Ventilation and Relative Humidity in Hot-Humid Climates}

Prepared for:

The National Renewable Energy Laboratory

On behalf of the U.S. Department of Energy's Building America Program

Office of Energy Efficiency and Renewable Energy

15013 Denver West Parkway

Golden, CO 80401

NREL Contract No. DE-AC36-08GO28308

Prepared by:

Charles R. Withers, Jr.

Building America Partnership for Improved Residential Construction

Florida Solar Energy Center

1679 Clearlake Road

Cocoa, FL 32922

NREL Technical Monitor: Stacey Rothgeb

Prepared under Subcontract No. KNDJ-0-40339-05

December 2016 
The work presented in this report does not represent performance of any product relative to regulated minimum efficiency requirements.

The laboratory and/or field sites used for this work are not certified rating test facilities. The conditions and methods under which products were characterized for this work differ from standard rating conditions, as described.

Because the methods and conditions differ, the reported results are not comparable to rated product performance and should only be used to estimate performance under the measured conditions. 


\section{Contents}

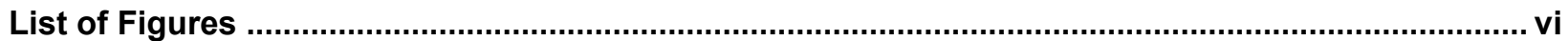

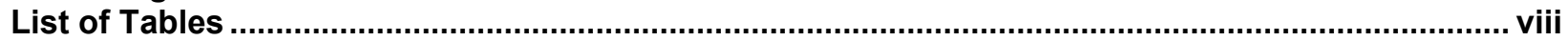

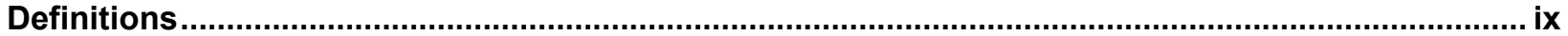

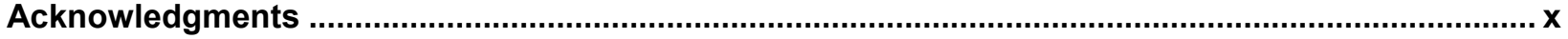

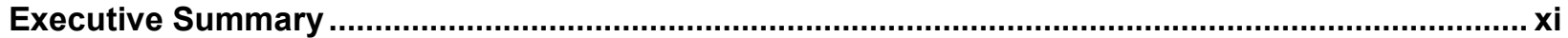

1 Introduction

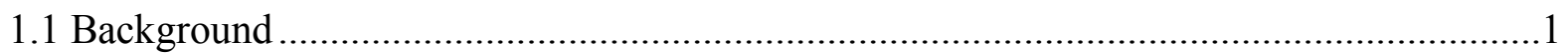

1.2 Relevance to Building America Goals........................................................................2

2 Experiment

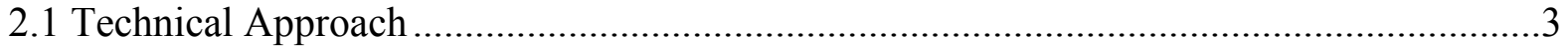

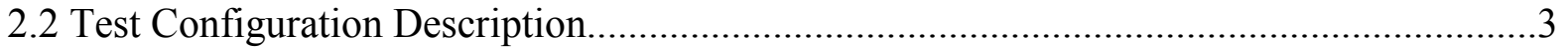

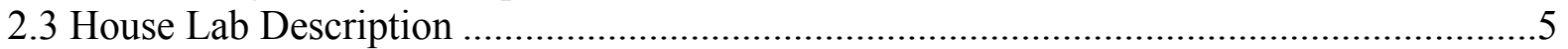

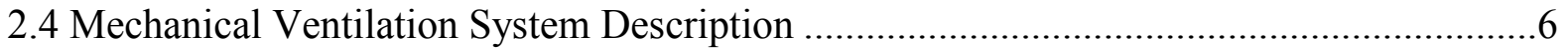

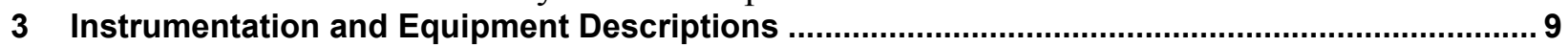

3.1 General Manufactured Housing Laboratory Instrumentation .......................................9

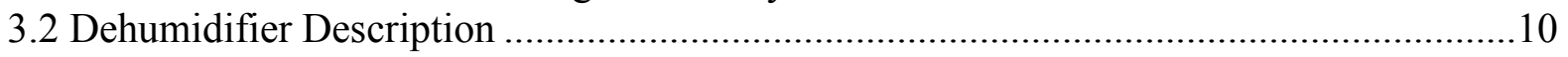

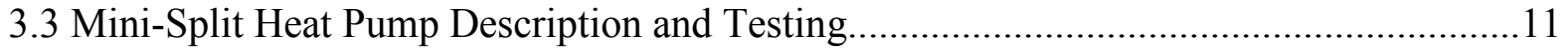

3.4 Building Design Cooling Load and Cooling System Capacities ................................... 14

3.5 Automation of Sensible and Latent Internal Loads ...................................................16

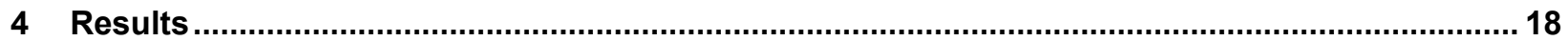

4.1 Cooling and Dehumidification Energy Use ......................................................... 18

4.1.1 Outdoor Air Supplied to Central Return in a Utility Room with the

Dehumidifier Enabled .................................................................................... 18

4.1.2 Outdoor Air Supplied to a Central Living Room Area with Dehumidifier

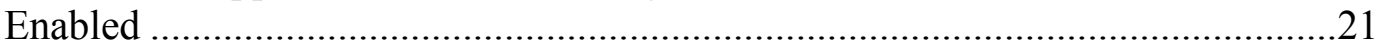

4.1.3 Outdoor Air Supplied to a Central Living Room Area with Mini-Split Heat

Pump Enabled .............................................................................................2.

4.1.4 Seasonal Energy Savings Comparisons ..............................................................26

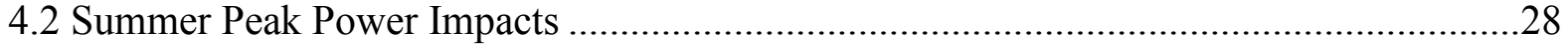

4.3 Indoor Temperature and Humidity Impacts..................................................................29

4.3.1 Temperature Variations with a Ductless Single-Head Mini-Split Heat Pump ......32

4.3.2 Indoor Relative Humidity Variations...................................................................33

4.4 Mini-Split Heat Pump Results in Dry Control Mode under Low Cooling Load...............50

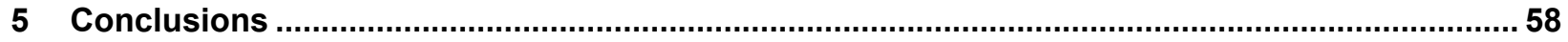

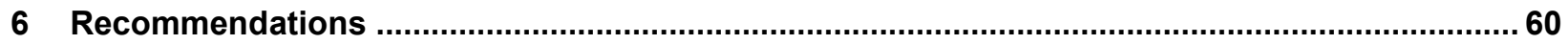

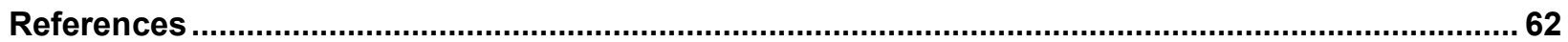

Appendix A: Leaky Nonvented versus Tighter Mechanically Vented Home .....................................64

Appendix B: Utility Room Relative Humidity with Outdoor Air at Central Return ...........................66

Appendix C: Challenges of Supplying Outdoor Air to Small Rooms or Closets ............................. 70 


\section{List of Figures}

Figure ES-1. Daily space-conditioning energy use for a typical summer day with $\mathrm{dT}=5^{\circ} \mathrm{F} \ldots \ldots \ldots . . . . \mathrm{xii}$ Figure 1. Florida Solar Energy Center MH Lab view of north exterior side .....................................5

Figure 2. MH Lab home floor plan showing open central area and three-bedroom/two-bath layout. Blue circles show locations where OA was supplied into home. A green arrow points to the wall area where all thermostat and $\mathrm{RH}$ control was located.

Figure 3. Mechanical ventilation OA is brought into the MH Lab using an in-line fan and measured with a calibrated iris damper. This photo shows the option that delivers the air near the return of the SEER 22 (top) and SEER 13 central systems.

Figure 4. Stand-alone dehumidifier with $O A$ intake plenum constructed on the left side ............... 11

Figure 5. MSHP indoor unit mounted high on the wall in the MH Lab main space. The return air of the unit is enclosed in a plenum with a calibrated flow station. As shown, the OA duct terminates at the intake to the MSHP. It can also be directed to the dehumidifier unit below the MSHP or redirected further into the central space.

Figure 6. TSI Wind Tunnel connected to a temporary test plenum that was used to capture the supply air from the MSHP. The airflow station is located inside the upper return plenum........ 13

Figure 7. MSHP flow calibration data at the four manufacturer fan speed settings ......................... 14

Figure 8. Design cooling load distribution of the main central area, bedrooms, and utility room... 16

Figure 9. Centrally ducted cooling and dehumidifier energy plotted against the daily average dT between outdoors and indoors with OA ducted near the central return ....................................19

Figure 10. Dehumidifier energy, space cooling energy, and outdoor and indoor dew point temperatures at 1-h intervals during a 5-day period in November.

Figure 11. Indoor and outdoor temperat

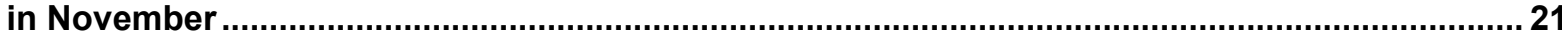

Figure 12. Daily cooling and dehumidifier energy plotted at daily average dT for SEER 13 central system with OA ducted into the living room area at two locations

Figure 13. Daily cooling and dehumidifier energy plotted at daily average dT for SEER 22 central system with OA ducted into the living room area at two locations

Figure 14. Daily cooling and dehumidifier energy plotted at daily average dT for SEER 22 central system with OA ducted into the living room area.................................................................. 24

Figure 15. Daily SEER 13 plus MSHP cooling energy versus daily average dT when OA was supplied to MSHP return intake with MSHP set to economy operational mode......................... 25

Figure 16. Daily SEER 22 plus MSHP cooling energy versus daily average dT when OA was supplied to MSHP return intake with MSHP set to economy operational mode

igure 17. Hourly cooling and dehumidification power versus hourly average dT between

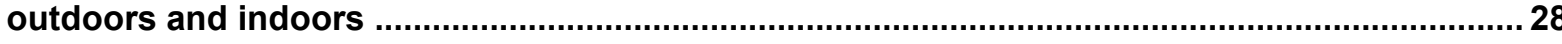

Figure 18. Indoor temperatures, $\mathrm{RHs}$, and space-conditioning runtimes at hourly intervals with OA supplied to SEER 13 return in a utility room ............................................................................ 36

Figure 19. Indoor temperatures, RHs, and space-conditioning runtimes at hourly intervals with OA supplied to SEER 22 return in a utility room ........................................................................ 37

Figure 20. Indoor temperatures, RHs, and space-conditioning runtimes at hourly intervals with OA supplied to the living room and SEER 13 central cooling ....................................................... 38

Figure 21. Indoor temperatures, RHs, and space-conditioning runtimes at hourly intervals with OA supplied to the living room and SEER 22 central cooling ......................................................... 38

Figure 22. Indoor temperatures, RHs, and space-conditioning runtimes at hourly intervals with OA supplied to a dehumidifier in the living room and SEER 13 central cooling ..............................39

Figure 23. Indoor temperatures, RHs, and space-conditioning runtimes at hourly intervals with $\mathrm{OA}$ supplied to a dehumidifier in the living room and SEER 22 central cooling ............................... 39

Figure 24. Indoor temperatures, RHs, and space-conditioning runtimes at hourly intervals with OA supplied to a MSHP in the living room and SEER 13 central secondary cooling.......................40

Figure 25. MSHP delivered cooling rates shown with indoor temperatures and RHs in the living room from September 4-11, 2014, with SEER 13 central secondary cooling ............................ 41

Figure 26. MSHP supply air temperatures plotted against the living room RHs with data at 15-min average intervals from September 4-11, 2014 
Figure 27. MSHP delivered cooling shown with the airflow rates per cooling (CFM/ton) from September 4-11, 2014, with SEER 13 central secondary cooling.

Figure 28. MSHP delivered cooling rates (kBtu/h) versus CFM/ton at five flow rates show distinct linear patterns depending upon the airflow rate

Figure 29. Indoor RH (living room) versus MSHP CFM/ton for September 4-11, 2014................... 44

Figure 30. Indoor RH (living room) versus MSHP CFM/ton during $17 \mathrm{~h}$ in September at a constant airflow rate of $300 \mathrm{CFM}$

Figure 31. Indoor temperatures, RHs, and space-conditioning runtimes at hourly intervals with $O A$ supplied to an MSHP in the living room and SEER 22 central cooling...

Figure 32. Indoor temperatures, RHs, and space-conditioning runtimes at hourly intervals with OA supplied to a MSHP in the living room with a very low cooling load on December 8, 2014 ...... 48

Figure 33. MSHP delivered cooling rates and supply air temperatures shown with the living room temperatures and RHs on 2 very low cooling load days December 7-8, 2014

Figure 34. MSHP delivered cooling shown with the airflow rates per delivered cooling (CFM/ton) during very low cooling loads from December 7-8, 2014.

Figure 35. Condensate latent heat rates evaporated from the MSHP cooling coil shown with elapsed times from the end of the previous cooling cycle

Figure 36. Indoor temperatures, RHs, and space-conditioning runtimes at hourly intervals with OA supplied to an MSHP operated in dry mode and SEER 13 central cooling. 51

Figure 37. MSHP in dry mode showing delivered cooling rate with indoor temperatures and RHs in the living room from December 27-January 4 ............................................................................52

Figure 38. MSHP in dry mode showing delivered cooling and the airflow rate per cooling (CFM/ton) from December 27-January 4 .

Figure 39. Two days (January 1 and 2, 2015) showing cooling output, supply temperature, indoor temperature, and $\mathrm{RH}$ with low cooling load while the MSHP operated in dry control mode......54

Figure 40. Two days (January 1 and 2, 2015) showing MSHP cooling output and CFM/ton with low cooling load while the MSHP operated in dry control mode

Figure 41. MSHP dry mode cooling output and SHR on January 1 and 2, $2015 \ldots \ldots \ldots \ldots \ldots \ldots \ldots \ldots . \ldots . \ldots \ldots$

Figure 42. MSHP dry mode latent heat removal from air and SHR .............................................55

Figure 43. MSHP dry mode SHR and resulting indoor living room RH ......................................55

Figure 44. Daily SEER 13 plus MSHP cooling energies versus daily average dT when OA was

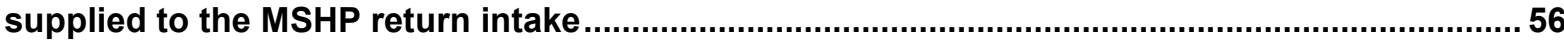

Figure A-1. Daily total cooling and dehumidifier energy plotted against the daily average dT between outdoors and indoors shown for the house lab with and without $O A$

Figure B-1. Indoor conditions comparing a sunny summer to a low solar summer day with OA delivered at SEER 13 central return in the utility room

Figure B-2. Indoor conditions comparing a sunny summer day to a low solar summer day with OA delivered at SEER 22 central return in the utility room .........................................................68

Figure B-3. Indoor RHs and space-conditioning runtimes with OA supplied at SEER 22 central return in utility room when outdoor dew point was $69^{\circ} \mathrm{F} \mathrm{dp}$ and with low solar radiation on November 23, 2014

Figure C-1. Process of mixing $55 \mathrm{CFM}$ humid OA with moist $750 \mathrm{CFM}$ indoor air with both at $75^{\circ} \mathrm{F}$ dry bulb results in a mixture at about $63.5 \% \mathrm{RH}$

Unless otherwise noted, all figures were created by Building America Partnership for Improved Residential Construction. 


\section{List of Tables}

Table 1. Lab Test Configurations 4

Table 2. Lab Testing and Monitoring Equipment Used in the Experiments .................................... 10

Table 3. Daily Space Conditioning Energy for a Typical Summer Day with $\mathrm{dT}=5^{\circ} \mathrm{F}$ for SEER 13 and SEER 22 Ducted Systems with OA Supplied to Different Locations

Table 4. Daily Space Conditioning Energy for a Typical Summer Day with dT $=5^{\circ} \mathrm{F}$ Comparing Results Based on OA Location and Dehumidification Method with SEER13 Central System... 27

Table 5. Daily Space Conditioning Energy for a Typical Summer Day with $\mathrm{dT}=5^{\circ} \mathrm{F}$ Comparing Results Based on OA Location and Dehumidification Method with SEER 22 Central System.. 27

Table 6. Predicted Peak Cooling and Dehumidification Power for Summer Peak Hour at $\mathrm{dT}=15^{\circ} \mathrm{F} 28$

Table 7. Daily Average Indoor Temperatures and RH When Outdoor Dew Point Temperature Was $70^{\circ} \mathrm{F}$ or Higher ....

Table 8. Frequency of Elevated Indoor RH When Outdoor Dew Point Is 70 ${ }^{\circ} \mathrm{F}$ or Greater...................34

Table 9. Indoor RH and MSHP Performance Data during High and Lower Indoor RH Periods ......... 46

Table C-1. Daily Average Indoor RH Comparison between Utility Room with OA Supply and Average of Three Other Indoor Locations during Different Types of Weather ...........................71

Table C-2. Indoor Airflow Rate Required To Produce a Mixture with OA at $60 \%$ RH and $55 \% \mathbf{R H}^{*} .72$

Table C-3. Resulting RH for Two Moist Indoor Air Mix Rates at $75^{\circ} \mathrm{F}$ and $60.6^{\circ} \mathrm{F} \mathrm{dp}$ When Mixed with $\mathrm{OA}$ at $55 \mathrm{CFM}$ at $75^{\circ} \mathrm{F}$ and $75^{\circ} \mathrm{F} \mathrm{dp}$.

Unless otherwise noted, all tables were created by Building America Partnership for Improved Residential Construction. 


\section{Definitions}

$\mathrm{ACH} \quad$ Air changes per hour

AHU Air handling unit

$\mathrm{Btu} / \mathrm{h} \quad$ British thermal units per hour

CFM Cubic feet per minute; a measure of volumetric airflow

dp Dew point; a measure of air temperature at which condensation occurs

dT Differential temperature; difference between outside and inside

EER Energy-efficiency ratio

HVAC Heating, ventilating, and air conditioning

Latent Load Portion of cooling load related to removing water vapor from air

OA Outside air delivered indoors by mechanical equipment for ventilation

RH Relative humidity

SEER Seasonal energy-efficiency ratio

SEER 13 Fixed-capacity heat pump with cooling efficiency rating of SEER13

SEER 22 Variable-capacity heat pump with cooling efficiency rating of SEER 22

SHR Sensible heat ratio; fraction of cooling energy related to lowering the dry bulb temperature of air

TMY Typical Meteorological Year

Ton Cooling capacity equal to $12,000 \mathrm{Btu} / \mathrm{h}$ 


\section{Acknowledgments}

The author gratefully acknowledges project support from David Hoak, who set up and calibrated lab instrumentation, kept experiments running smoothly, and completed test changeovers. Thanks to John Sherwin who installed the ductless mini-split and to Eric Martin and Wanda Dutton for report editing. We are thankful to the National Renewable Energy Laboratory team for support and input of this research within the U.S. Department of Energy Building America Program. 


\section{Executive Summary}

In the past, most homes received their ventilation passively via infiltration and open windows. New homes are becoming increasingly tighter and mechanical ventilation is becoming more widely mandated by residential codes such as the International Energy Conservation Code (ICC 2012a). During hot and humid weather, ventilation introduces latent load, which tends to increase indoor relative humidity $(\mathrm{RH})$. In hot-humid climates, it is challenging to meet indoor $\mathrm{RH}$ targets and simultaneously provide the required outside air (OA) ventilation in an energyefficient manner, particularly in high-performance low-cooling-load homes. Elevated indoor RH may increase the potential for indoor environmental quality problems, building degradation, and occupant discomfort.

The fundamental problem with relying solely on fixed-capacity central cooling systems to manage moisture during low sensible load periods is that the systems are oversized for cooler periods of the year-despite being "properly sized" for a very hot design cooling day. This reliance results in shorter runtimes during low cooling load periods and less dehumidification. Standard dehumidifiers are commonly used for supplemental dehumidification and effectively control RH in an appropriate application. However, they are not the most energy-efficient method of controlling humidity during the cooling season.

The U.S. Department of Energy's Building America research team Building America Partnership for Improved Residential Construction conducted this research project to gain data and insight into these issues. The project focused on energy-efficient management of mechanical ventilation and RH during the cooling season. It consisted of eight test configurations. A particular focus evaluated how well a ductless seasonal energy-efficiency ratio (SEER) 21.5 mini-split heat pump (MSHP) could perform as the primary cooling system without a dehumidifier for supplemental dehumidification in a continuously mechanically ventilated house.

The team conducted testing to compare a fixed-capacity SEER 13 centrally ducted system configuration to a variable-capacity SEER 22 central-ducted system with humidity control mode. The MSHP tests were operated with the MSHP as the primary space conditioner, which was set a few degrees cooler than the centrally ducted SEER 22 or SEER 13 system. The centrally ducted systems were used with a fan circulation schedule to improve air circulation and provided cooling only when the MSHP could not keep up with the cooling load.

The tests were completed in a furnished three-bedroom lab home that was continuously ventilated in accordance with ASHRAE 62.2-2013. This home was unoccupied during testing but had internal sensible and latent loads that were simulated to mimic occupancy similar to that of a three- or four-person family.

The MSHP configurations used the least seasonal and peak demand energy; they usually provided reasonable thermal distribution and adequate RH control. The daily energy results for a typical summer day with an average outdoor temperature of $81^{\circ} \mathrm{F}$ and indoor temperature of $76^{\circ} \mathrm{F}$ are shown in Figure ES-1. The MSHP/SEER 13 central combination had the greatest seasonal and peak demand savings compared to the SEER 13 with OA delivered near a dehumidifier test. Seasonal savings were $6.1 \mathrm{kWh} /$ day $(24.8 \%)$ and summer peak demand reduction was $0.55 \mathrm{~kW}(27 \%)$. The dehumidifier did not operate during peak summer hours for 
any of the test configurations; therefore, the peak summer power impacts were due to cooling energy reduction.

When using a minimum-efficiency SEER 13 central system, the cost increase from replacing an ENERGY STAR ${ }^{\circledR}$ dehumidifier controlled by remote dehumidisat with a SEER 21.5 MSHP is about $\$ 2,400$. The cost difference could be less if special construction is required to accommodate the dehumidifier. The variable-capacity MSHP had long runtimes that averaged about $95 \%$ on summer days. Long runtimes increase OA mixing and improve thermal distribution.

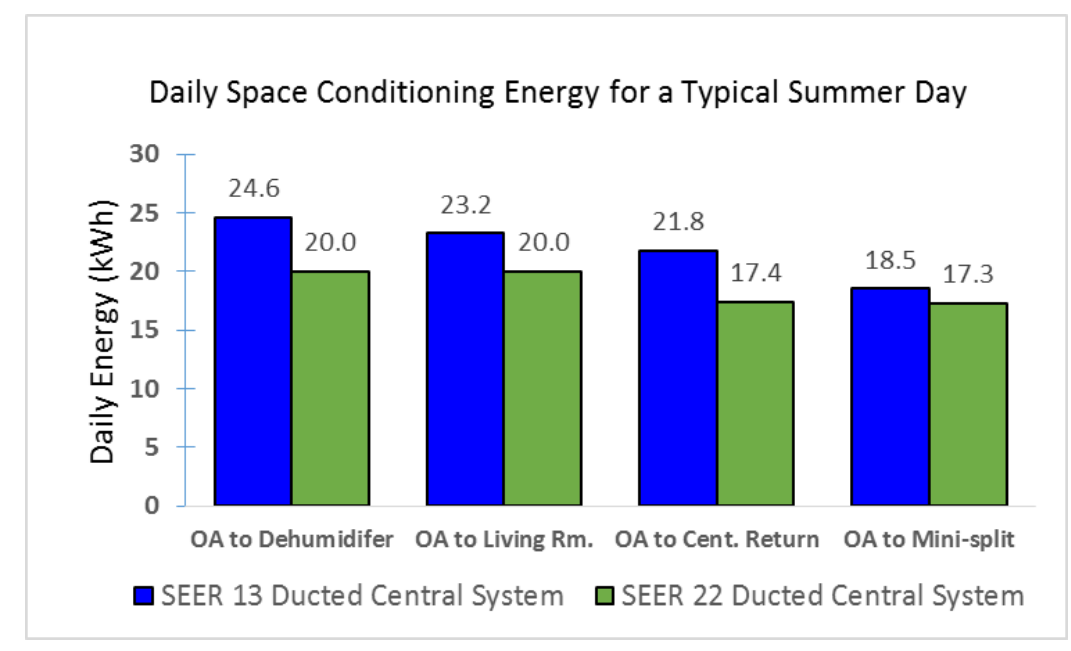

Figure ES-1. Daily space-conditioning energy use for a typical summer day with $d T=5^{\circ} \mathrm{F}$

The dehumidifier typically operated only occasionally from about 2 a.m. to 9 a.m. during normal summer weather. The dehumidifier energy represented less than $1 \%$ of the daily total conditioning energy on hot and humid days and averaged about $9 \%$ on low cooling load days. The average dehumidifier runtime was less than $0.1 \%$ on average summer days for SEER 13 configurations with the dehumidifier enabled. The dehumidifier runtime averaged about $2.5 \%$ on average summer days for SEER 22 configurations with the dehumidifier enabled at $60 \% \mathrm{RH}$. On days when the dehumidifier operated, it used $0.5-0.9 \mathrm{kWh} /$ day.

$\mathrm{RH}$ control was evaluated based on maintaining indoor conditions lower than $60 \%$. The dehumidifier test configurations demonstrated the ability to maintain indoor RH below $60 \%$ except in the utility room when OA was delivered near the centrally ducted returns in this room. When $\mathrm{RH}$ exceeded $60 \%$, it usually remained at $60 \%-65 \%$; no moisture issues were observed during testing.

This study was not intended to evaluate a worst-case scenario for dehumidifiers that would most likely result in high dehumidifier energy consumption. The dehumidifier was installed with a remote dehumidistat away from the OA supply location in the central living room area to enable dehumidifier operation based on RH in a large representative zone of the home with a single sensor-based control. It is similar to how centrally ducted cooling systems are controlled by a single thermostat. This design minimized dehumidifier operation by eliminating the direct impact of high RH in the OA upon the RH control. 
As tested, the dehumidifier consumed a very small proportion of the total energy used for space cooling and dehumidification. However, a dehumidifier's location and control can cause excessive dehumidifier energy use. For example, dehumidifier energy use had the potential to be around 12 times greater than measured in this study if the dehumidifier and its control were placed in an enclosed area — such as a closet—with OA delivered to it. Typical Meteorological Year data show that outdoor RH exceeded $60 \%$ for about $80 \%$ of the annual hours in hot-humid climates, which could result in $80 \%$ dehumidifier runtime.

The MSHP configurations were initially expected to be able to maintain indoor RH lower than $60 \%$ based on temperature control only, because the manufacturer data indicated that the variable-capacity system could cool 3,100-18,400 Btu/h. This range was well-suited to provide low cooling output during very low load periods. During most summer days, the MSHP maintained acceptable humidity levels; however, it tended to drift toward the $60 \% \mathrm{RH}$ level during the early morning hours and then maintained $\mathrm{RH}$ in the mid-50\% range from 12 p.m. to 12 a.m. On days with low cooling load and outdoor dew points (dp) above $60^{\circ} \mathrm{F} \mathrm{dp}$, the average indoor RH exceeded $60 \%$ at a frequency of $65 \%$ during all hours within a 2-day period with the MSHP in standard control mode. Operating the MSHP in its dry improved RH control mode significantly reduced the frequency of RH higher than $60 \%$ to $15 \%$ of all hours during a 9 -day low cooling load period.

Standard or economy control modes that operate for periods at more than $400 \mathrm{CFM} /$ ton improve sensible cooling efficiency and are well-suited for drier cooling climates; however, they are not desirable for good RH control in hot-humid climates - especially during low cooling load conditions.

The humidity control for variable-capacity cooling systems using dry or RH control modes in humid climate regions could be improved by:

- Limiting maximum real-time operational CFM/ton to $400 \mathrm{CFM} /$ ton or less and increasing the time at rates closer to $250 \mathrm{CFM} /$ ton during low load conditions.

- Enabling operation at the lowest cooling capacity for prolonged periods to increase runtime and dehumidification during very low load periods. Limiting CFM/ton during this stage will improve moisture removal and limit overcooling.

- Eliminating indoor unit fan-on circulation for at least 15-20 min after the cooling cycle. 


\section{Introduction}

\subsection{Background}

In the past, most homes received their ventilation passively via infiltration and open windows. New homes are becoming increasingly tighter and mechanical ventilation is becoming more widely mandated by residential codes such as the International Energy Conservation Code (ICC 2012a). During hot and humid weather ventilation introduces latent load, which tends to increase indoor relative humidity $(\mathrm{RH})$. In hot-humid climates, meeting indoor RH targets and simultaneously providing the required ventilation is challenging. The fundamental problem with relying solely on central cooling systems to manage moisture during low sensible load periods is that they are oversized for cooler periods of the year despite being "properly sized" for a very hot design cooling day. Air conditioning relies on cooling set points that are set lower than the room temperature. Lowering the cooling set point during cooler weather increases runtime somewhat, but ultimately the space can become overcooled and runtime is not adequate to remove much moisture from the air. This low set point can cause cool humid (cave-like) and uncomfortable conditions.

Martin et al. (2014) conducted a study of occupied mechanically ventilated homes in Florida without supplemental dehumidification. They found indoor RH levels that exceeded $60 \%$ for significant periods of time. Six homes in north-central Florida with continuous exhaust ventilation had indoor RH that exceeded $60 \%$ at an average frequency of $27 \%$ of all hours evaluated through one summer period in 2013. The exhaust flow rates averaged about $60 \mathrm{CFM}$ and were close to what ASHRAE 62.2-2010 would have required. The homes did not report having supplemental dehumidification. They were of newer construction, met the U.S. Department of Energy's Builders Challenge 1.0 requirements, and had a Home Energy Rating System Index less than 65 .

A variety of other studies, which primarily used modeling, determined that supplemental dehumidification is required to meet RH control targets when ventilation is supplied at ASHRAE 62.2 levels (Rudd et al. 2013; Rudd and Henderson 2007; Walker and Sherman 2007). Dehumidifiers can effectively control indoor RH but at lower efficiency than air conditioners. Dehumidifiers that short-cycle or that employ fan run-on at the end of cycles operate very inefficiently (Winkler et al. 2014). Many of the most energy-efficient dehumidifiers operate at negative cooling efficiency (energy-efficiency ratio [EER] of -3.4) because the refrigerant heat is discharged into the space.

Preliminary research demonstrated the potential for ductless mini-split heat pumps (MSHPs) to condition mechanical ventilation and indoor air to effectively manage indoor RH during hot and humid weather (Withers and Sonne 2014). These authors found that hourly indoor RH was managed at $45 \%-51 \%$ on warm days that had an outdoor dew point (dp) of at least $68^{\circ} \mathrm{F}$ dp. The earlier study was short and could only evaluate days with moderate to high cooling loads in a high mass building; that study could not evaluate indoor RH control on low cooling demand with high OA latent loads.

The U.S. Department of Energy's Building America research team Building America Partnership for Improved Residential Construction focused primarily on an efficient ductless variablecapacity MSHP to condition ventilation air and to provide the bulk of the general space- 
conditioning needs. The anticipated benefits of this approach were to reduce energy use and maintain acceptable RH control compared to centrally ducted cooling systems with separate dehumidifier RH control. The reasons for the expected benefits include:

- Excellent $\mathrm{RH}$ control due to delivery of cold supply air —often $45^{\circ}-55^{\circ} \mathrm{F}$ depending on the mode of operation and long runtimes.

- The best MSHPs have variable capacity and higher seasonal energy-efficiency ratio (SEER) ratings than the best centrally ducted systems.

- Because of conductive and air leakage duct losses, ducted systems often lose $25 \%-30 \%$ of their capacity and efficiency; ductless MSHPs avoid these losses.

- Use of an MSHP to displace lower-efficiency operation of a central system is by itself a cost-effective energy retrofit - apart from obviating dehumidifier operation energy waste.

- If an MSHP operates as the primary system and has a central system as the backup, it can effectively condition ventilation air and control indoor RH. Substantial or even dramatic energy savings can thus be achieved.

\subsection{Relevance to Building America Goals}

Integrating effective mechanical ventilation and indoor humidity control into well-engineered homes is critical to the overall goal of the Building America program. Such integration involves reducing energy use up to $50 \%$ compared to 2009 energy codes for new homes and goals of $40 \%$ (pre-post) energy savings in existing homes by 2030. The program also has goals of increasing comfort, safety, and durability.

Ventilation air is an important part of maintaining good indoor air quality by diluting concentrations of indoor air pollutants; however, ventilation during hot and humid conditions results in added latent heat (moisture) that must be removed to control indoor RH. Highefficiency envelopes in hot-humid climates reduce sensible cooling loads and result in reduced space-conditioning runtime, which reduces incidental dehumidification. At the same time, the mechanical ventilation is continuously adding moisture that must be removed. Therefore, effective humidity control is also becoming increasingly important to maintain good indoor air quality, comfort, and durability in high-performance housing. 


\section{Experiment}

This project was carried out during a period covering late spring through early winter. In central Florida this period tends to have weather conditions that vary between warm dry, warm moist, hot moist, cool moist, and cool/cold dry (short heating periods). The warm/hot moist conditions dominate weather between June and September. Days with low cooling load and high moisture content occur more sporadically and less predictably because of summer thunderstorm and tropical storm patterns. Because limited time was available for this study, the number of test configurations that could be evaluated under a representative range of space cooling weather conditions was limited. Each test configuration provided continuous mechanical ventilation according to ASHRAE 62.2-2013 in a supply delivery design.

\subsection{Technical Approach}

The following research questions were to be answered as part of this task:

1. What space RH and measured cooling season energy use/demand result from operating centrally ducted, fixed-capacity SEER 13 and centrally ducted variable-capacity SEER 22 systems with supplemental dehumidification when ASHRAE Standard 62.2-2013 ventilation is introduced?

2. What energy and demand savings and $\mathrm{RH}$ outcomes result from operating a ductless MSHP as the primary cooling system with ducted central SEER 13 and central SEER 22 as secondary systems, with ventilation introduced near the MSHP return intake?

3. What is the impact on space $\mathrm{RH}$ and energy/demand when ventilation air is introduced directly into the central living room space versus delivery near the centrally ducted system's return intake?

Experiments were conducted in the Manufactured Housing (MH) Lab (Figure 1 in Section 2.3) at the Florida Solar Energy Center. Occupancy was simulated with added sensible and latent heat that was controlled by automation schedules. More than 100 channels of data were used to characterize indoor and outdoor temperatures, RH, solar radiation, system airflows, condensate, and energy consumption for about 7 months to obtain a variety of seasonal data. Various approaches to conditioning ventilation air and controlling indoor temperature and $\mathrm{RH}$ were explored, and the ability of the various heating, ventilating, and air-conditioning (HVAC) configurations to energy-efficiently control indoor temperature and $\mathrm{RH}$ were examined.

Tests were run either with a dehumidifier that was enabled to operate at $60 \% \mathrm{RH}$ by a remote wall dehumidistat control or with a ductless MSHP controlled only by temperature. The dehumidifier and MSHP were located near each other in the living room area, and only one was enabled at a time. The locations of these are labeled in Figure 2 (Section 2.3). Evaluation of other ventilation and dehumidification methods would be valuable but could not be fit into this time period.

\subsection{Test Configuration Description}

A test plan was developed and reviewed that included eight test configurations to be evaluated. In an effort to acquire as much data under varying weather conditions as possible for each test configuration, each configuration had to be rotated throughout the project period. Table 1 lists the experimental test configurations that were cycled through approximately every 10 days 
depending upon weather conditions. Testing was conducted to compare low-efficiency configurations (SEER 13 system with dehumidifier) to higher-efficiency configurations (SEER 22 and SEER 13 systems with MSHP). The SEER 22 system was operated using the manufacturer's RH control mode and is noted as SEER $22(\mathrm{RH})$ in Table 1. The tests were rotated approximately every 10 days so each test could operate under different weather conditions.

Table 1. Lab Test Configurations

\begin{tabular}{c|c|c|c}
\hline $\begin{array}{c}\text { Centrally } \\
\text { Ducted } \\
\text { System Used }\end{array}$ & $\begin{array}{c}\text { Test Configurations OA } \\
\text { Supply Location }\end{array}$ & $\begin{array}{c}\text { Dehumidifier } \\
\text { Operational } \\
\text { Status }\end{array}$ & $\begin{array}{c}\text { MSHP } \\
\text { Operational } \\
\text { Status }\end{array}$ \\
\hline SEER 13 & To MSHP return in living room & OFF & ON \\
SEER 13 & To dehumidifier return in living room & ON & OFF \\
SEER 13 & To SEER 13 central return & ON & OFF \\
SEER 22 (RH) & To MSHP return in living room & OFF & ON \\
SEER 22 (RH) & To dehumidifier return in living room & ON & OFF \\
SEER 22 $(\mathbf{R H})$ & To SEER 22 central return & ON & OFF \\
SEER 22 $(\mathbf{R H})$ & To central zone living room & ON & OFF \\
SEER 13 & To central zone living room & ON & OFF \\
\hline
\end{tabular}

At the time of experimental test planning, it was not known how much the dehumidifier would operate. Significant periods of dehumidifier operation were anticipated, particularly during low cooling load periods. The OA direct-to-dehumidifier configuration was arranged to be similar to the OA direct-to-MSHP test configuration such that OA could be dehumidified then delivered into to the living room when the dehumidifier operated. If the dehumidifier did not operate, the OA passed into the living room unconditioned.

In two test configurations the $\mathrm{OA}$ was delivered to the living room and the dehumidifier was enabled. The primary difference between these two configurations is that the unconditioned OA was supplied directly to an intake capture plenum at the dehumidifier in one; in the other, OA was supplied directly into the living room. The OA termination location of these two tests occurred in the same living room area except at different heights. In one configuration the OA was ducted directly to the dehumidifier about $4 \mathrm{ft}$ above the floor instead of being supplied directly into the living room $7 \mathrm{ft}$ above the floor. The remote humidity control for the dehumidifier remained at the same location on the living room wall for all dehumidifier test configurations.

The MSHP also had a dry RH control mode that was designed for better humidity control and operated within a much more limited cooling capacity. The dry mode was still controlled only by the thermostat set point without any RH-based control. Manufacturer data on this mode were very limited and indicated only that it operated at "low speed" but did not indicate its operational cooling capacity. Therefore, this mode was not used in the main test configurations during the hot summer weather. A better understanding about how the dry mode operated was not realized until after the system was run. A ninth test configuration in dry mode was added late in the project during a very low cooling load period, December into January, to evaluate the dry control mode of the MSHP under challenging RH control conditions. 


\subsection{House Lab Description}

The MH Lab is a $1600-\mathrm{ft}^{2}$ double-wide manufactured home with an unvented crawl space, R-19 floor insulation, a vented attic with at least R-30 insulation on the ceiling, woodframe wall construction with R-19 insulation, three bedrooms, two bathrooms, and a large open central area. The floor plan is shown in Figure 2. The centrally ducted air handling units (AHUs) were installed in the utility room area. A ductless MSHP head unit (indoor fan and evaporator coil) and a stand-alone dehumidifier were placed in the living room area.

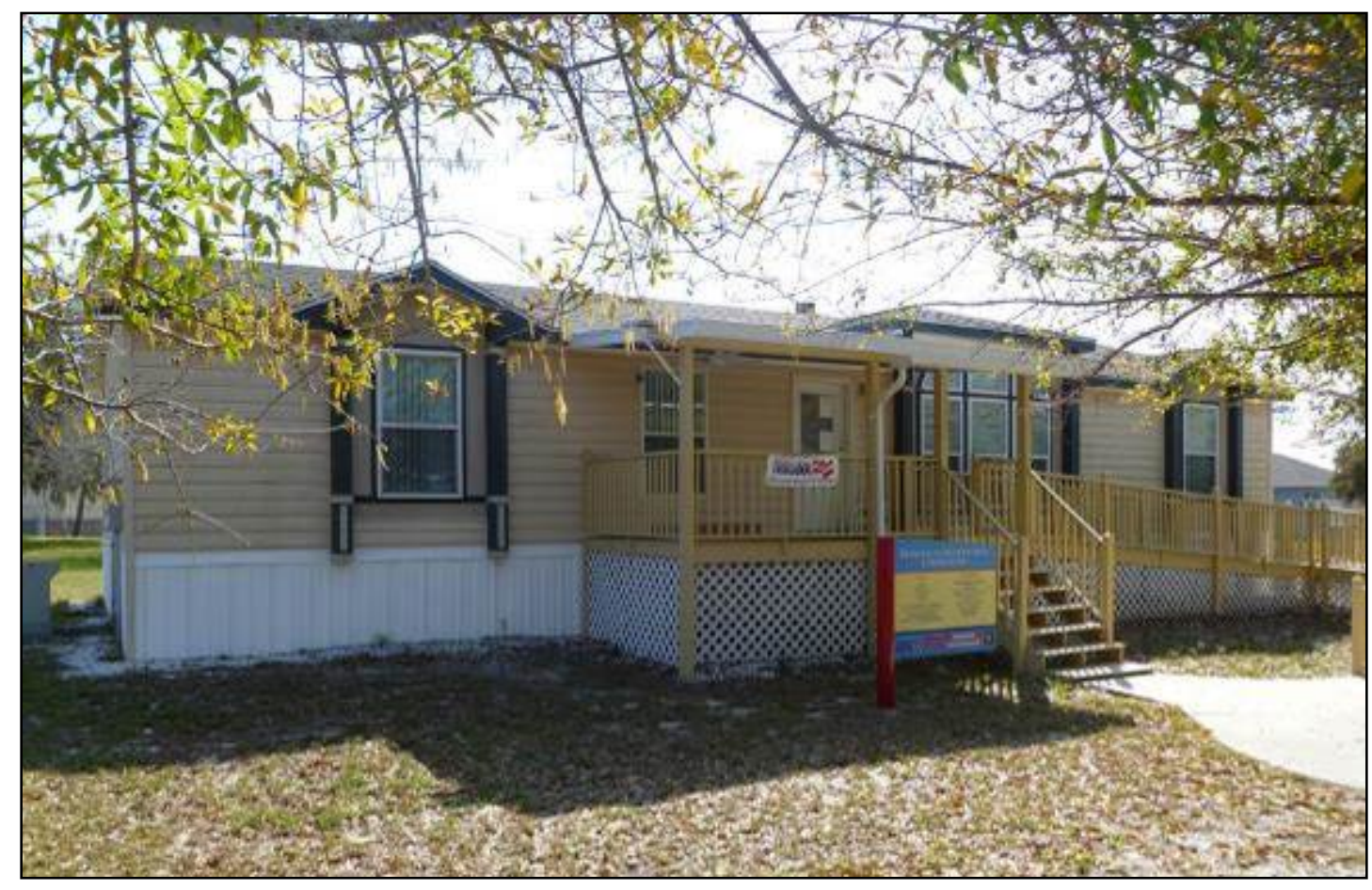

Figure 1. Florida Solar Energy Center MH Lab view of north exterior side 


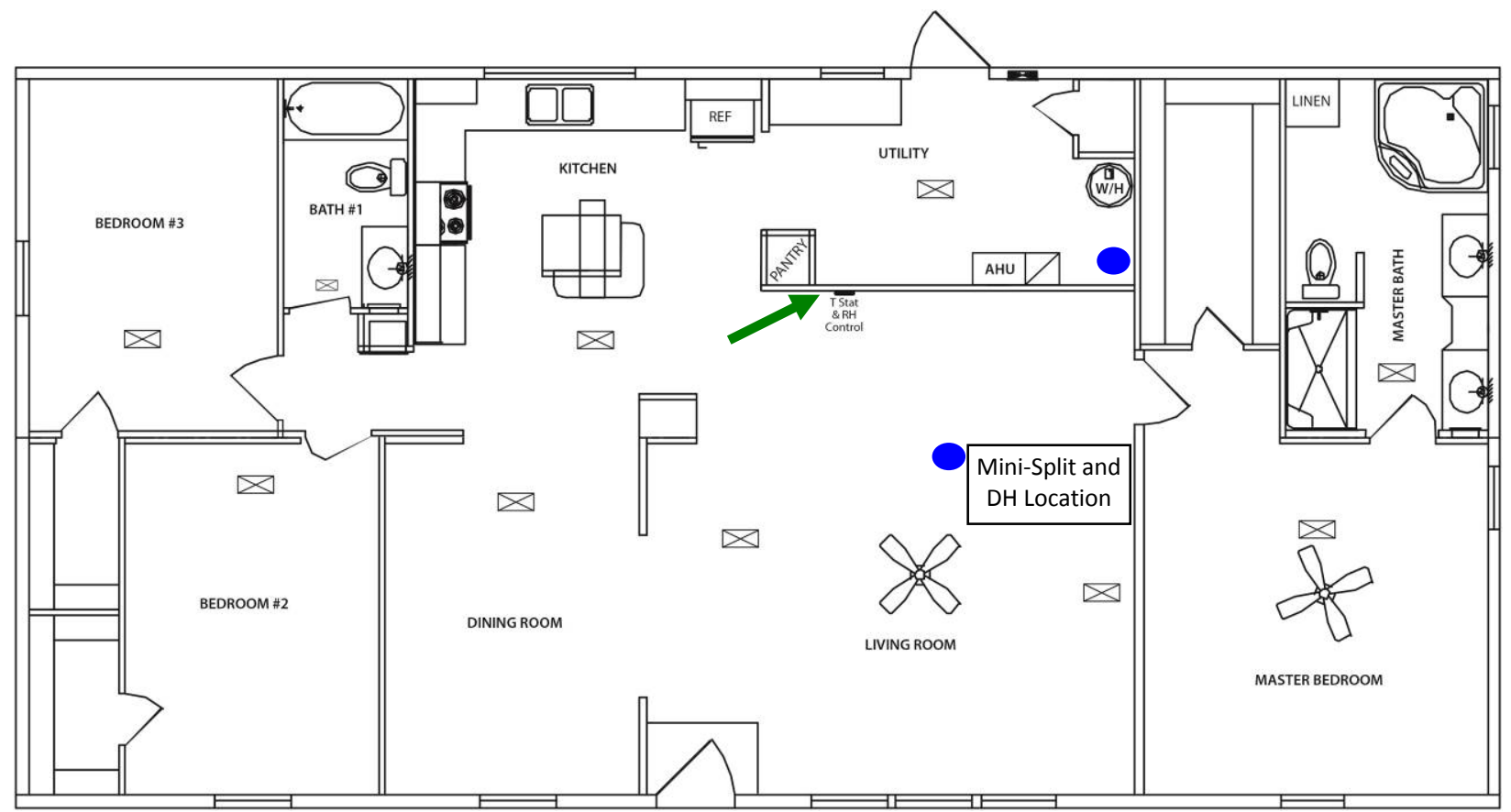

Figure 2. MH Lab home floor plan showing open central area and three-bedroom/two-bath layout. Blue circles show locations where OA was supplied into home. A green arrow points to the wall area where all thermostat and $\mathrm{RH}$ control was located.

The centrally ducted system test configurations were completed with ducts in the attic and had insulation with an effective R-value of 11.6.

Fixed-capacity SEER 13 and variable-capacity SEER 22 heat pumps were tested with OA delivered to a location near the central return or in the main body of the space (living room). The terminal supply locations of OA are marked by blue circles in Figure 2. In each mechanically vented experiment without MSHP operation, a stand-alone, supplemental dehumidifier was operated to control indoor RH when living room RH exceeded $60 \%$.

Before the experimental testing commenced, airtightening of the $\mathrm{MH}$ Lab enclosure was completed and resulted in a tested ACH50 of $4.48(\mathrm{C}=88.1, \mathrm{n}=0.621, \mathrm{r}=0.9988)$. This level of airtightness was chosen because it complies with the upcoming Florida code and the International Energy Conservation Code (ICC 2012a) requirement for new home construction to have measured airtightness of $5 \mathrm{ACH} 50$ or lower. Based upon the house characteristics and measured tightness, ASHRAE 62.2-2013 required a continuous mechanical ventilation rate of 55 CFM, which was provided to the home.

\subsection{Mechanical Ventilation System Description}

Continuous mechanical ventilation was supplied into the MH Lab during all testing. It was supplied into the main central living room area in six of the eight test configurations. In two other tests, it was supplied in the utility room area close to the centrally ducted return intakes. The OA supply location in the living room was very close to the blue circle shown in the living room area of Figure 2; however, some adjustments were made depending upon which dehumidification strategy was implemented. When OA was directed to a cooling system return intake, it was ducted close to the return, but not directly into the return plenum. This allowed dry 
indoor air to mix with the OA, which helped decrease the RH before the air contacted any indoor surfaces. The OA was delivered at a low enough velocity that it could be effectively captured by the return air when the cooling system was on.

Figure 3 shows an in-line fan (top left of image) that was used to bring the OA into the lab continuously through a 6-in.-diameter rigid metal duct. An adjustable iris damper (below the fan) was calibrated against a TSI Wind Tunnel model 8390. The iris damper and digital micromanometer were used to monitor the flow of the OA at 10-s intervals during every test configuration. The OA fan speed could also be controlled to allow small adjustments to ensure the flow rate was the same regardless of where the OA was delivered. The OA intake was located at the shaded north side of the building (just out of view near the stairs in Figure 1). The OA was pulled in through an air filter at the intake box outdoors. From the intake filter, a 6-in.diameter metal pipe with R-6 insulation was run under the home through the crawl space, then up through the utility room floor (Figure 3). Some branches of the OA duct allowed the air to be delivered at four locations:

- At the return intake of either SEER 13 or SEER 22 central systems

- At the return air intake of the MSHP in the living room

- Into the living room about $7 \mathrm{ft}$ above the floor

- Directly to the intake of the dehumidifier about $4 \mathrm{ft}$ above the floor.

The test configurations evaluated only the impact of OA delivered to one location at a time. The average velocity at the OA supply termination was about $280 \mathrm{ft} / \mathrm{min}$.

Testing and balancing were completed to verify all configurations maintained the same mechanical ventilation. Tracer gas decay was tested with the OA system on and measured an air exchange rate of $0.353 \mathrm{ACH}$. Accounting for the conditioned volume, the total air exchange of Qinf + Qfan = 78.7 CFM (ASHRAE 2013). The ASHRAE 62.2 total predicted ventilation (based on measured house blower door tightness and size) was 78.6 CFM with predicted Qinf $=22.5$ $\mathrm{CFM}$ and $\mathrm{Qfan}=56.1 \mathrm{CFM}$. The delivered OA agreed very well with the ASHRAE 62.2 predicted rate because the weather test conditions were similar to assumed conditions in the prediction. The measured air exchange rate of 0.353 also meets the International Mechanical Code (ICC 2012b) minimum prescribed requirement of $0.35 \mathrm{ACH}$ for private dwellings. 


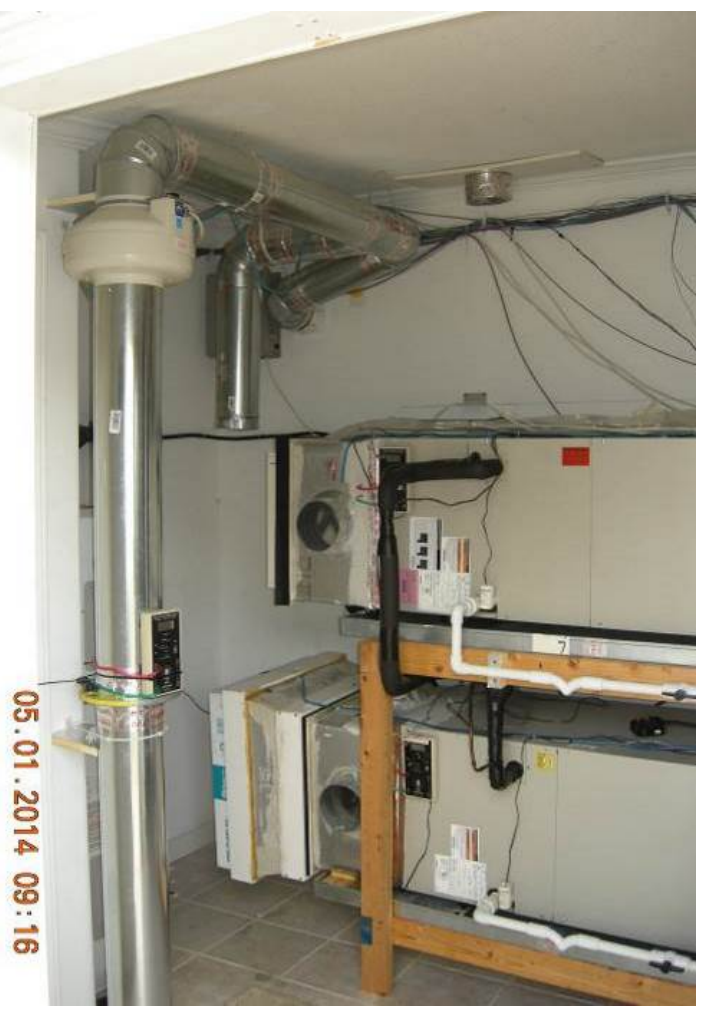

Figure 3. Mechanical ventilation OA is brought into the MH Lab using an in-line fan and measured with a calibrated iris damper. This photo shows the option that delivers the air near the return of the SEER 22 (top) and SEER 13 central systems. 


\section{Instrumentation and Equipment Descriptions}

More than 100 channels of data were collected for meteorological parameters, the envelope, the HVAC systems, and interior space conditions. The instrumentation package consisted of multiple data loggers and associated peripheral devices. Sensors were read every $10 \mathrm{~s}$ and stored at 15-min intervals. Therefore, each 15-min data interval was represented by 90 samples.

\subsection{General Manufactured Housing Laboratory Instrumentation}

A data acquisition system recorded a variety of information about the HVAC system operation, energy consumption of various items within the house (including internally generated sensible and latent loads), and indoor and outdoor conditions. Temperature and RH of air flowing into and out of the HVAC systems were recorded only when the systems were operating (conditionally). A list of test equipment and monitoring sensors used is presented in Table 2.

- Temperatures were recorded conditionally at the entrance to the system returns (which were in the conditioned space and less than $2 \mathrm{ft}$ long), at the discharge from the systems, and at five supply registers for the ducted systems. Temperatures entering the condenser coil (outdoor units) were also recorded.

- Temperatures were recorded unconditionally (continuously) at various indoor locations, in the attic, in the crawl space, and at various locations on the roof system.

- $\mathrm{RH}$ was recorded conditionally at the entrance to the return and the discharge from each system.

- RH was also recorded at various indoor locations, in the attic, in the crawl space, and outdoors, all unconditionally (continuously).

- The airflow rate of cooling systems was recorded by airflow stations located at the entrance to the returns.

- Power meters recorded energy use for the house, HVAC indoor and outdoor units, the refrigerator, the domestic water heater, the oven, air circulation fans, the dishwasher, and heat lamps that simulated internal loads.

- Condensate draining from the HVAC systems and the dehumidifier was measured by a pair of tipping buckets that provided redundant measurements of moisture that was removed by the coils.

- Weather conditions of air temperature, $\mathrm{RH}$, rainfall, wind speed/direction, and solar radiation (on the horizontal) were measured. 
Table 2. Lab Testing and Monitoring Equipment Used in the Experiments

\begin{tabular}{|c|c|}
\hline Measurement & Equipment \\
\hline Data Collection & $\begin{array}{l}\text { Campbell Scientific CR10 with (2) AM416 } \\
\text { multiplexers and (1) SW8A pulse expansion } \\
\text { module }\end{array}$ \\
\hline $\begin{array}{c}\text { Pressure Differentials (Airflow Sensors, Air } \\
\text { Distribution Pressures) }\end{array}$ & $\begin{array}{c}\text { DG700 and DG-2 digital pressure gauge with } \\
\text { analog output }\end{array}$ \\
\hline Return System Airflow (in situ Calibration) & Shortridge Velgrid \\
\hline Ventilation Airflow (in situ calibration) & Continental Fan Manufacturing Iris Damper \\
\hline Airflow Calibration & TSI Model 8390 Bench Top Wind Tunnel \\
\hline Temperature & Type T thermocouple \\
\hline $\begin{array}{l}\text { Relative Humidity (Return, Supply, OA, } \\
\text { Indoor, Outdoor, Attic) }\end{array}$ & Vaisala HMP50, and HMP60 \\
\hline Condensate & $\begin{array}{l}\text { Texas Electronic TR-4 and TR-525I tipping } \\
\text { buckets }\end{array}$ \\
\hline $\begin{array}{c}\text { Energy (Whole House, AHU, Condenser } \\
\text { Unit, Domestic Hot Water, Oven, } \\
\text { Refrigerator, Dishwasher, Heat Lamp } \\
\text { Circuit) }\end{array}$ & $\begin{array}{l}\text { Continental Wattnode and Ohio Semitronics } \\
\text { Inc. energy transducers with current } \\
\text { transformers from } 5 \text { to } 200 \text { amps }\end{array}$ \\
\hline Domestic Hot Water Consumption & Kent C700 Flow Meter \\
\hline Latent Delivery & FMI Lab Pump Jr. model RHSY \\
\hline Building Envelope Air Leakage & $\begin{array}{l}\text { Minneapolis Blower Door System with DG- } \\
700 \text { digital gauge }\end{array}$ \\
\hline Duct System Air Leakage & Minneapolis DuctBlaster System with DG-700 \\
\hline Automation Internal Loads & $\begin{array}{l}\text { Insteon based load switches controlled by } \\
\text { ISY-99i Automation controller }\end{array}$ \\
\hline
\end{tabular}

\subsection{Dehumidifier Description}

The stand-alone Sunpentown SPT model SD-71E supplemental dehumidifier was placed in the living room main space. This dehumidifier had a rated moisture removal rate of 70 pints/day and a rated energy factor of $1.85 \mathrm{~L} / \mathrm{kWh}$. The listed power draw was 720 watts. On-board dehumidistats were limited to sensing the appliance's location, which may not be the best for sensor control. The dehumidifier operation was controlled by a separate dehumidistat controller that was placed on the interior wall in the large central living room area next to the space-cooling thermostat controls. A Green Products dehumidistat that was designed for placement at remote locations had a built-in power relay control that turned power on and off to the dehumidifier as needed. The dehumidifier on-board RH control was set at the lowest (driest) setting so it would not turn the unit off before the remote control called for it to do so. A plenum was constructed around the dehumidifier intake to enable the OA to also be directed at its intake (Figure 4). The plenum contained sufficient intake grille area so the dehumidifier had an ample air supply and did not increase the OA flow when the static pressure increased during dehumidifier operation. The dehumidifier's airflow rate was measured using a powered flow hood with rated accuracy $\pm 5 \%$ of measured flow. Measured airflow nearly matched the manufacturer's stated flow rates.

One of the dehumidifier design test configurations represented a case in which the dehumidifier was well-connected to a central conditioned space area, and OA was directed for direct capture by the dehumidifier when it was on. When the dehumidifier was on, it captured and conditioned 
all ventilation air before it passed into the central living room area. The dehumidifier intake plenum was designed to allow the mechanical ventilation to pass directly into the room if the dehumidifier was not on.

Simply supplying untreated OA directly to a dehumidifier in a small isolated enclosure or a closed-in closet and using the on-board dehumidifier RH control is likely to result in excessive energy use, because high RH OA would effectively fill a small isolated area. A review of Typical Meteorological Year (TMY) data for hot-humid climate areas shows several cities where the annual hourly average outdoor RH exceeds $60 \%$ for about $80 \%$ of the year. Concerns about supplying untreated OA into small indoor rooms or enclosures are discussed in more detail in Appendix C. This experiment was intended to model a design in which dehumidifier operation resulted from conditions at a single representative indoor living space (living room). It was also designed to have the dehumidifier well-connected to the living space, surrounded by dry indoor air, and able to discharge dehumidified air into the central living room area. As such, the experiments that used the dehumidifier were not set up to exaggerate operation because the dehumidifier enclosure was poorly designed.

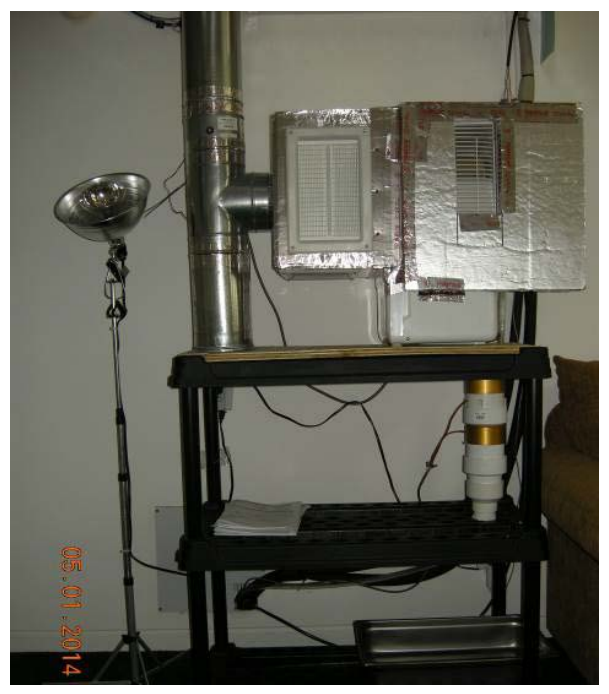

Figure 4. Stand-alone dehumidifier with OA intake plenum constructed on the left side

\subsection{Mini-Split Heat Pump Description and Testing}

The MSHP chosen for testing was a 1.25-ton Fujitsu variable-capacity heat pump model ASU15RLS with a rated SEER of 21.5 and heating seasonal performance factor of 10.3. This ductless single-head unit had only one indoor fan and evaporator coil assembly connected to the outdoor condensing unit. During MSHP test configurations, ventilation air was delivered at the return intake of the MSHP (Figure 5). 


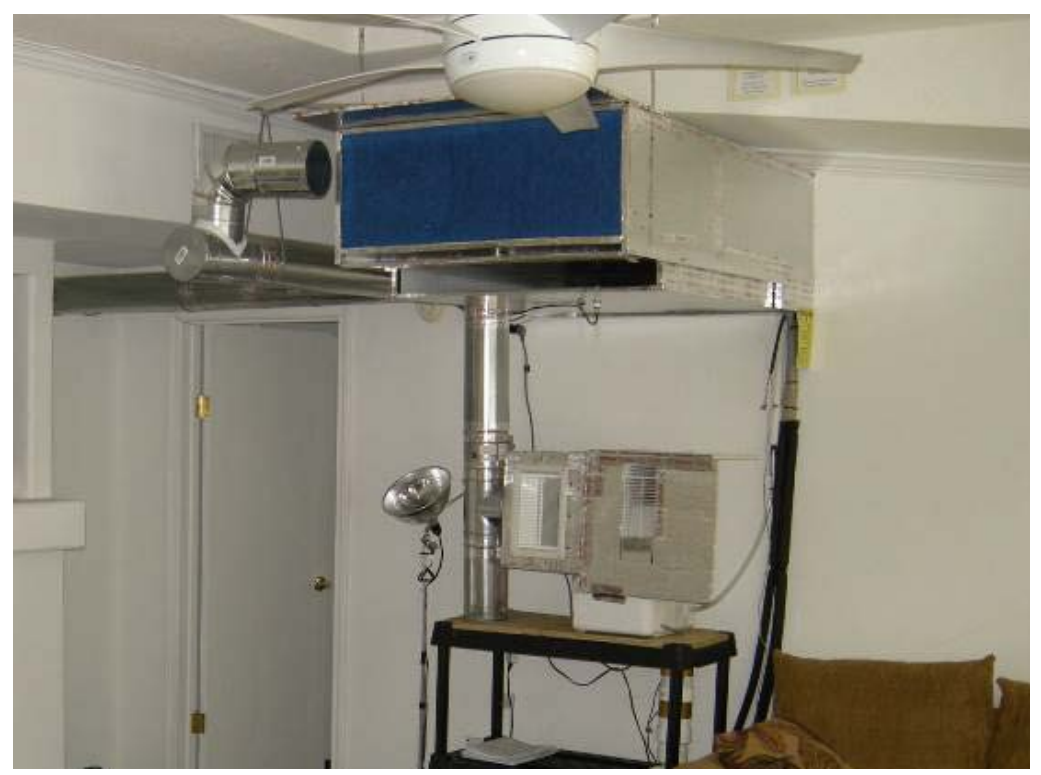

Figure 5. MSHP indoor unit mounted high on the wall in the MH Lab main space. The return air of the unit is enclosed in a plenum with a calibrated flow station. As shown, the OA duct terminates at the intake to the MSHP. It can also be directed to the dehumidifier unit below the MSHP or redirected further into the central space.

The MSHP has three main cooling control modes: standard cool, economy cool, and dry cool. The primary test configurations used the economy cool mode unless noted otherwise because it was the most energy-efficient. The economy cooling mode operates with a warmer cooling coil and allows room temperature to be maintained a little warmer on average than in standard mode. This results in higher indoor RH in economy mode than the standard mode. Standard and dry cool modes were operated for short periods during low cooling load days to compare RH control to the economy mode.

The rated MSHP capacity was nearly $70 \%$ of design cooling load; however, this variablecapacity system can operate with a rated delivered cooling capacity of 3,100-18,400 Btu/h. Thus, this system was expected to operate continuously throughout essentially all hours when the outdoor dew point temperature was $60^{\circ} \mathrm{F}$ and higher (ventilation air at $60^{\circ} \mathrm{F}$ ambient dew point might only slightly elevate indoor humidity levels). Previous data from the Florida Solar Energy Center MH Lab showed that the home cooling load was always higher than the MSHP minimum capacity of $3,100 \mathrm{Btu} / \mathrm{h}$ when the outdoor ambient dew point was $60^{\circ} \mathrm{F}$ dp or higher. The MSHP did not operate nonstop when the outdoor dew point was $60^{\circ} \mathrm{F}$ dp or higher, because the lowest capacity sustained during 15-min periods for the MSHP unit was about 7,000-8,000 Btu/h instead of the manufacturer's stated low capacity of 3,100 Btu/h. The lowest capacity apparently occurred for short transitional periods only, such as the start-up or cycle-off parts of operation instead of being sustainable for several minutes at a time.

Because the MSHP could vary airflow from 229 CFM to 529 CFM, an airflow station was constructed inside a return plenum to measure the flow rate whenever the system was on. It was calibrated using a TSI Wind Tunnel Model 8390 connected up to the system (Figure 6). The flow station on the return side (at the top) and the temporary flow test supply capture plenum (at the bottom) block the view of the actual MSHP head (indoor) unit. The plenum connections were 
made reasonably airtight before testing using foil metal tape squeegeed onto foil-faced insulation board at seams and closed-cell gaskets and putty at plenum-to-MSHP connections.

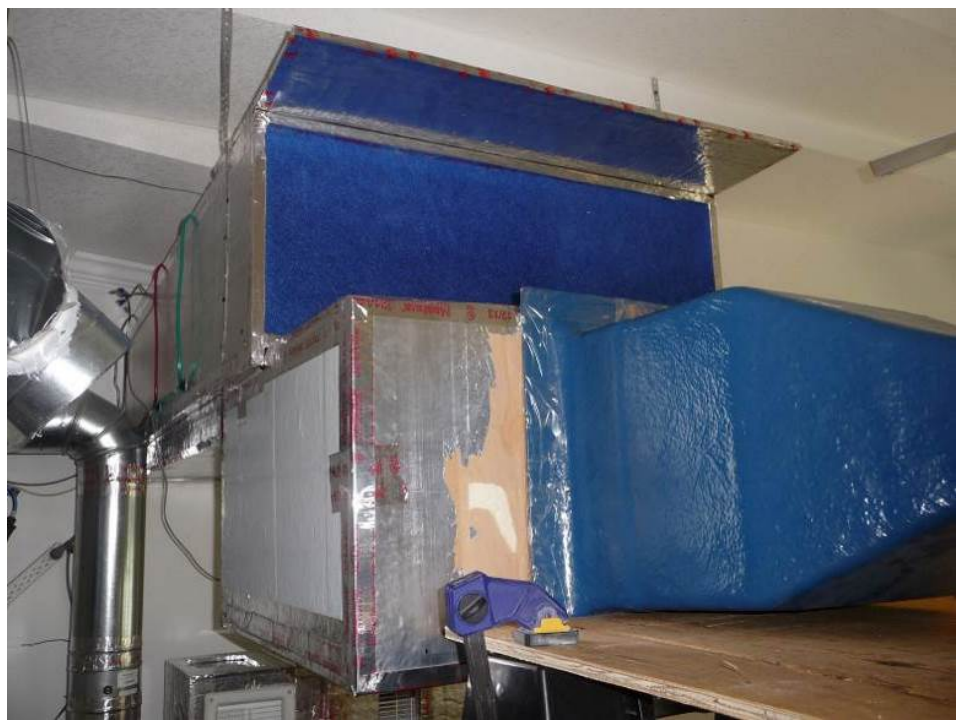

Figure 6. TSI Wind Tunnel connected to a temporary test plenum that was used to capture the supply air from the MSHP. The airflow station is located inside the upper return plenum.

The following steps were taken to calibrate the flow grid:

1. The MSHP system fan was turned on at the quiet, low, medium, and high settings.

1. The flow grid pressure was measured at each fan setting.

2. A temporary capture hood was constructed over the supply part of the MSHP and the wind tunnel sealed up to it.

3. The MSHP fan was turned on again at each of the four settings.

4. The wind tunnel fan speed was adjusted until the supply capture hood pressure was 0.0 Pa with reference to the room.

5. The wind tunnel airflow was measured to determine the airflow at the specific fan setting.

6. Wind tunnel airflow was determined by directly measuring the pressure differential across the tunnel orifice.

7. Differential pressure was measured using an Energy Conservatory DG700 micromanometer calibrated to a National Institute of Standards and Technology-traceable standard.

Figure 7 shows the resulting wind tunnel airflow versus the MSHP flow station differential pressure. The MSHP flow rate was about 6\% lower than the manufacturer's stated high flow rate with the return plenum assembly in place. The manufacturer's stated error of measurement with the wind tunnel was only $\pm 1 \%$. The wind tunnel is more accurate than other powered flow hood applications with a stated flow accuracy of $\pm 5 \%$. The air filter at the intake of the return flow grid assembly apparently accounted for the difference between the in-situ measurement and manufacturer's stated flow rates. One flow measurement was also made at high speed with the 
filter removed from the return plenum intake. The wind tunnel measurement of 529 CFM exactly matched the manufacturer's stated flow rate at high speed. The filter was a low-efficiency medium with only about $4 \mathrm{~Pa}$ (0.016 in. water column) measured pressure drop at the common operable flow rate around 300 CFM.

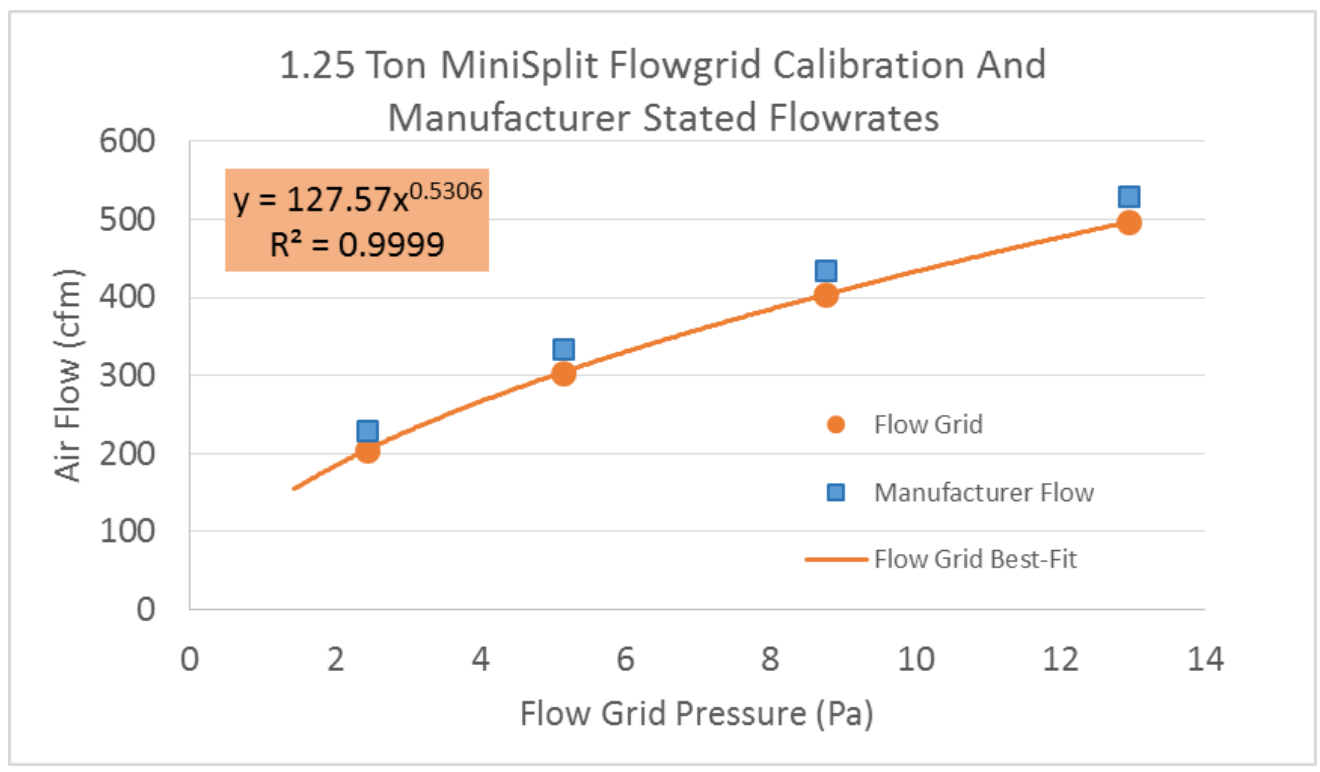

Figure 7. MSHP flow calibration data at the four manufacturer fan speed settings

The temperature and $\mathrm{RH}$ were also measured on the return and supply sides of the indoor unit when the system was on. This could be used to determine the delivered cooling to the space and periodically check that the system was operating as expected. The latent removal was measured with two tipping buckets in series that allowed redundancy and a check of one against the other. All condensate measurements were calibrated by measuring the number of tips from a known mass of water that was delivered at about the expected rate of condensate delivery.

\subsection{Building Design Cooling Load and Cooling System Capacities}

A cooling load calculation of the MH Lab was completed per ACCA Manual $\mathrm{J} 8^{\text {th }}$ Edition, Version 2 and revealed that 1.75 tons of cooling capacity are required. The lab was designed to provide centrally ducted cooling by either a SEER 13 or SEER 22 heat pump system. The SEER 13 unit has a fixed nominal cooling capacity of $23,900 \mathrm{Btu} / \mathrm{h}$ ( 2 tons). This unit was oversized by about $14 \%$ on a design cooling day, but was the closest match of nominal rated capacity to design load. The SEER 22 central system was nominally rated at almost 2 tons but actually has variable cooling capacity; it can deliver a wide range of cooling capacity depending upon the cooling load.

The 2-ton iQ Drive SEER 22 heat pump used in these experiments had a nominal rated cooling capacity of $23,000 \mathrm{Btu} / \mathrm{h}$ (1.92 tons) and $22,600 \mathrm{Btu} / \mathrm{h}$ rated heating capacity. This system was rated to produce $11,300 \mathrm{Btu} / \mathrm{h}$ (0.94 tons) of cooling at lowest cooling capacity ( $46 \%$ lower than design cooling load) and up to $26,900 \mathrm{Btu} / \mathrm{h}$ (2.24 tons) of cooling at its highest cooling capacity ( $28 \%$ higher than the design cooling load). The cooling capacity of this variable-capacity heat pump can vary by a factor of 2.4 , from $42 \%$ to $100 \%$ of its maximum capacity. 
The SEER 22 centrally ducted variable-capacity system thermostat control tries to match the cooling load by carefully monitoring the indoor temperature against the set point. At the beginning of a cooling cycle startup, the system begins around the nominal cooling capacity; it then makes small capacity modifications (typically downward) depending upon the difference between the indoor temperature and the set point. Very small drops in indoor temperature (tenths of a degree Fahrenheit) prompt the system to drop to lower capacity. If the indoor temperature is rising, adjustments are made to increase the cooling output. Because the typical cooling load is much lower than design loads during most of the cooling season, the system usually operates at the lower capacities when it is more efficient (Cummings and Withers 2011; Cummings et al. 2013).

The MSHP was a variable-capacity ductless heat pump with a rated cooling capacity of 14,500 $\mathrm{Btu} / \mathrm{h}$ (1.21 tons). This system was rated to produce $3,100 \mathrm{Btu} / \mathrm{h}(0.26$ tons $)$ of cooling at its lowest cooling capacity (85\% lower than the design cooling load) and up to $18,400 \mathrm{Btu} / \mathrm{h}(1.53$ tons) of cooling at its highest cooling capacity (12\% lower than the design cooling load). The MSHP cooling capacity had a much wider range than the centrally ducted system. The MSHP capacity can vary by a factor of 5.9 , from $17 \%$ to $100 \%$ of its maximum capacity.

Figure 8 shows the cooling load on a design day in proportion to three areas of the home:

- The central open core, which comprised the living room, dining room, and kitchen spaces

- The bedroom/bathroom areas, which consisted of the master bedroom, master bathroom, master walk-in closet, bedroom 2, and bedroom 3

- The utility room area, which was wide open to the kitchen area; it had no separating wall or doorway and was separated from the main core by an internal wall between the utility room and the living room.

Thermal distribution will be discussed in more detail in Section 4.

Figure 8 also shows that $58 \%$ of the cooling load was in the central area of the home. This equates to about $12,180 \mathrm{Btu} / \mathrm{h}$ design cooling load. The MSHP in this area seemed to be wellsuited given the range of capacity of 3,100-18,400 Btu/h. 


\section{DESIGN COOLING LOAD DISTRIBUTION}

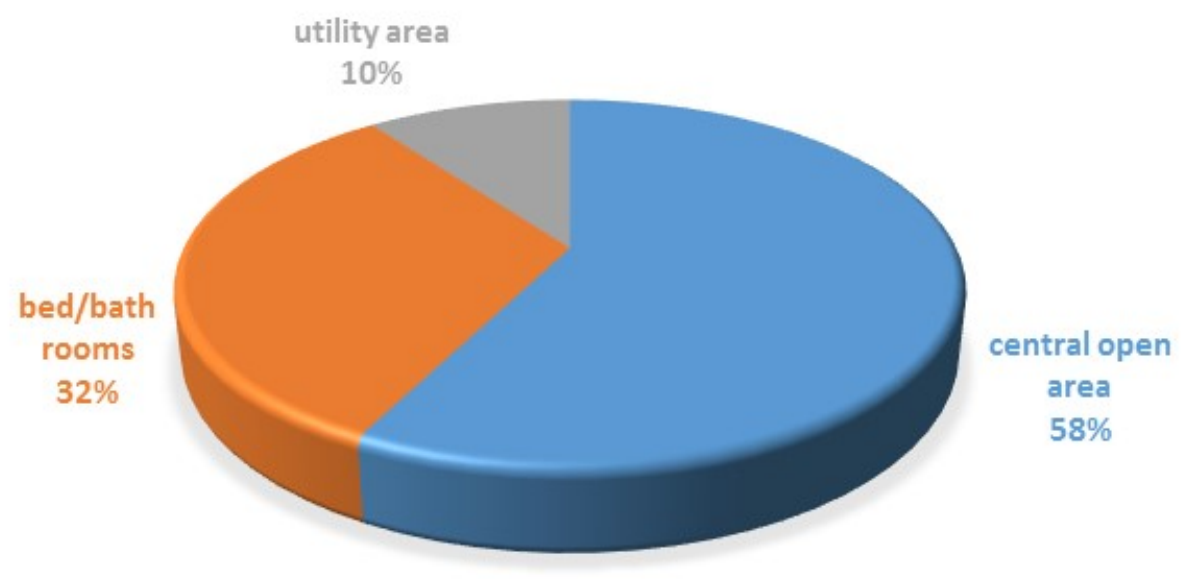

Figure 8. Design cooling load distribution of the main central area, bedrooms, and utility room

\subsection{Automation of Sensible and Latent Internal Loads}

Internal loads were automatically generated in the MH Lab to simulate occupancy similar to that of a three- or four-person family. Cummings and Withers (2011) presented a detailed discussion of internally generated loads and occupant activities in Appendix A, which contains schedules of occupant activities and internal loads. In most cases, the source for the occupancy or load schedule is Hendron (2008).

Internal loads were generated by automatically operating various appliances on a schedule. In the MH Lab, the operations of the oven, dishwasher, and showers were automated. The electric water heater (installed in the utility room) and the refrigerator also operated (cycled) normally except that the doors to the refrigerator and dishwasher remained closed. Including all internal sources, a total internal sensible heat load of $81,546 \mathrm{Btu} /$ day $(3,398 \mathrm{Btu} / \mathrm{h}$ daily average rate) and an internal latent heat load of about $10,700 \mathrm{Btu} /$ day (446 Btu/h daily average rate) were generated indoors each day. The internal latent heat can also be expressed as $10.2 \mathrm{lb} / \mathrm{day}$.

Internal loads can also be simulated by means of alternative heat and water vapor sources. Two other types of heat sources were used to simulate all other sources of sensible heat: the kitchen oven and heat lamps. The oven cycled on 11 times throughout a day (the MH Lab was operated as if all days were weekdays) typically for 20-40 minutes at a time. Each oven "on" cycle was sufficiently short that the oven did not reach its target temperature setting; therefore, the oven heating element operated continuously at full capacity during the "on" cycle. Two floor fans and a ceiling fan operated continuously to distribute the heat from the kitchen to other spaces. The heat lamps were placed in the living room, kitchen, and master bedroom and were scheduled on and off throughout the day. When they were on, the heat output was also varied at times; energy output varied from $44 \mathrm{~W}$ to $472 \mathrm{~W}$.

Latent heat was added to the space in part through operation of the master bedroom shower and by operation of the dishwasher. Together, these two appliances consumed approximately 46 gallons per day. Only a small fraction of the water consumed by the shower and dishwasher 
entered the indoor air; most exited down the drains. Latent heat was also added to the space by means of water metered into an evaporation pan in the oven, which represented the latent load that would come from the occupants (perspiration and respiration), cooking, and the refrigerator (from moisture in the refrigerator that would enter the space through door openings).

Based on Equation 16 from Hendron (2008), the dishwasher would be operated 215 times per year, or 4.1 times per week. To reduce day-to-day variability in internal loads, the research team determined that operating the dishwasher once each day would be better for the experiments. 


\section{Results}

This research project focused on answering the three key research questions discussed in Section 2 of this report. The key results covered are seasonal and peak cooling energy impacts, thermal distribution variations, and RH control effectiveness of eight primary ventilation test configurations indicated in Table 1. A brief ninth test evaluation that used the MSHP dry control mode was added later during weather with sustained low cooling load periods. The measured energy impact from going from a leaky nonmechanically ventilated building to a tighter 4.5 ACH50 with continuous mechanical ventilation was not a primary focus; however, Appendix A includes this information.

\subsection{Cooling and Dehumidification Energy Use}

The combined energy of space cooling and dehumidifier was plotted against the daily average difference in temperature (dT) between outdoors and indoors. The indoor temperature is represented by the average of five locations around the home: three bedrooms, a central hallway, and at the thermostat location in the living room. A least-squares best-fit analysis was used to develop equations of space-conditioning energy versus dT using measured data. The best-fit equations can also be used in conjunction with TMY3 data to predict seasonal and peak demand energy consumption for each HVAC operational configuration for representative southern cities in the hot-humid climate zone.

\subsubsection{Outdoor Air Supplied to Central Return in a Utility Room with the Dehumidifier Enabled}

One test configuration involved supplying 55 CFM OA to a utility room directed nearby the central return intake. The OA was not ducted directly into the return plenum, mostly because it avoided an OA fan pressure differential that would change depending upon whether the central system was on or off. A changing fan differential would change the actual amount of OA and would involve a more sophisticated control to maintain a constant amount of OA. The OA supply drop was done in a way that resulted in some mixing of room air with OA just before it entered the return. Allowing OA to mix with room air reduced the risk of moisture issues such as high surface humidity and condensation on cold surfaces. A dehumidifier was enabled to operate in the central living room area if that area reached or exceeded $60 \% \mathrm{RH}$.

Figure 9 shows the combination of cooling and dehumidifier energy plotted against dT when OA is supplied near the central return. The SEER 22 system including dehumidifier operation used about $4.41 \mathrm{kWh}$ /day less than the SEER 13 configuration $(20.3 \%)$ for $\mathrm{dT}=5^{\circ} \mathrm{F}$. 


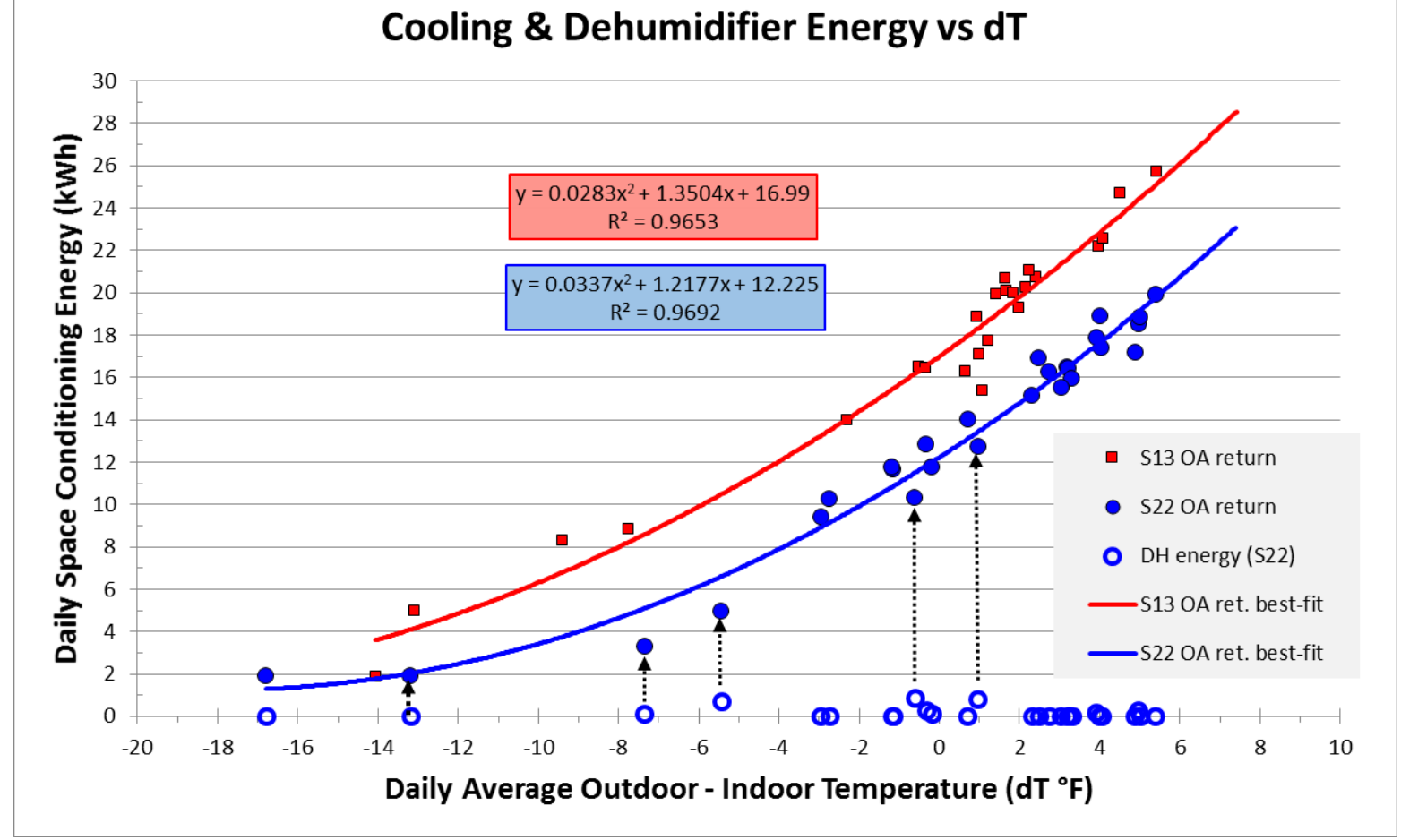

Figure 9. Centrally ducted cooling and dehumidifier energy plotted against the daily average dT between outdoors and indoors with OA ducted near the central return

The group of SEER 13 data did not have any dehumidifier operation, probably because the SEER 13 system had (1) better dehumidification, (2) more days with greater solar energy on average, and (3) fewer days with OA dew point of at least $70^{\circ} \mathrm{F}$ dp in the data set (only 3 days compared to 8 days in the SEER 22 data set). During days with outdoor dew point of at least $70^{\circ} \mathrm{F} \mathrm{dp}$, the indoor RH was about 3.1\% lower with the SEER 13 compared to SEER 22 system, which had about 33\% longer runtime. The average daily total runtime was 59\% SEER 13 versus $78.6 \%$ runtime for SEER 22. The SEER 13 data set also did not have consecutive days with low solar energy and the SEER 22 data set had a 4-day period. In previous work without OA, the indoor RH that occurred during the use of these systems was compared using days when outdoor dew point was at least $70^{\circ} \mathrm{F}$ dp and the SEER 13 system had daily average indoor $\mathrm{RH} 1.6 \%$ lower than the SEER 22 system even though the SEER 22 system had about $89 \%$ longer runtime (Cummings et al. 2013).

Five arrows in Figure 9 point from the daily total dehumidifier use to the combined total cooling and dehumidifier use for 5 consecutive November days during SEER 22 OA at return test configuration. These 5 days are an example of lower cooling load that create more challenging $\mathrm{RH}$ control conditions. The red squares that represent dehumidifier energy use in Figure 9 show that the dehumidifier energy represented a small fraction of the total conditioning energy $(0 \%-$ $14 \%$ ). It represented only the higher energy share of $14 \%$ on days without space cooling. The dehumidifier energy was not represented as $100 \%$ of the total energy on days with no space cooling because of standby energy use of the centrally ducted systems. Standby energy is the energy consumed during "idle" periods between cooling or heating operation. The standby energy use of the SEER 22 system total was $1.9 \mathrm{kWh} /$ day. The first arrow on the left is for the 
first of 5 consecutive days from November 20-24, 2014 and each progressive arrow to the right representing the next consecutive day. This period represented a weather trend that changed from cool dry air to warmer moister OA. The first day of this period had no dehumidifier or space cooling operation.

So what specific conditions resulted in the dehumidifier operation because it did not operate most of the time? To better understand the conditions that brought about dehumidifier operation with the SEER 22 system, the team looked at the times the dehumidifier operated over the 5 days from November 20-24, 2014. The next two figures help illustrate when cooling and dehumidifier operation occurred and under what conditions. Figure 10 shows the dehumidifier was operating mainly during the overnight hours. The dehumidifier operation during daytime hours on November 22 was due to very cloudy conditions. A close examination of the data showed the dehumidifier cycles did not occur during cooling cycles and typically happened an hour or more after the last cooling cycle ended. The dehumidifier cycle then ended as a cooling cycle was beginning. Four dehumidifier cycles occurred on 3 of the days with daily total energy use of $0.137-0.859 \mathrm{kWh}$. The outdoor dew point (blue-dashed line) in Figure 10 shows a trend increasing from drier to moister air.

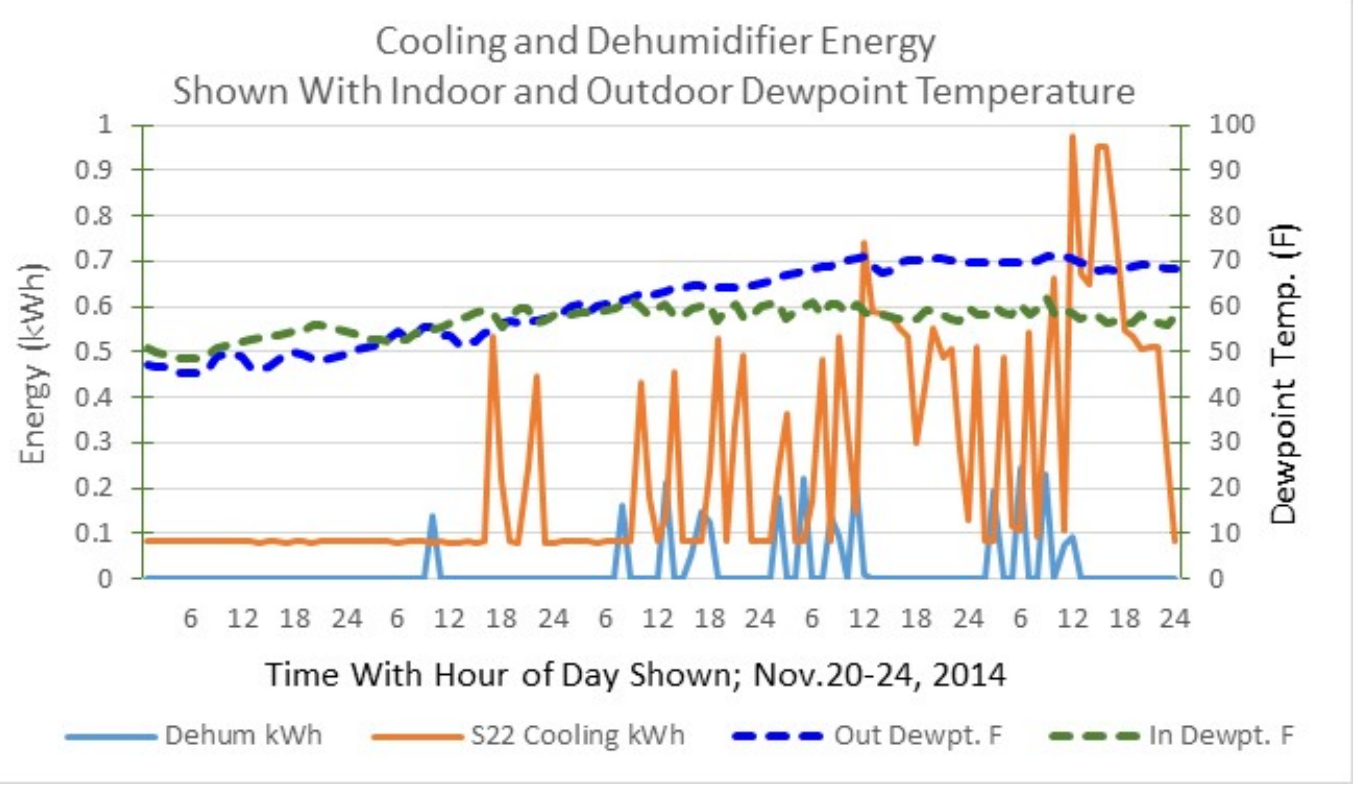

Figure 10. Dehumidifier energy, space cooling energy, and outdoor and indoor dew point temperatures at 1 -h intervals during a 5-day period in November

Figure 11 shows indoor and outdoor temperature and RH conditions that correspond to the dehumidifier energy shown in Figure 10. The single dehumidifier cycle on November 21 was 16 min long and occurred at 9:15 a.m.; outdoor dew point was $56^{\circ} \mathrm{F}$ dp and indoor dew point was $55.1^{\circ} \mathrm{F}$ dp. After this cycle, the outdoor dropped to about $52^{\circ} \mathrm{F}$ dp by midafternoon and indoor climbed to $60^{\circ} \mathrm{F}$ dp by around 8 p.m. The overnight dehumidifier cycles were 18-24 min long and occurred with outdoor dew points of $66^{\circ}-71^{\circ} \mathrm{F} \mathrm{dp}$. 


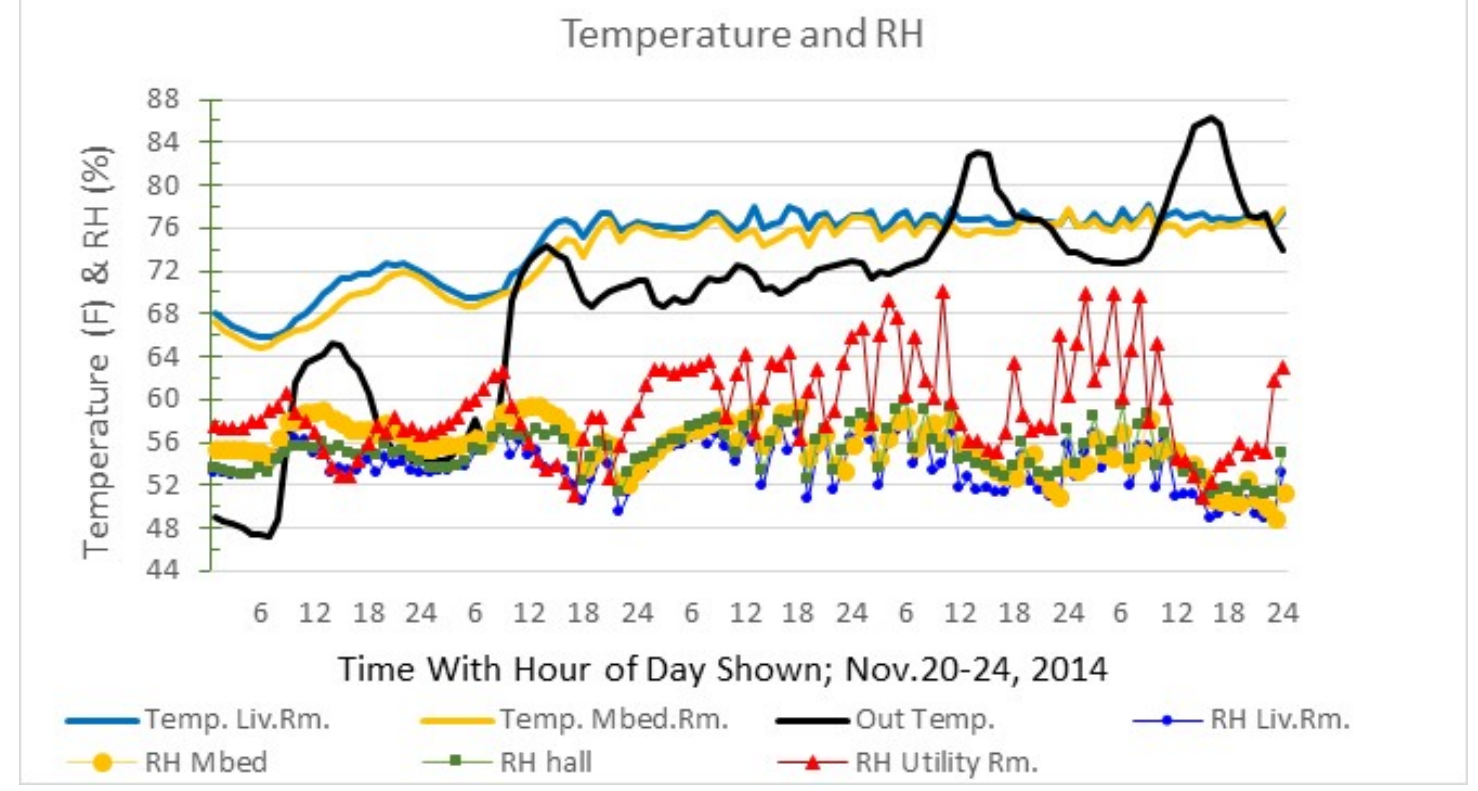

Figure 11. Indoor and outdoor temperatures and indoor RHs at 1-h intervals during a 5-day period in November

Figure 11 also shows that indoor RH was under control in the main living spaces; however, the utility room where the OA was supplied to the central returns had several hours that exceeded $60 \% \mathrm{RH}$ by the time the outdoor dew point exceeded $58^{\circ} \mathrm{F}$ dp. The utility room RH was lower than $60 \%$ whenever the central space cooling was operating. During daytime hours (of a very low solar day November 22) when the central system cycled off, the utility room RH varied from $60 \%$ to $64 \%$. The utility room $\mathrm{RH}$ was higher overnight during cooling off-cycle periods at $60 \%-70 \%$.

The indoor RH stayed considerably lower than $60 \%$ in all primary habitable areas (bedrooms, hall/kitchen, dining room, and living room) during hot-humid weather when OA dropped at the return intake in the utility room area regardless of the centrally ducted system used. However, the utility room did have some hours when the RH exceeded $60 \%$. Impacts of various test configurations on indoor RH are covered in more detail in Section 4.3.2.

\subsubsection{Outdoor Air Supplied to a Central Living Room Area with Dehumidifier Enabled}

Four test configurations involved providing the 55-CFM continuous OA into the living room space when the dehumidifier was enabled to operate. They were:

1. SEER 13 central cooling with OA to living room

2. SEER 13 central cooling with OA ducted to dehumidifier in living room

3. SEER 22 variable-capacity central cooling with OA to living room

4. SEER 22 variable-capacity central cooling with OA ducted to dehumidifier in living room. 
Two ways of delivering OA into the living room locations were selected:

1. A simple OA horizontal supply discharge out of a 6-in.-diameter duct with no diffuser located about $7 \mathrm{ft}$ above the floor. The air was directed across the living room toward the open plan dining and kitchen areas (Figure 2). This method would represent a simple low-cost way of supplying OA to one central location in a home. A dehumidifier in the living room space was controlled by a remote dehumidistat on the living room wall near the thermostats (see green arrow in Figure 2). It was enabled to turn on if the living room space reached $60 \% \mathrm{RH}$.

8. The OA was ducted directly to a small plenum that was attached to the dehumidifier in the living room. The OA was directed in the same direction as previously described except at about $4 \mathrm{ft}$ above the floor level. This method of OA delivery could represent a simple small closet method of OA capture that would allow some dehumidification of OA if the living room space called for it. The dehumidifier was controlled the same way as the previously described configuration by the remote dehumidistat on the wall set to $60 \% \mathrm{RH}$ away from where the OA was ducted to living room. Placing a dehumidifier inside a small closet or small room where OA enters can result in excessive energy use.

Concerns about OA supplied to small interior spaces are discussed in greater detail in Appendix C.

The combined daily total energy of central cooling and dehumidifier was plotted against the daily average dT between outdoors and indoors in a series of figures. A least-squares best-fit regression analysis was completed. (Results are shown in Figure 12 for the SEER 13 system.) Regression analysis using a second-order polynomial was not statistically significant at 95\% confidence; therefore, linear best-fit was used here. Ducting the OA to the dehumidifier apparently used more energy. P-values indicated the difference was statistically significant at 95\% confidence level; however, there available data for the OA direct to dehumidifier configuration were lacking. The regression analysis suggested that running the OA directly to the dehumidifier used $1.04 \mathrm{kWh} /$ day $(4.4 \%)$ more than OA direct into the living room for an average summer day with $\mathrm{dT}=5^{\circ} \mathrm{F}$. 


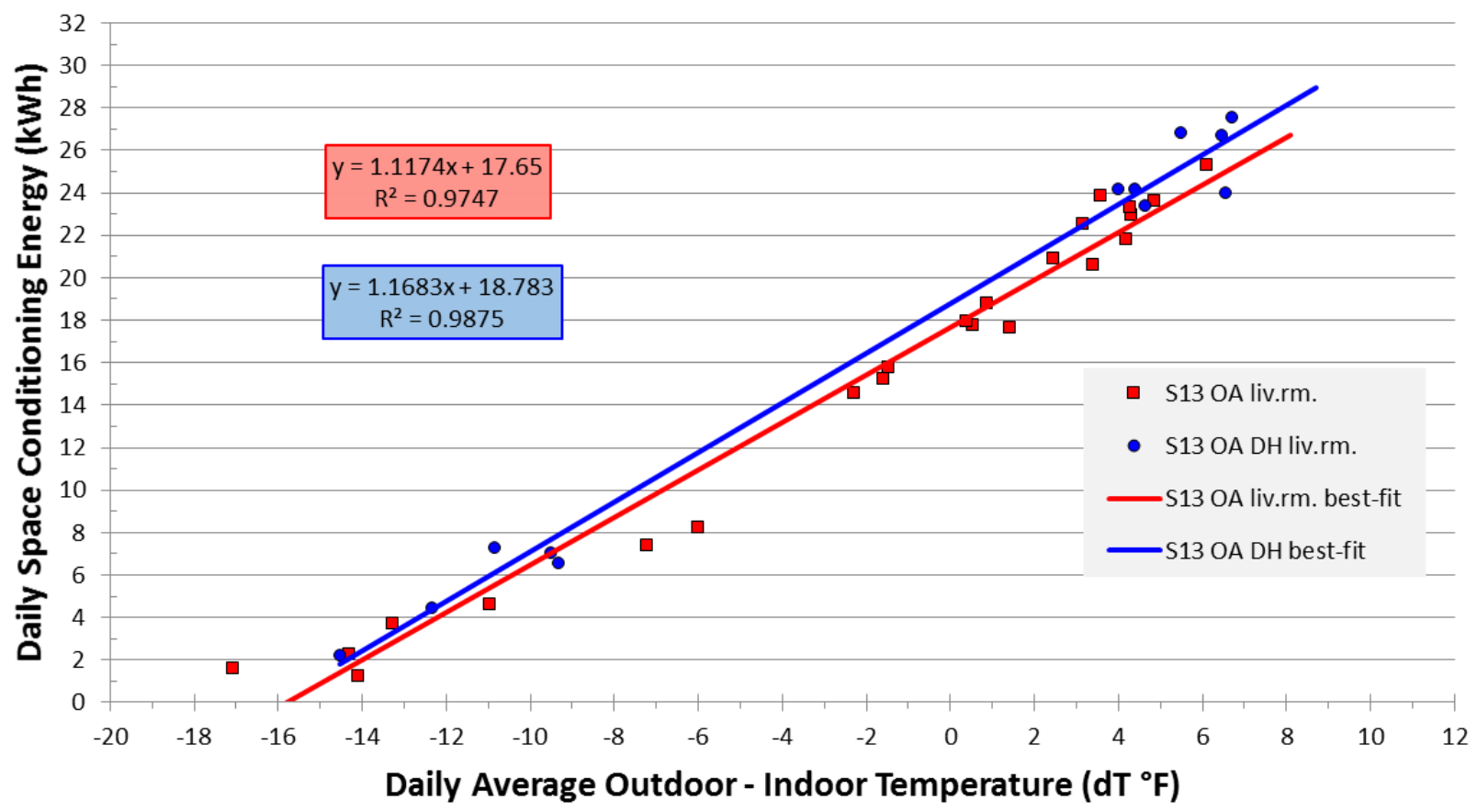

Figure 12. Daily cooling and dehumidifier energy plotted at daily average dT for SEER 13 central system with OA ducted into the living room area at two locations

The least-squares best-fit analysis was completed for the SEER 22 system (Figure 13). Statistical analysis indicated that the P-value was too high to support a statistically significant difference between these two configurations at 95\% confidence. Additional data (not available), particularly in the SEER 22 OA-to-dehumidifier configuration, may have been able to establish a statistically significant difference. Because the SEER 22 system had nearly twice the runtime as the SEER 13 system, indoor air may have mixed more and thus had less impact on where the OA was supplied in the living room. 


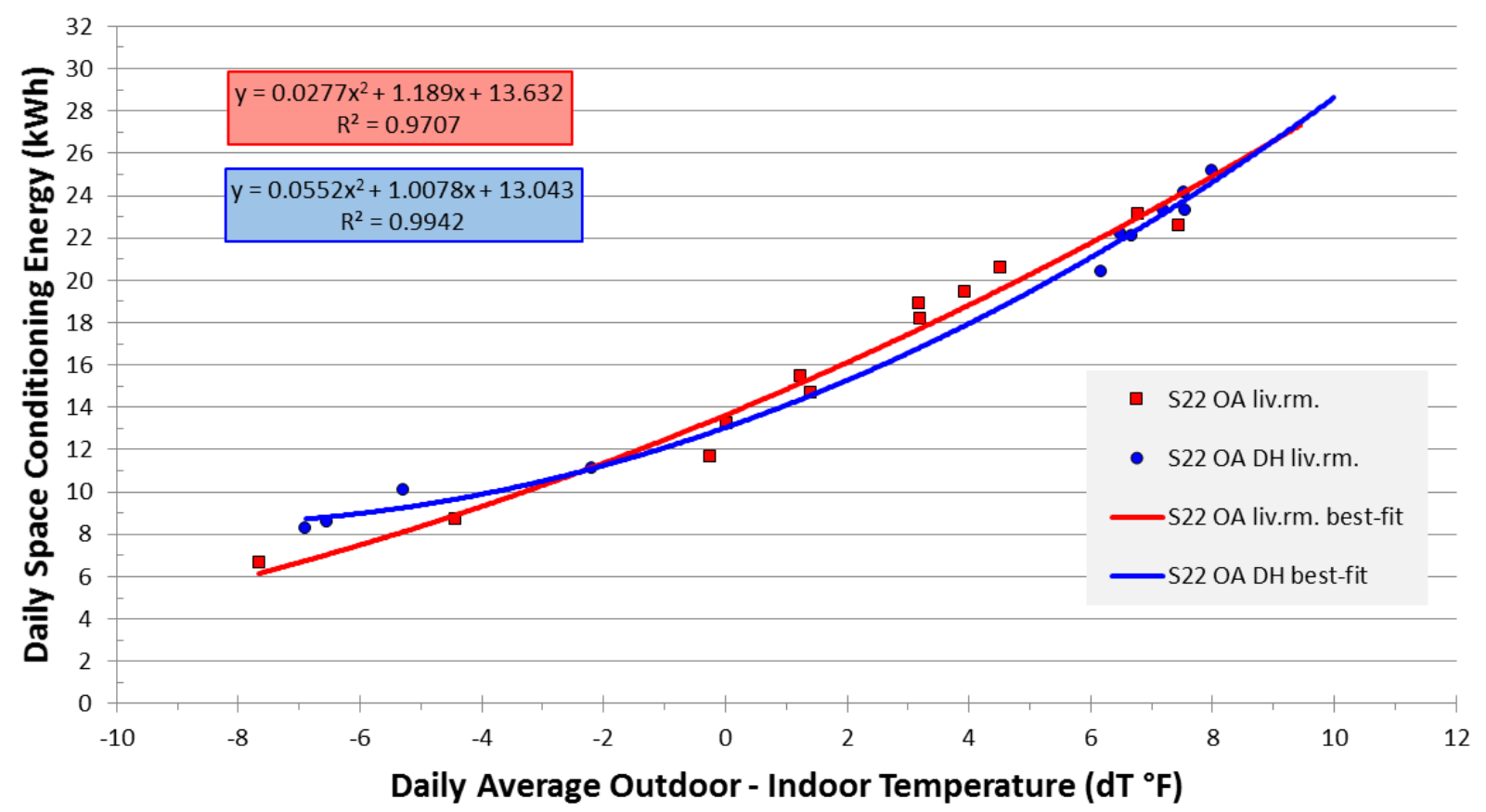

Figure 13. Daily cooling and dehumidifier energy plotted at daily average dT for SEER 22 central system with OA ducted into the living room area at two locations

Combining both test configurations produced the results shown in Figure 14, which were used in the seasonal energy analysis, because the difference between the individual tests of Figure 13 was not statistically significant.

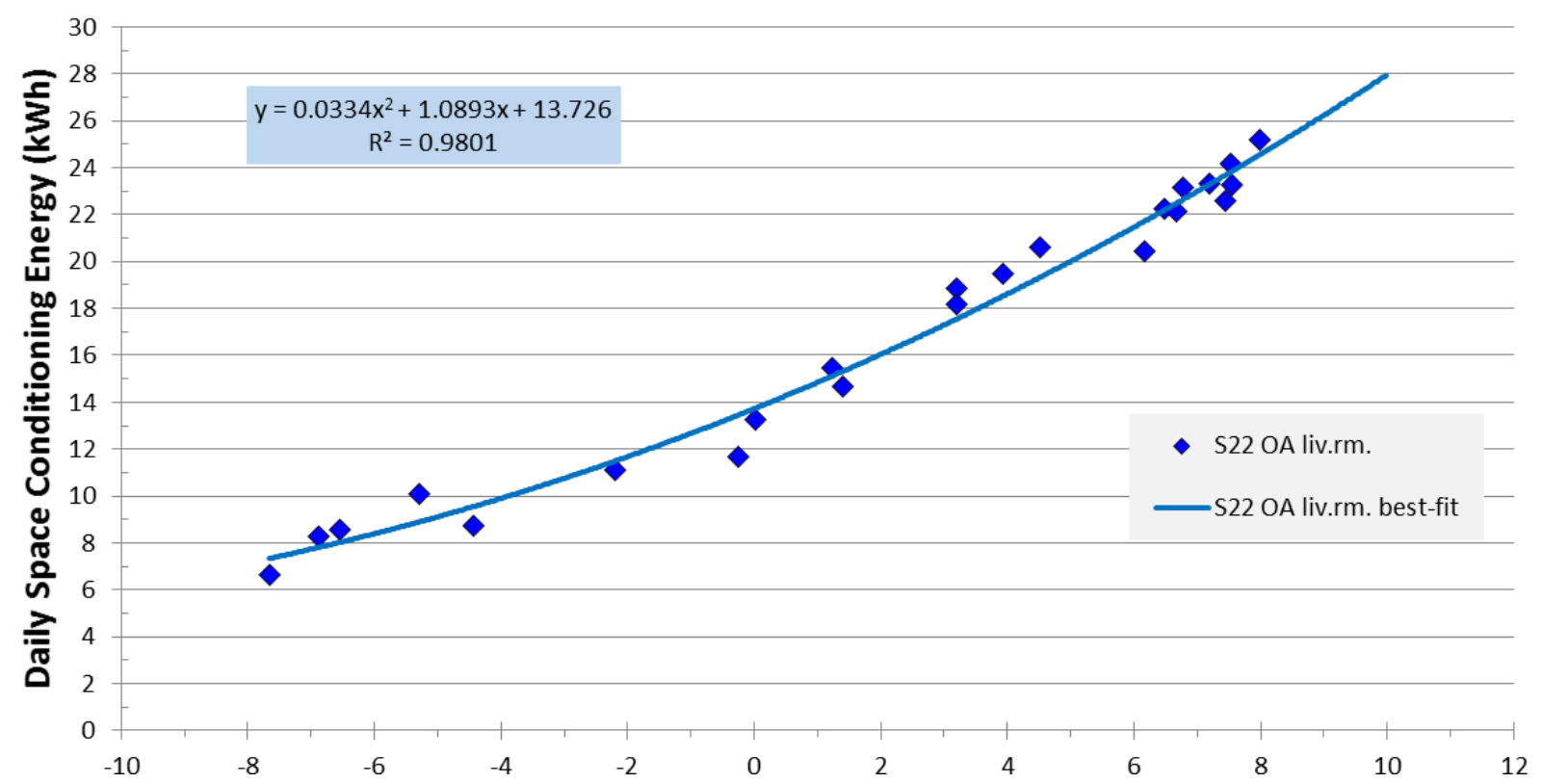

Figure 14. Daily cooling and dehumidifier energy plotted at daily average dT for SEER 22 central system with OA ducted into the living room area 


\subsubsection{Outdoor Air Supplied to a Central Living Room Area with Mini-Split Heat Pump Enabled}

Two test configurations were run with an MSHP in the economy control mode unless stated otherwise. One configuration ran the SEER 13 ducted system with MSHP and the other ran the SEER 22 ducted system with MSHP. In each configuration, OA was delivered directly to the return intake of an MSHP, which was operated as the primary cooling system and was enabled to run along with a centrally ducted system. More cooling load was shifted to the MSHP by setting its cooling set point a few degrees lower than the centrally ducted system. Each centrally ducted system had a $76^{\circ} \mathrm{F}$ set point and would cycle on if the MSHP did not keep up with the cooling load.

Evaluation of a MSHP was desirable, because it would have long runtime that would have resulted in capture of the OA at the MSHP and conditioning of the OA before mixing indoors. Figure 15 shows the combined cooling energy of the SEER 13 centrally ducted system with the ductless MSHP plotted against the daily average dT between outdoors and indoors. Figure 16 shows the combined cooling energy of the SEER 22 ducted system with the ductless MSHP plotted against the daily average dT.

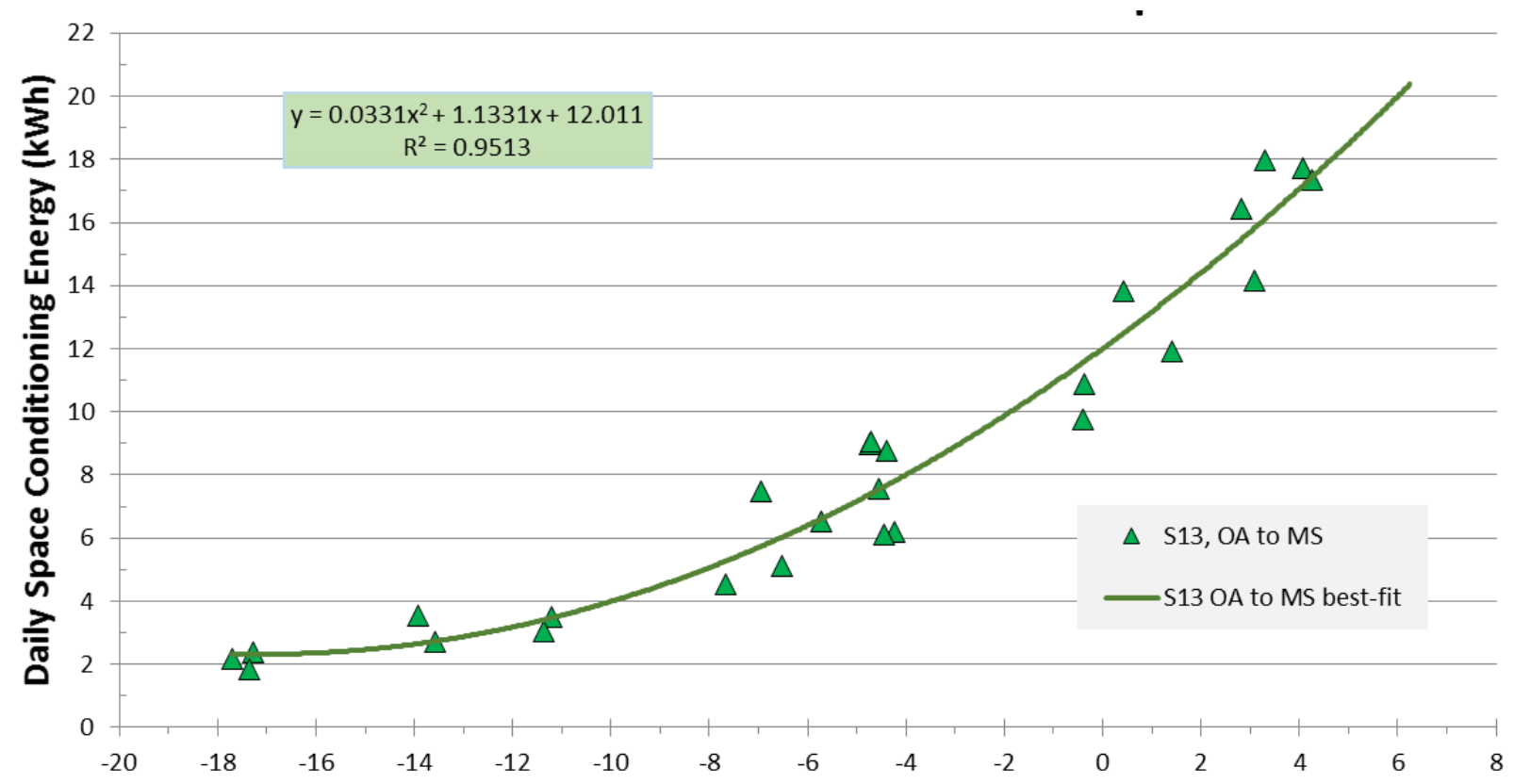

Figure 15. Daily SEER 13 plus MSHP cooling energy versus daily average dT when OA was supplied to MSHP return intake with MSHP set to economy operational mode 


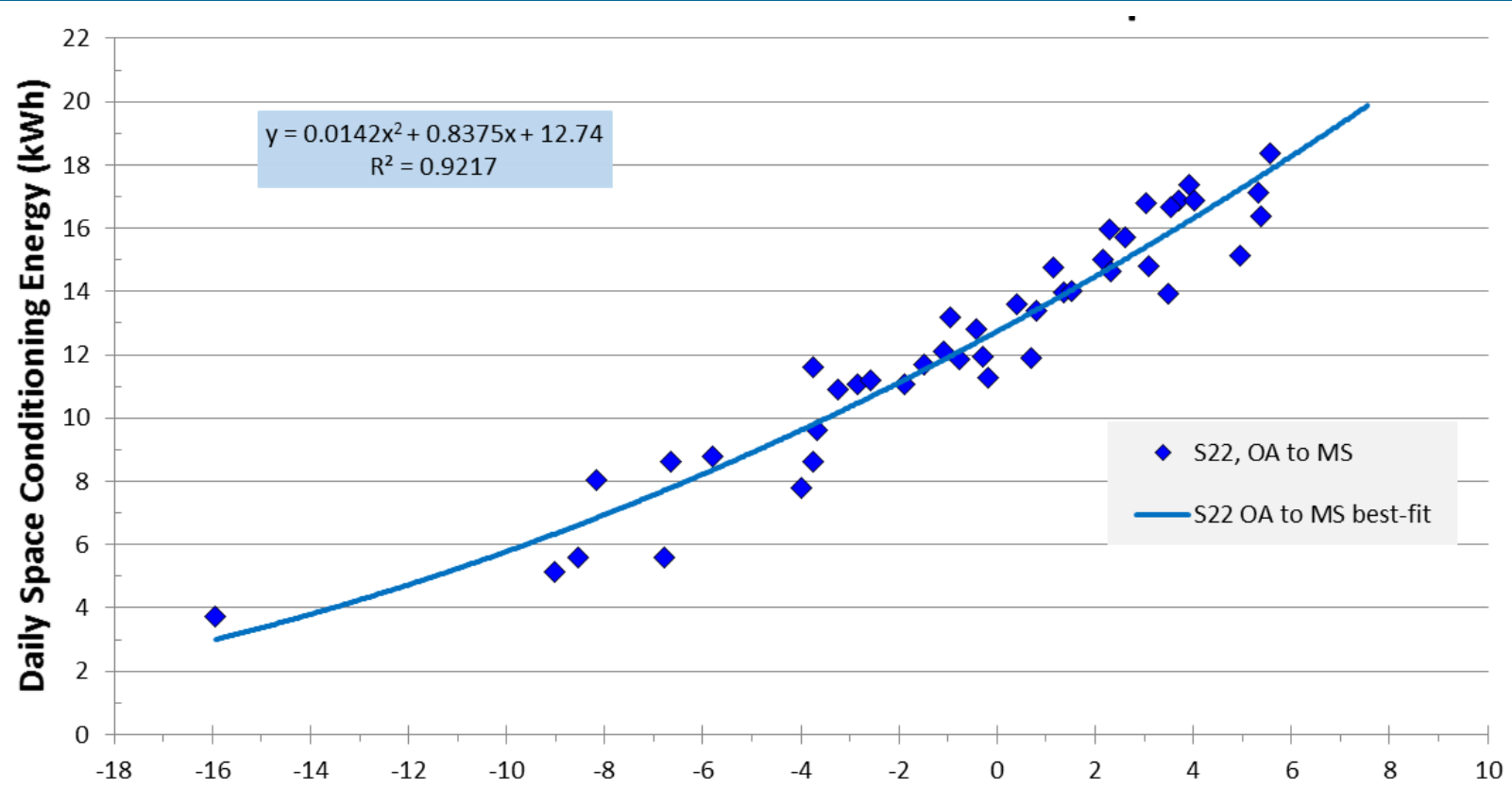

Figure 16. Daily SEER 22 plus MSHP cooling energy versus daily average dT when OA was supplied to MSHP return intake with MSHP set to economy operational mode

Based on an average summer day with $\mathrm{dT}=5^{\circ} \mathrm{F}$ and $\mathrm{OA}$ delivered to the MSHP in the living room, the SEER 13 system configuration would use $18.5 \mathrm{kWh}$ /day and the SEER 22 configuration would use $17.3 \mathrm{kWh} /$ day. This indicates that the SEER 22 system saved 1.2 $\mathrm{kWh} /$ day $(6.5 \%)$ compared to the SEER 13 configuration.

\subsubsection{Seasonal Energy Savings Comparisons}

Table 3 summarizes the daily cooling energy for a typical summer day having a dT $=5^{\circ} \mathrm{F}$ (outdoor $81^{\circ} \mathrm{F}$ - indoor $76^{\circ} \mathrm{F}$ ) for the eight primary test configurations. The reduction in energy use from the SEER 13-based ducted system to SEER 22 ducted system is shown in the far right column of Table 3 .

Table 3. Daily Space Conditioning Energy for a Typical Summer Day with dT $=5^{\circ} \mathrm{F}$ for SEER 13 and SEER 22 Ducted Systems with OA Supplied to Different Locations

\begin{tabular}{c|c|c|c}
\hline Test Configuration & $\begin{array}{c}\text { SEER 13 } \\
\text { (kWh/day) }\end{array}$ & $\begin{array}{c}\text { SEER 22 } \\
\text { (kWh/day) }\end{array}$ & $\begin{array}{c}\text { SEER 22 } \\
\text { Savings } \\
\text { (kWh/day [\%]) }\end{array}$ \\
\hline OA to Central Return; Dehumidifier Enabled & 21.8 & 17.4 & $4.4(20.2 \%)$ \\
OA to Living Room; Dehumidifier Enabled & 23.2 & 20.0 & $3.2(13.8 \%)$ \\
OA to Dehumidifier in Living Room & 24.6 & 20.0 & $4.6(18.7)$ \\
\hline OA to MSHP in Living Room & 18.5 & 17.3 & $1.2(6.5 \%)$ \\
\hline
\end{tabular}

OA supplied directly to the dehumidifier in the living room used the most energy for the SEER 13 system. There was not a statistically significant difference to claim greater energy use with OA ducted to the dehumidifier when the SEER 22 system was used, but OA supplied to the living room/dehumidifier did use the most energy for the SEER 22 system test configurations. 
For convenience the results shown in Table 3 have been reorganized to show the energy impacts based on the OA supply location and dehumidification strategy with the SEER 13 centrally ducted system. The energy reduction for each test configuration shown is compared to the OA ducted to the dehumidifier test configuration (Table 4).

Table 4. Daily Space Conditioning Energy for a Typical Summer Day with $\mathrm{dT}=5^{\circ} \mathrm{F}$ Comparing Results Based on OA Location and Dehumidification Method with SEER13 Central System

\begin{tabular}{c|c|c|c}
\hline Test Configuration & $\begin{array}{c}\text { Daily Use } \\
(\mathbf{k W h} / \mathbf{d a y})\end{array}$ & $\begin{array}{c}\text { Savings } \\
(\mathbf{k W h} / \mathbf{d a y})\end{array}$ & $\begin{array}{c}\text { Savings } \\
\mathbf{( \% )}\end{array}$ \\
\hline OA to Dehumidifier in Living Room & 24.6 & - & - \\
OA to Living Room; Dehumidifier Enabled & 23.2 & 1.4 & $5.7 \%$ \\
\hline OA to Central Return; Dehumidifier Enabled & 21.8 & 2.8 & $11.4 \%$ \\
\hline OA to MSHP in Living Room & 18.5 & 6.1 & $24.8 \%$ \\
\hline
\end{tabular}

The SEER 13 OA-to-dehumidifier configuration used 6.1 more $\mathrm{kWh} /$ day $(33 \%)$ than the SEER 13 with OA supplied to the living room and the MSHP enabled. This was the largest impact and was expected, because the MSHP was operated at a lower set point than the centrally ducted system and had a much higher rated efficiency with a SEER of 21.5. This shifted more of the cooling load from the lower-efficiency ducted system to the higher-efficiency ductless system and reduced conductive loads through the attic ducts.

The daily energy use results have also been reorganized to show energy impacts based on the OA supply location and dehumidification strategy with the SEER 22 centrally ducted system. The energy reduction for each test configuration shown is compared to test configuration with OA ducted to living room and to the dehumidifier (Table 5).

Table 5. Daily Space Conditioning Energy for a Typical Summer Day with $\mathrm{dT}=5^{\circ} \mathrm{F}$ Comparing Results Based on OA Location and Dehumidification Method with SEER 22 Central System

\begin{tabular}{c|c|c|c}
\hline Test Configuration & $\begin{array}{c}\text { Daily Use } \\
\text { (kWh/day) }\end{array}$ & $\begin{array}{c}\text { Savings } \\
(\mathbf{k W h} / \mathbf{d a y})\end{array}$ & $\begin{array}{c}\text { Savings } \\
\mathbf{( \% )}\end{array}$ \\
\hline OA to Dehumidifier in Living Room & 20.0 & - & - \\
\hline OA to Living Room; Dehumidifier Enabled & 20.0 & - & - \\
\hline OA to Central Return; Dehumidifier Enabled & 17.4 & 2.6 & $13 \%$ \\
\hline OA to MSHP in Living Room & 17.3 & 2.7 & $13.5 \%$ \\
\hline
\end{tabular}

The percentage savings were about half as much with the MSHP for the SEER 22 system as the SEER 13 system used with the MSHP (13.5\% versus $24.8 \%$, respectively). The measured savings from operating the SEER 22 with SEER 21.5 MSHP compared to SEER 22 with no MSHP were primarily from eliminating attic duct conductive gains by reducing the cooling distributed through the centrally ducted system. The difference in efficiency was not large enough to account for the savings, because the rated efficiencies of the SEER 22 ducted system and the ductless MSHP differed by only $2.3 \%$. In fact, based solely upon the MSHP lower rated SEER efficiency, the MSHP would be expected to use more energy. Of course, efficiencies under rated conditions are different than individual ducted installations and do not account for added loads because of ducts in unconditioned space. The impacts of centrally ducted systems on space-conditioning energy have been determined and documented in the MH Lab. Cummings et al. (2013) found that moving the ducts from the attic to indoors reduced SEER 22 ducted system 
energy use by $2.3 \mathrm{kWh} /$ day (12.4\%). This was reasonably close to the $13.5 \%$ reduction impact of the MSHP. The savings could have been somewhat greater if the centrally ducted AHU fan had not been needed to periodically circulate air throughout the home.

\subsection{Summer Peak Power Impacts}

The summer peak power use of each test configuration was evaluated by using hourly energy versus hourly average dT data in a least-squares best-fit linear regression analysis. Linear equations were used with $\mathrm{dT}$ for a typical summer peak hour dT of $15^{\circ} \mathrm{F}\left(92^{\circ} \mathrm{F}\right.$ outside $-77^{\circ} \mathrm{F}$ inside). An example of one such regression analysis plot is shown in Figure 17. These data represented the test configuration with OA supplied to the SEER 13 central return. The results for eight test configurations with predicted $\mathrm{kW}$ at $\mathrm{dT}=15^{\circ} \mathrm{F}$ are shown in Table 6 .

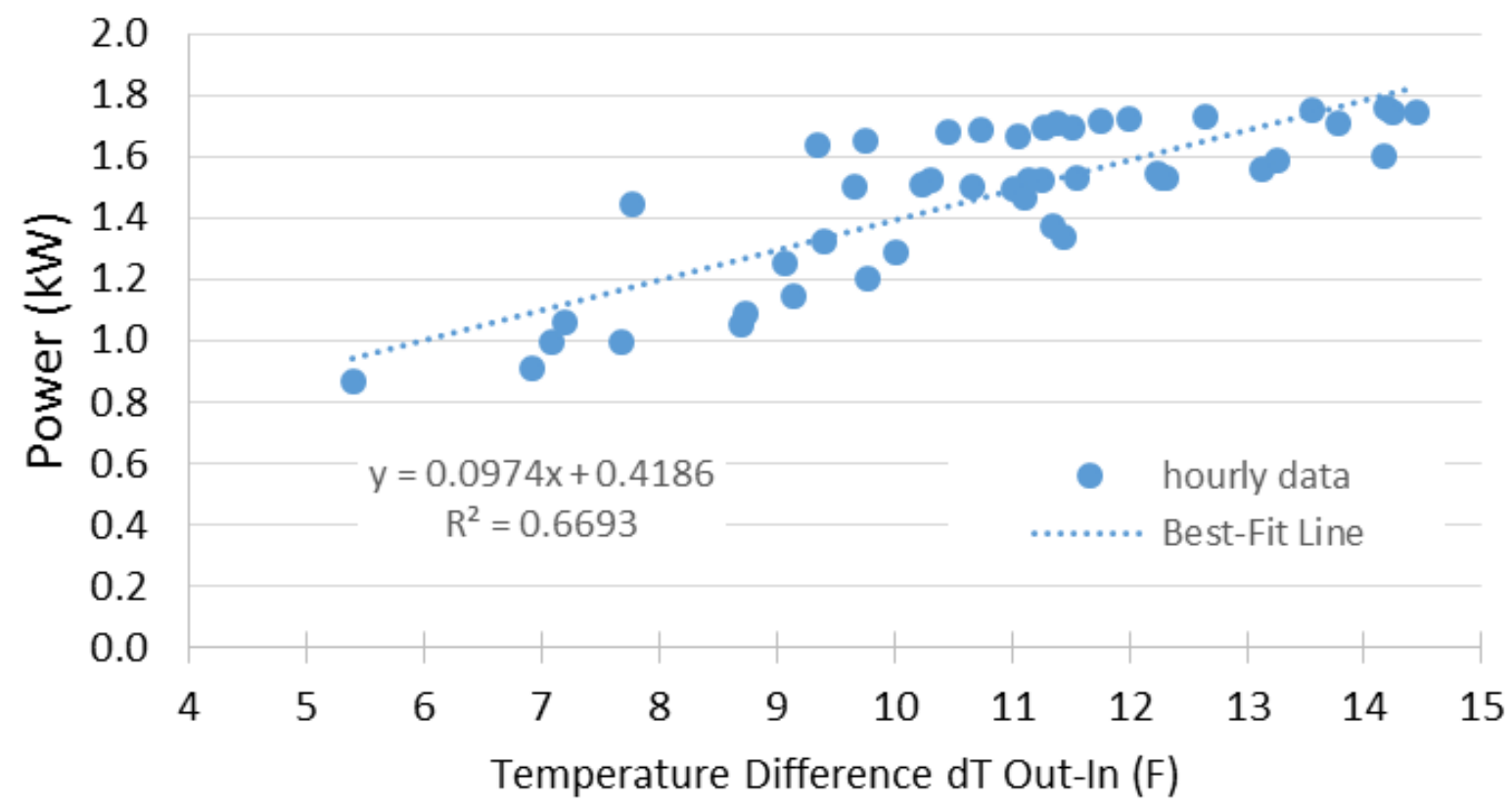

Figure 17. Hourly cooling and dehumidification power versus hourly average dT between outdoors and indoors

Table 6. Predicted Peak Cooling and Dehumidification Power for Summer Peak Hour at $\mathrm{dT}=15^{\circ} \mathrm{F}$

\begin{tabular}{c|c|c|c|c}
\hline Test Configuration & $\begin{array}{c}\text { SEER 13 } \\
(\mathbf{k W})\end{array}$ & $\begin{array}{c}\text { SEER 22 } \\
(\mathbf{k W})\end{array}$ & $\begin{array}{c}\text { SEER 22 } \\
\text { Reduction } \\
\mathbf{( k W )}\end{array}$ & $\begin{array}{c}\text { SEER 22 } \\
\text { Reduction } \\
(\mathbf{\%})\end{array}$ \\
\hline OA to Central Return; Dehumidifier \\
$\begin{array}{c}\text { Enabled } \\
\text { OA to Living Room; Dehumidifier } \\
\text { Enabled }\end{array}$ & 1.88 & 1.54 & $0.34( \pm 0.41)$ & $18 \%$ \\
\hline OA to Dehumidifier in Living Room & 2.04 & 1.56 & $0.49( \pm 0.40)$ & $23.9 \%$ \\
\hline OA to Living Room; MSHP Enabled & 1.49 & 1.13 & $0.36( \pm 0.35)$ & $24.6 \%$ \\
\hline
\end{tabular}

Due to high cooling loads and long cooling runtimes, the dehumidifier never operated during peak summer conditions. This means the peak power indicated was solely from space-cooling 
energy use (by ducted system and/or ductless MSHP if enabled). The dehumidifier operated during the summer for a few cycles in the early mornings (not during summer peak periods).

Peak power use was highest for both the SEER 13 and SEER 22 test configurations with OA ducted to the dehumidifier. Some observations about test comparisons when the SEER 13 system was used follow:

- OA supplied directly to the dehumidifier in the living room used the most peak power when using the SEER 13 ducted system.

O The SEER 13 OA-to-dehumidifier configuration used $0.28 \mathrm{~kW}(15.9 \%)$ more than the SEER 13 with OA direct into the living room.

○ The SEER 13 OA-to-dehumidifier configuration used $0.16 \mathrm{~kW}(8.5 \%)$ more than the SEER 13 with OA supplied to the central return and dehumidifier enabled.

O The SEER 13 OA-to-dehumidifier configuration used $0.55 \mathrm{~kW}(36.9 \%)$ more than the SEER 13 with OA supplied to the living room and MSHP enabled. Just as with the daily energy savings, this was the largest impact and was expected, because this shifted more of the cooling load from the lower-efficiency ducted system to the higher-efficiency ductless system and reduced conductive loads through the attic ducts.

Some observations about test comparisons when the SEER 22 system was used follow:

- OA supplied directly to the dehumidifier in the living room used slightly more peak energy than the other configurations when using the SEER 22 ducted system.

○ The SEER 22 OA-to-dehumidifier configuration used $0.02 \mathrm{~kW}(1.3 \%)$ more than $\mathrm{OA}$ direct into the living room.

○ The SEER 22 OA-to-dehumidifier configuration used $0.02 \mathrm{~kW}(1.3 \%)$ more than with OA supplied to the central return and dehumidifier enabled.

○ The SEER 22 OA-to-dehumidifier configuration used $0.43 \mathrm{~kW}(38.1 \%)$ more than with OA supplied to the living room and MSHP enabled. Most of this impact was expected due to reduced conductive loads through the attic ducts.

\subsection{Indoor Temperature and Humidity Impacts}

Indoor temperatures were measured in each bedroom and in the living room, hall, and utility room. The indoor RH was measured at four locations using seven RH sensors. Three locations had more than one sensor. Redundant measurements were taken in the utility room, in the living room at thermostat/dehumidistat location, and in the master bedroom. The other measurement location was in the central hall area.

Table 7 shows outdoor conditions and indoor conditions at several select indoor locations for eight test configurations during periods when the outdoor dew point was $70^{\circ} \mathrm{F} \mathrm{dp}$ or higher. Daily indoor average temperatures are shown in for primary habitable spaces such as the living room and the average of all three bedrooms. Indoor RH is shown for the living room and the whole-house average. RH for the living room is shown in Table 7, because it was a primary occupied space where OA was delivered in seven of the nine configurations shown. A ninth test 
configuration with the MSHP run in the dry control mode has been added at the bottom of Table 7, but the available outdoor conditions were cooler and drier than in the other eight tests with only 2 days available at elevated outdoor moisture levels. Details about indoor RH in specific areas of the lab home are covered further in Section 4.3.2. 
Table 7. Daily Average Indoor Temperatures and RH When Outdoor Dew Point Temperature Was $70^{\circ} \mathrm{F}$ or Higher

\begin{tabular}{|c|c|c|c|c|c|c|c|c|c|c|c|c|}
\hline & 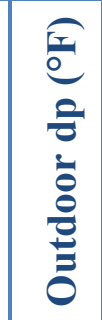 & 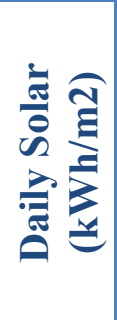 & $\begin{array}{l}\text { I } \\
0 \\
\dot{0} \\
0 \\
0 \\
0 \\
0 \\
0\end{array}$ & 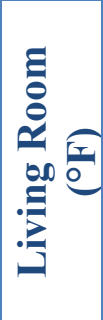 & 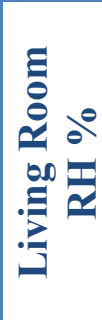 & 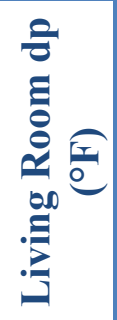 & 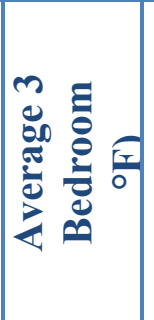 & 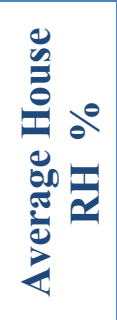 & 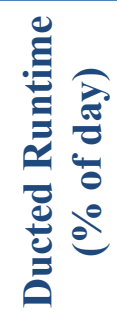 & 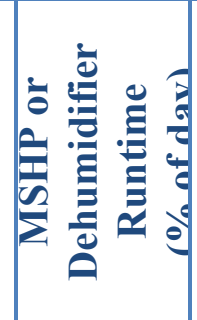 & 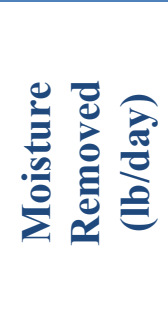 & $\sum_{\text {\# }}^{\infty}$ \\
\hline SEER 13 OA Return Utility Room & 70.2 & 6.0 & 80.1 & 76.9 & 46.3 & 54.7 & 76.7 & 47.7 & 57.2 & 0.0 & 70.4 & 6 \\
\hline SEER 22 OA Return Utility Room & 71.9 & 5.0 & 80.2 & 77.0 & 49.2 & 56.5 & 77.2 & 50.9 & 78.6 & 0.9 & 79.7 & 8 \\
\hline SEER 13 OA Living Room & 71.2 & 4.9 & 79.8 & 77.0 & 51.2 & 57.6 & 76.9 & 52.0 & 55.2 & 0.2 & 74.9 & 11 \\
\hline SEER 22 OA Living Room & 72.3 & 6.0 & 81.7 & 77.0 & 51.4 & 57.7 & 76.8 & 52.8 & 81.0 & 4.3 & 79.2 & 6 \\
\hline SEER 13 OA to DH Living Room & 71.7 & 6.3 & 82.3 & 77.3 & 49.8 & 57.1 & 77.0 & 50.3 & 64.8 & 0.0 & 78.9 & 6 \\
\hline SEER 22 OA to DH Living Room & 72.6 & 6.3 & 84.0 & 77.2 & 51.3 & 57.8 & 76.9 & 52.2 & 87.3 & 2.0 & 84.3 & 7 \\
\hline SEER 13 OA to MSHP Living Room & 71.1 & 5.0 & 80.0 & 75.4 & 53.3 & 57.3 & 78.2 & 52.3 & 9.2 & 95.0 & 67.3 & 10 \\
\hline SEER 22 OA to MSHP Living Room & 72.0 & 3.7 & 77.8 & 75.7 & 55.1 & 58.5 & 78.2 & 54.8 & 0.0 & 99.1 & 61.4 & 8 \\
\hline $\begin{array}{c}\text { SEER 13* OA to MSHP Living Room } \\
\text { Dry Mode }\end{array}$ & 67.5 & 3.4 & 74.5 & 75.0 & 55.9 & 58.2 & 76.5 & 56.1 & 2.8 & 97.7 & 51.4 & 2 \\
\hline
\end{tabular}

Note: Dehumidifier enabled at $60 \%$ RH set point; MSHP in economy control mode set point at $72^{\circ} \mathrm{F}$; MSHP dry in dry control mode set point at $70^{\circ} \mathrm{F}$.

* SEER 13 OA-to-MSHP dry test occurred during much lower cooling load period than other tests shown in Table 7. 
The SEER 22 with OA-to-MSHP living room configuration occurred during a late September period with more cloudiness than others that resulted in a lower average outdoor temperature. Less solar radiant energy and lower outdoor temperature tend to decrease the cooling load and result in somewhat higher indoor RH (Table 7). The cooling load was low enough that the SEER 22 centrally ducted system had no runtime during this period.

Some general observations about daily average conditions follow:

- The daily average indoor RH is considerably lower than $60 \%$ for typical summer days for all test configurations. This does not mean the indoor RH never exceeded $60 \%$ in some rooms. Results for $\mathrm{RH}$ that exceeded $60 \%$ during hourly periods are covered in more detail later.

- Operation with the SEER 22 system resulted in higher average indoor RH. The average $\mathrm{RH}$ of three indoor locations ranged from $0.8 \%$ higher to $3.2 \%$ higher with SEER 22 system test configurations than with SEER 13 test configurations with an average of $2.1 \%$ higher overall.

- Test configurations using only the centrally ducted cooling systems without the MSHP had bedroom to living room temperature differences of $0.3^{\circ} \mathrm{F}$ or less on average.

- The SEER 22 system had about $40 \%$ more daily runtime than the fixed-capacity SEER 13 system. This is based on average daily runtimes in Table 7 for the centrally ducted tests that were performed without the MSHP. The longer runtime was expected, because the SEER 22 system control tried to match load and limit cycling.

- Operation with the MSHP as the primary cooling system caused greater temperature differences between bedrooms and the central living room area where the MSHP was placed. The MSHP test configuration (set point at $72^{\circ} \mathrm{F}$ ) with SEER 13 back-up cooling and fan cycling distribution had an average bedroom to living room temperature difference of $2.8^{\circ} \mathrm{F}$. The MSHP test configuration with SEER 22 back-up cooling and air distribution had an average bedroom to living room temperature difference of $2.5^{\circ} \mathrm{F}$. The daily average difference is smaller than the sustained hourly average difference during the hottest time of year. The typical peak hourly difference between bedrooms and the living room during hot weather was $3^{\circ} \mathrm{F}$ with either central system. The largest difference observed between the warmest bedroom and the living room was about $3.4^{\circ} \mathrm{F}$ before any centrally ducted fan air cycling began.

\subsubsection{Temperature Variations with a Ductless Single-Head Mini-Split Heat Pump}

Thermal distribution was good when the centrally ducted cooling systems were operated as the primary cooling system without the MSHP enabled. During these test configurations the difference between the bedrooms and the central living area was $0.3^{\circ} \mathrm{F}$ or less. Temperature variations increased when the ductless MSHP operated as the primary cooling system and the centrally ducted system provided only back-up cooling without any central system air mixing. Without central system air circulation, the perimeter bedrooms averaged about $2.5^{\circ} \mathrm{F}$ warmer than the central interior area of the $\mathrm{MH} \mathrm{Lab}$ and had a peak difference of $3.9^{\circ} \mathrm{F}$ during the hottest hours of summer. After implementing a centrally ducted fan system air circulation schedule, the average temperature difference between the bedrooms and central area was about $1.6^{\circ} \mathrm{F}$ and had a peak difference below $2.5^{\circ} \mathrm{F}$ during the hottest time of hot summer days. The greatest variation 
occurred between the northeast bedroom and the living room because of a desktop computer and uninterruptible power supply that remained on throughout all the test configurations and added heat to this small room. Greater temperature variation with MSHP operation was expected, because its set point was set at least $2^{\circ}-6^{\circ} \mathrm{F}$ lower than the centrally ducted set points at $76^{\circ} \mathrm{F}$. This intentionally shifted more load to the MSHP where OA was delivered. The goal was to have the MSHP run continuously without cooling the living room lower than $74^{\circ} \mathrm{F}$ during the hottest time of the summer.

Optimal MSHP set point temperature and centrally ducted fan circulation time were determined through a trial-and-error process. Temperature variations could be limited by enabling a centrally ducted fan on cycle of 20 min if no cooling cycle or period of previous fan-on cycle had occurred for $20 \mathrm{~min}$ ( $20 \mathrm{~min}$ off $/ 20 \mathrm{~min}$ fan-on). The delay allowed time for moisture to drain off the coil, which minimized re-evaporation into the space because of flow through a warm coil. This cycle would be interrupted if the centrally ducted thermostat called for cooling.

The MSHP set point was first set at $74^{\circ} \mathrm{F}$, just $2^{\circ} \mathrm{F}$ lower than the central system set point. Although the MSHP had a 100\% runtime on the hottest days, it ran in a very low stage of delivered cooling with supply air around $62^{\circ}-64^{\circ} \mathrm{F}$ during overnight hours. The warmer coil periods resulted in very poor dehumidification. The MSHP control design allowed the room temperature to slowly approach the set point without cycling the unit off. The average room temperature was thus about $2^{\circ} \mathrm{F}$ warmer than set point and the lowest temperature still $0.5^{\circ} \mathrm{F}$ higher than set point. The set point was then reduced to $72^{\circ} \mathrm{F}$. This caused the living room $\mathrm{RH}$ to drop from a daily average of $57 \%$ at $74^{\circ} \mathrm{F}$ set point to about $53 \%$ at $72^{\circ} \mathrm{F}$ set point. Even at $72^{\circ} \mathrm{F}$ set point, the daily average living room temperature was $3.5^{\circ} \mathrm{F}$ (MSHP and SEER 13 ) to $3.7^{\circ} \mathrm{F}$ (MSHP and SEER 22) warmer than the set point as indicated in the average living room temperatures shown in Table 7. By the late fall/winter period (the cooling weather was still prevalent), the MSHP set point was reduced to $70^{\circ} \mathrm{F}$. By the time this set point was used, outdoor conditions were much cooler, the house was "floating" between the heating and cooling balance points, and the living room did not feel as cold as it would during peak cooling season. The periods of floating resulted in overnight conditions with no cooling and interior temperatures that dropped to about $68^{\circ} \mathrm{F}$, then increased to as warm as $75^{\circ} \mathrm{F}$ as internal and external cooling loads increased.

The Fujitsu MSHP also had a dry control mode that was tested late in the project. The dry mode was designed to run at a lower sensible heat ratio (SHR) and allowed room temperature to exceed set point by a few degrees without ramping up the delivered cooling. This design provided improved dehumidification during low load periods. Results from operation in the dry mode are shared in Section 4.4.

\subsubsection{Indoor Relative Humidity Variations}

The indoor humidity results varied according to the test configuration and the outdoor moisture levels (OA latent load). Indoor RH was usually maintained lower than $60 \%$ during the summertime period in the primary habitable areas such as the central living area and bedrooms. The frequency of elevated RH increased in the utility room when OA was brought into it near the centrally ducted system return and in the living room during some overnight hours when OA was brought to the MSHP (operated in the economy mode) in living room. 
Table 8 summarizes the total hours that exceeded $60 \% \mathrm{RH}$ daily average for three indoor habitable spaces using days with an average outdoor dew point of $70^{\circ} \mathrm{F}$ dp or higher. Indoor $\mathrm{RH}$ never exceeded $65 \%$ when the outdoor dew point was $70^{\circ} \mathrm{F}$ or higher, so the hours indicated would have RH limited to $60 \%-65 \%$. The first value of Table 8 is the total hours that RH exceeded $60 \%$, the second value is the total hours of the test data used for the indicated test configuration evaluation, and the last value in parentheses is the percentage of time the $\mathrm{RH}$ exceeded $60 \%$.

Table 8. Frequency of Elevated Indoor RH When Outdoor Dew Point Is $70^{\circ} \mathrm{F}$ or Greater

\begin{tabular}{c|c|c|c|c|c|c|c|c}
\hline $\begin{array}{c}\text { Three } \\
\text { Interior } \\
\text { Locations }\end{array}$ & $\begin{array}{c}\text { SEER } \\
\text { 13 OA } \\
\text { Return } \\
\text { Utility } \\
\text { Room }\end{array}$ & $\begin{array}{c}\text { SEER } \\
\text { 22 OA } \\
\text { Return } \\
\text { Utility } \\
\text { Room }\end{array}$ & $\begin{array}{c}\text { SEER } \\
\text { 13 OA } \\
\text { to } \\
\text { Living } \\
\text { Room }\end{array}$ & $\begin{array}{c}\text { SEER } \\
\text { 22 OA } \\
\text { to } \\
\text { Living } \\
\text { Room }\end{array}$ & $\begin{array}{c}\text { SEER } \\
\text { 13 OA } \\
\text { to DH } \\
\text { Living } \\
\text { Room }\end{array}$ & $\begin{array}{c}\text { SEER } \\
\text { 22 OA } \\
\text { to DH } \\
\text { Living } \\
\text { Room }\end{array}$ & $\begin{array}{c}\text { SEER } \\
\text { 13 OA } \\
\text { to } \\
\text { MSHP* } \\
\text { Living } \\
\text { Room }\end{array}$ & $\begin{array}{c}\text { SEER } \\
\text { 22 OA } \\
\text { to } \\
\text { MSHP } \\
\text { Living } \\
\text { Room }\end{array}$ \\
\hline Central & $0 / 96$ & $0 / 168$ & $2 / 120$ & $0 / 120$ & $0 / 144$ & $0 / 168$ & $0 / 216$ & $0 / 216$ \\
Hallway & $(0 \%)$ & $(0 \%)$ & $(1.7 \%)$ & $(0 \%)$ & $(0 \%)$ & $(0 \%)$ & $(0 \%)$ & $(0 \%)$ \\
Living & $0 / 96$ & $0 / 168$ & $0 / 120$ & $0 / 120$ & $0 / 144$ & $0 / 168$ & $9 / 216$ & $25 / 168$ \\
Room & $(0 \%)$ & $(0 \%)$ & $(0 \%)$ & $(0 \%)$ & $(0 \%)$ & $(0 \%)$ & $(4.2 \%)$ & $(14.9 \%)$ \\
Master & $0 / 96$ & $0 / 168$ & $0 / 120$ & $0 / 120$ & $0 / 144$ & $0 / 168$ & $8 / 216$ & $11 / 168$ \\
Bedroom & $(0 \%)$ & $(0 \%)$ & $(0 \%)$ & $(0 \%)$ & $(0 \%)$ & $(0 \%)$ & $(3.7 \%)$ & $(6.5 \%)$ \\
\hline
\end{tabular}

* MSHP in economy mode.

Hours $>60 \%$ RH are shown beside the total hours of each configuration evaluation period.

In configurations that used the dehumidifier, the hallway was the only location that had any hours with RH higher than $60 \%$ that occurred during the SEER 13 OA directly into living room test. The occurrence was limited to one event covering 2 consecutive hours ( 4 a.m. and 5 a.m.), both of which had an RH of $60.9 \%$.

The test configurations using the MSHP in economy control mode had a noticeable increase in the frequency of elevated $\mathrm{RH}$ in the living room and master bedroom areas of $4 \%-15 \%$. The highest frequency $(15 \%)$ occurred in the living room where OA was supplied for the SEER 22 /MSHP test configuration. RH higher than $60 \%$ was likely during the early mornings when the MSHP was cooling at higher supply air temperatures around $59^{\circ} \mathrm{F}$ to as high as $64^{\circ} \mathrm{F}$, which resulted in poor dehumidification. During late morning through evening hours, cooling output was greater and MSHP supply air temperature operated at $53^{\circ}-55^{\circ} \mathrm{F}$. The colder coil removed more moisture from the air; indoor RH therefore dropped. This is illustrated and discussed in greater detail in Section 4.3.2.4 and subsections thereof that focus on RH impacts with MSHP operation. The MSHP "dry" mode has a much more limited cooling output range designed to improve dehumidification. This control mode could be run during low cooling load period and could improve dehumidification; however, it could likely be improved through thermostat control algorithm modification. Results from the dry control mode are covered in more detail in Section 4.4.

Martin et al. (2014) provide an opportunity to compare resulting indoor RH of continuous exhaust ventilation in occupied homes to the continuous supply ventilation method in the controlled MH Lab. Six occupied high-performance homes with continuous exhaust ventilation 
at about ASHRAE 62.2-2010 levels (averaging about 61 CFM) monitored from late June through mid-October 2014 in Florida had indoor RH that exceeded $60 \%$ an average frequency of $27.4 \%$ of all hours evaluated (calculated from data provided in Figure 2 from Martin et al. 2014). The frequency of hours that exceed $60 \% \mathrm{RH}$ was $14.4 \%-47.9 \%$ of all hours evaluated. Elevated RH is much more frequent for the continuously exhaust-ventilated homes of Martin et al. (2014) compared to any of the continuous supply test configurations evaluated in the MH Lab. Occupancy preferences for cooling set points and occupancy impacts were variable in Martin et al. (2014), whereas occupancy impacts of the MH Lab study were constant. Although that study was conducted during hot and humid weather conditions, weather and internal loads were not exactly the same as during this MH Lab ventilation study. Therefore, the two studies do not provide the basis for a controlled comparison between continuous exhaust and continuous supply ventilation methods. However, the comparison is interesting to consider and may indicate the potential for continuous exhaust methodology to result in higher average indoor RH than continuous supply without supplemental dehumidification.

A composite day of each of the eight test configurations was developed; these configurations are discussed in the next four sections. The composite day comprised 4-9 days when the outdoor average dew point was at least $70^{\circ} \mathrm{F}$ dp. The data that made up these composites covered the period from June 23 through October 1, 2014. The data were at hourly intervals and consisted of indoor temperature and $\mathrm{RH}$ as well as space-conditioning runtime.

The remaining subsections of 4.3.2 and Section 4.4 provide further details about the indoor humidity, temperature, and space-conditioning equipment runtimes. The central living room and bedroom temperatures remain close except when the MSHP was used. As expected, the indoor $\mathrm{RH}$ tended to rise during the overnight hours due to the decreased cooling load and subsequently reduced the air-conditioning runtime. When the MSHP runtime was continuous overnight, the increased RH coincided with an increased SHR.

\subsubsection{Relative Humidity Impacts with Outdoor Air Supplied to Central Return in a Utility Room}

An example of the first two of these composites for test configurations with OA supplied to SEER 13 and SEER 22 returns are shown in Figure 18 and Figure 19, respectively. Figure 18 is a composite day developed from 4 days and shows an increase in hourly average indoor RH to as high as 52\% after the reduced runtime of the SEER 13 central cooling system during overnight hours. The indoor RH dropped to the mid to upper $40 \%$ range just after the longest runtime periods that occurred between 2 p.m. and 4 p.m. 


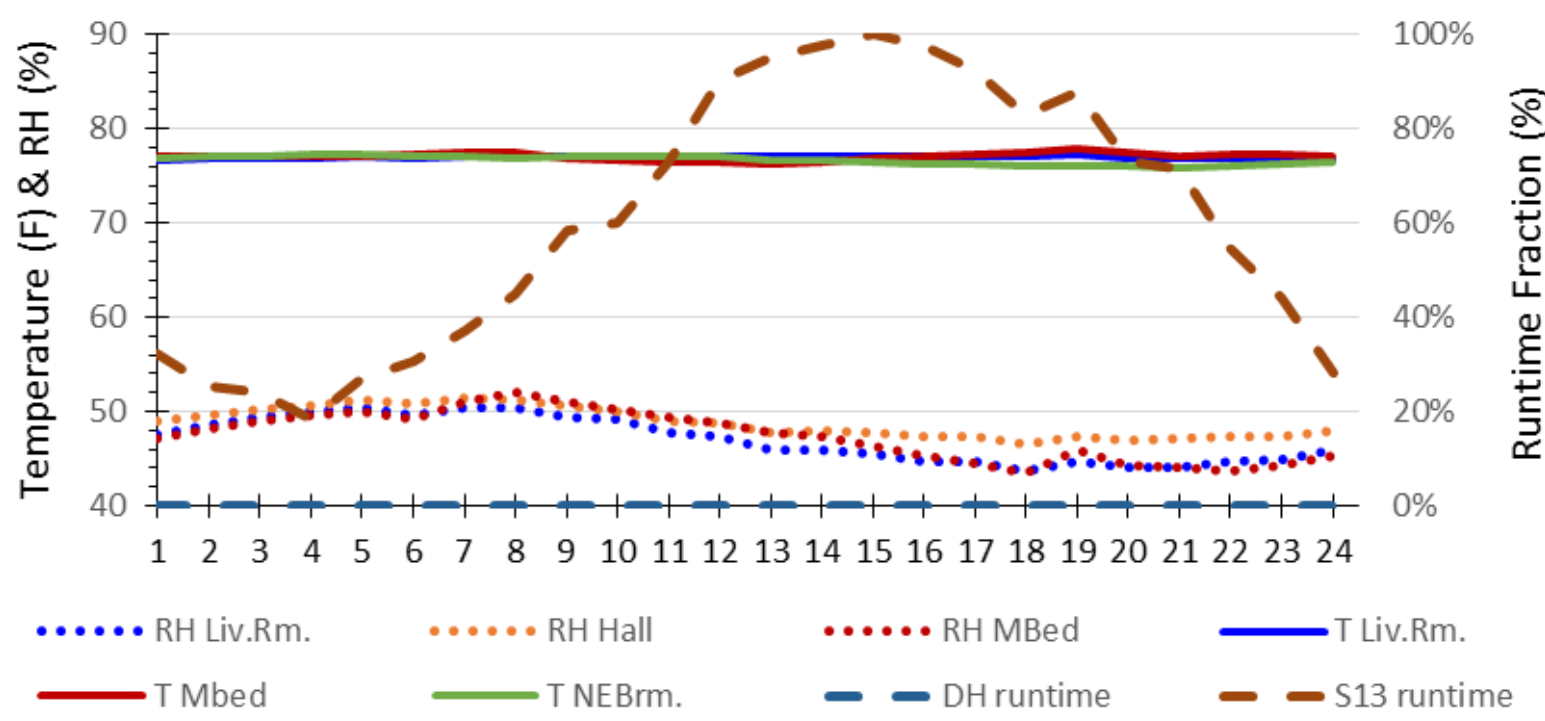

Figure 18. Indoor temperatures, RHs, and space-conditioning runtimes at hourly intervals with OA supplied to SEER 13 return in a utility room

The composite day shown in Figure 19 comprised 7 days. These data also show an increase in hourly average indoor RH after the reduced runtime of the SEER 22 central cooling system during overnight hours. The indoor RH dropped from a high of about $56 \%$ to around $47 \%-49 \%$ at 6 p.m. Actual dehumidifier operation occurred on only 4 of the 7 days represented in this composite. When the dehumidifier operated, only one to two cycles ran per day. An operational cycle would last 13-21 min. The shortest runtimes occurred when the central system cooling cycled on, which increased the mixing of drier air inside the home with the central living room air around the OA supply location. The circulation of air and space conditioning caused the living room area RH to decrease to lower than $60 \%$ and interrupted the dehumidifier cycle. Dehumidifier operation (Figure 19) showed that the probability of operation was most likely during the early morning hours with an average hourly runtime of $0 \%-6 \%$. Due to infrequent cycles, limited runtime, and the possibility that a cycle might begin in one hourly period and run into the next, the indicated runtime in this composite figure is much shorter than the actual runtimes on days with dehumidifier operation. When the dehumidifier cycled on, actual runtimes were 13-21 min, which represented actual hourly runtime fractions of $22 \%-35 \%$ (instead of the graph-indicated composite day average of $3 \%-6 \%$ ). 


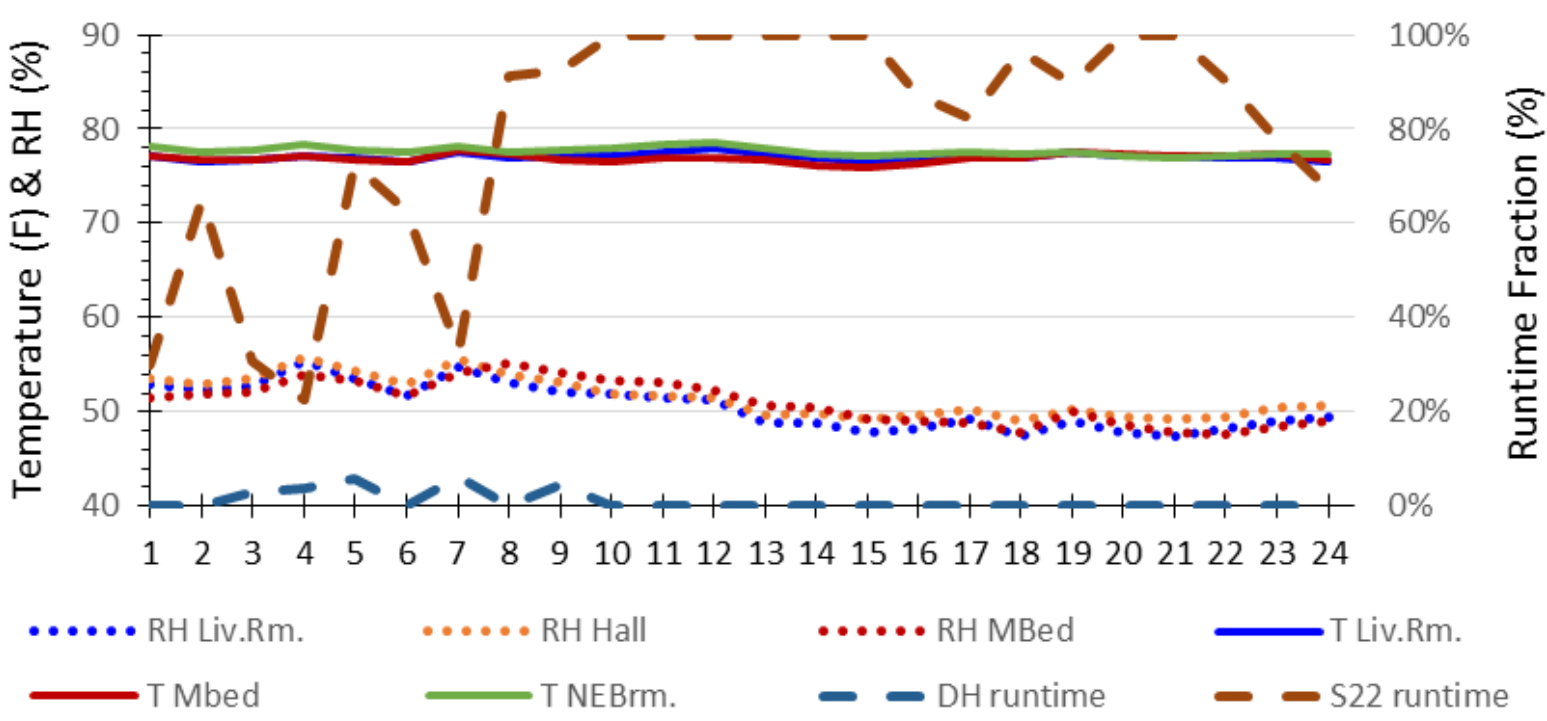

Figure 19. Indoor temperatures, RHs, and space-conditioning runtimes at hourly intervals with OA supplied to SEER 22 return in a utility room

Based on data from Table 8, Figure 18, and Figure 19, no significant periods of elevated indoor $\mathrm{RH}$ occurred during the test configurations with OA supplied to either central return during hot and humid weather. However, the possibility for elevated RH in the utility room, where OA was supplied, was considered after monitoring began. To determine if the utility room had significant periods of elevated RH, two Onset Computer temperature and RH sensors were added to the monitoring effort in the utility room. The sensors were placed on a workspace countertop at about $3 \mathrm{ft}$ above the floor at a distance of about $6 \mathrm{ft}$ from where the OA was supplied to central return intake and within $3 \mathrm{ft}$ of cold supply sections of the ductwork within the room.

Indoor RH was managed well in all areas of the home except sometimes in the utility room with the OA delivered near the central return located in the utility room. Appendix B includes further details about the patterns and conditions at which this occurred.

\subsubsection{Relative Humidity Impacts with Outdoor Air Supplied to Living Room}

Figure 20 and Figure 21 show daily composites of indoor temperature and RH along with the runtimes of the centrally ducted cooling system and dehumidifier. The data were in hourly intervals. Indoor RH rises during the early morning hours with a shorter runtime and falls midday during the longest cooling runtime and higher cooling load. The indoor RH approached $60 \%$ with the SEER 13 central system but stayed lower than the $60 \%$ dehumidifier control point and had no runtime under these weather conditions. The indoor RH shown in Figure 21 with the SEER 22 system is actually a little lower than with the SEER 13 system during early morning hours, because the dehumidifier cycled on. Three dehumidifier cycles occurred each day on average with individual operational cycles that lasted 18-29 minutes. The average daily total dehumidifier energy used on days with three cycles was $0.664 \mathrm{kWh}$. 


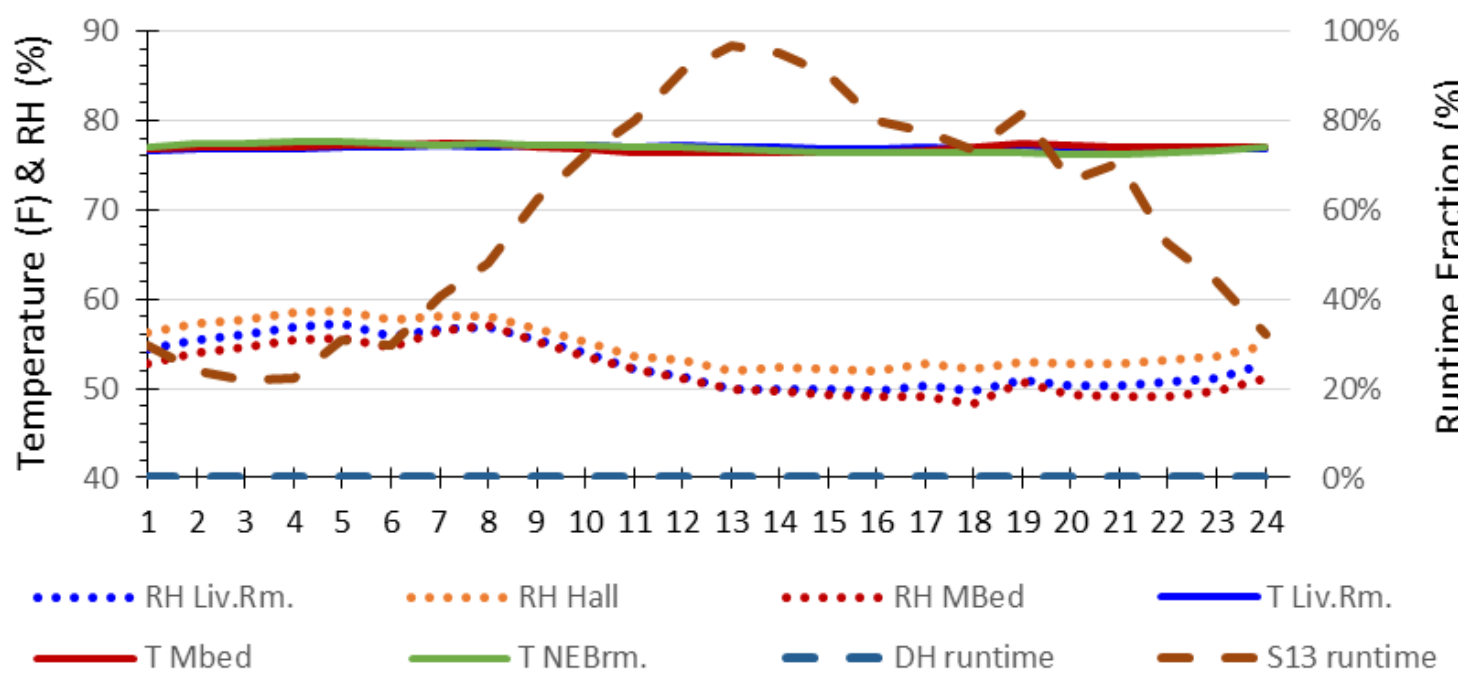

Figure 20. Indoor temperatures, RHs, and space-conditioning runtimes at hourly intervals with OA supplied to the living room and SEER 13 central cooling

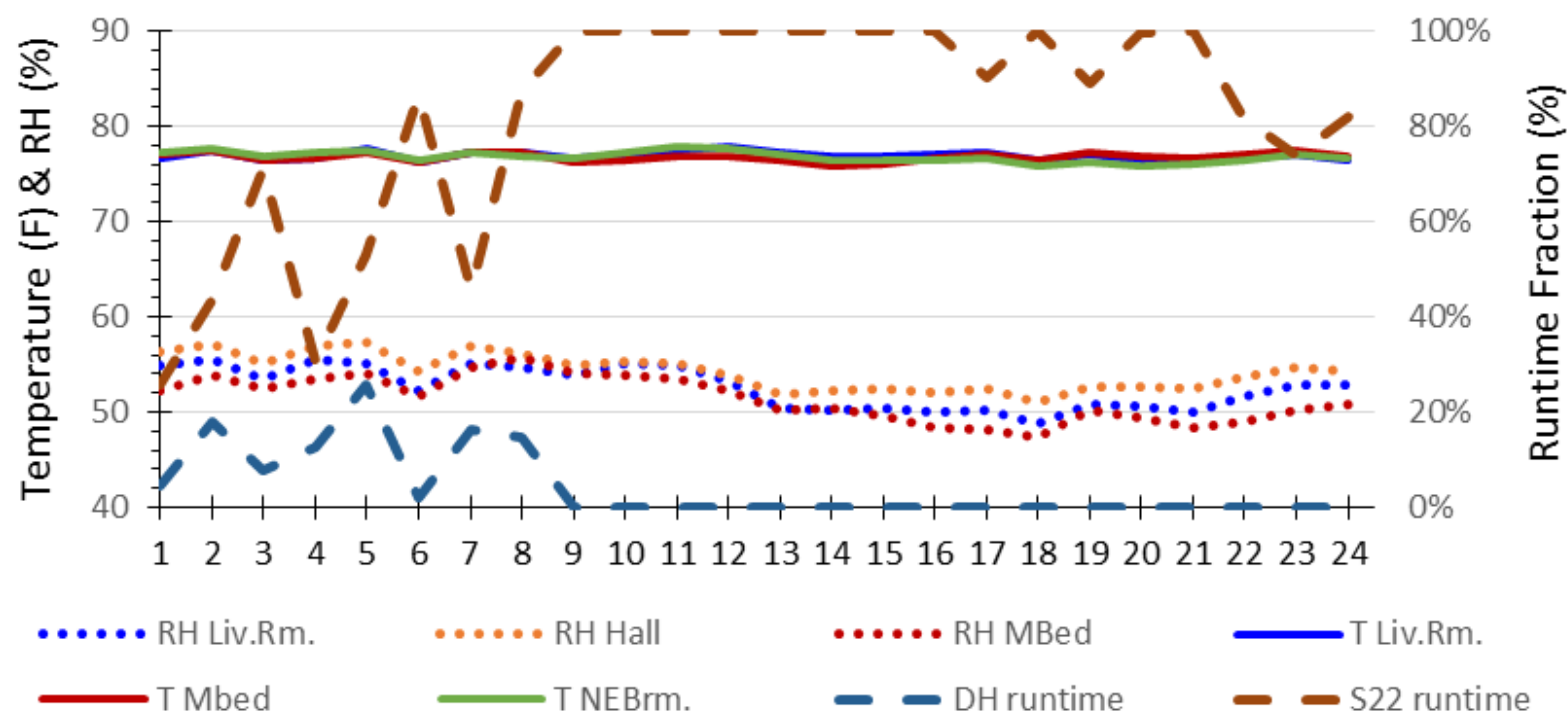

Figure 21. Indoor temperatures, RHs, and space-conditioning runtimes at hourly intervals with OA supplied to the living room and SEER 22 central cooling

\subsubsection{Relative Humidity Impacts with Outdoor Air Supplied Direct to Dehumidifier in the Living Room}

This configuration was nearly the same as the previous covered configuration, except the OA was ducted directly to the dehumidifier about $4 \mathrm{ft}$ above the floor instead of being supplied directly into the living room $7 \mathrm{ft}$ above the floor. The humidity control for the dehumidifier remained at the same location on the living room wall.

Figure 22 and Figure 23 show daily composites of indoor temperature and $\mathrm{RH}$ and the runtimes of the centrally ducted cooling system and dehumidifier. Indoor RH rose during the early morning hours with a shorter runtime and fell midday during the longest cooling runtime and 
higher cooling load period. The indoor RH had similar trends as the other configurations, when the highest RH occurred in early morning hours and lower RH occurred during the warmer daytime hours.

The dehumidifier did not operate during the SEER 13 system tests when the outside dew point was $70^{\circ} \mathrm{F} \mathrm{dp}$ or greater. The dehumidifier operation varied across the 7 days used for the SEER 22 composite in Figure 23. One day had no dehumidifier operation, 3 days had only one dehumidifier cycle averaging $0.177 \mathrm{kWh}$ /day, 2 days had two operational cycles averaging 0.428 $\mathrm{kWh} /$ day, and 1 day had three operational cycles that consumed $0.577 \mathrm{kWh} /$ day. The day that used the most dehumidifier energy followed a previous day of lower solar energy that resulted in less cooling and an increase in indoor humidity.

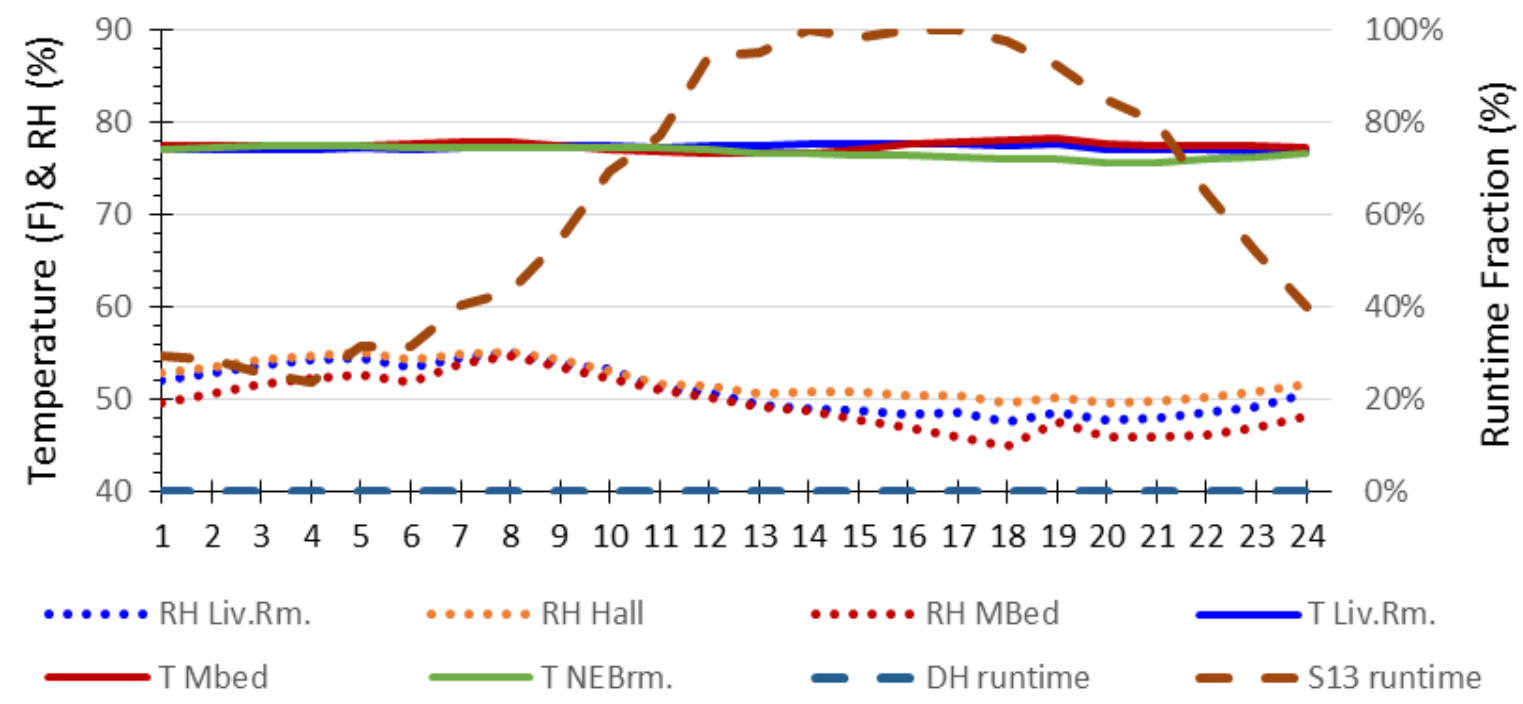

Figure 22. Indoor temperatures, RHs, and space-conditioning runtimes at hourly intervals with OA supplied to a dehumidifier in the living room and SEER 13 central cooling

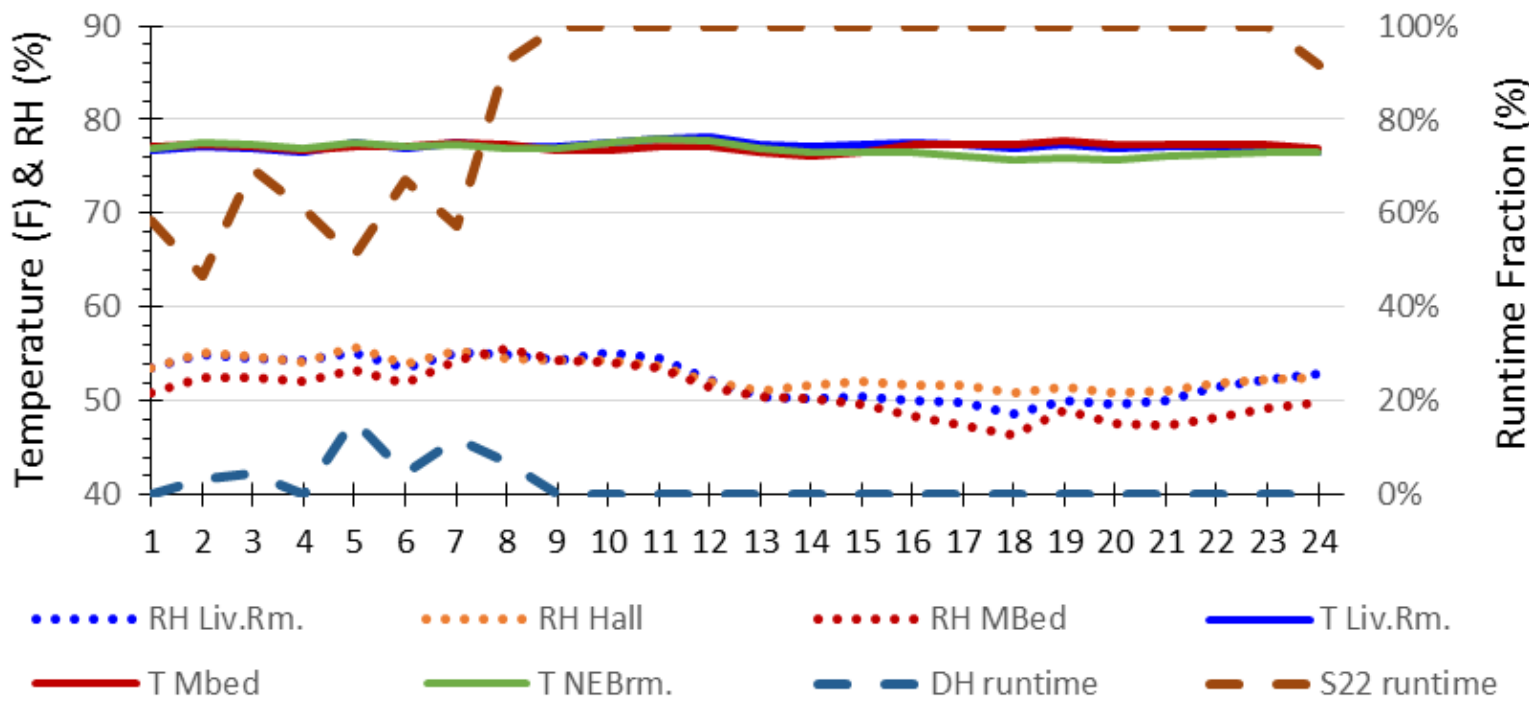

Figure 23. Indoor temperatures, RHs, and space-conditioning runtimes at hourly intervals with OA supplied to a dehumidifier in the living room and SEER 22 central cooling 


\subsubsection{Relative Humidity Impacts with Outdoor Air Supplied to a Ductless Mini-Split Heat Pump in Living Room}

One notable difference this test configuration had compared to others was that the MSHP ran $100 \%$ of the time in the SEER 13 configuration and nearly $100 \%$ of the time with the SEER 22 configuration during typical summer weather. The central cooling systems ran much less than expected. The central SEER 13 had a daily runtime of about $6 \%$ and the central SEER 22 system had a daily runtime of about $5 \%$. The temperature distribution also varied. Daily composites of indoor temperature and $\mathrm{RH}$ are shown along with the runtimes of the ductless MSHP and the SEER 13 centrally ducted cooling system in Figure 24.

Figure 24 is a composite of 9 days from September 3-11, 2014. It shows the indoor RH rose during the late morning hours and fell midday during the longest cooling runtime and higher cooling load period.

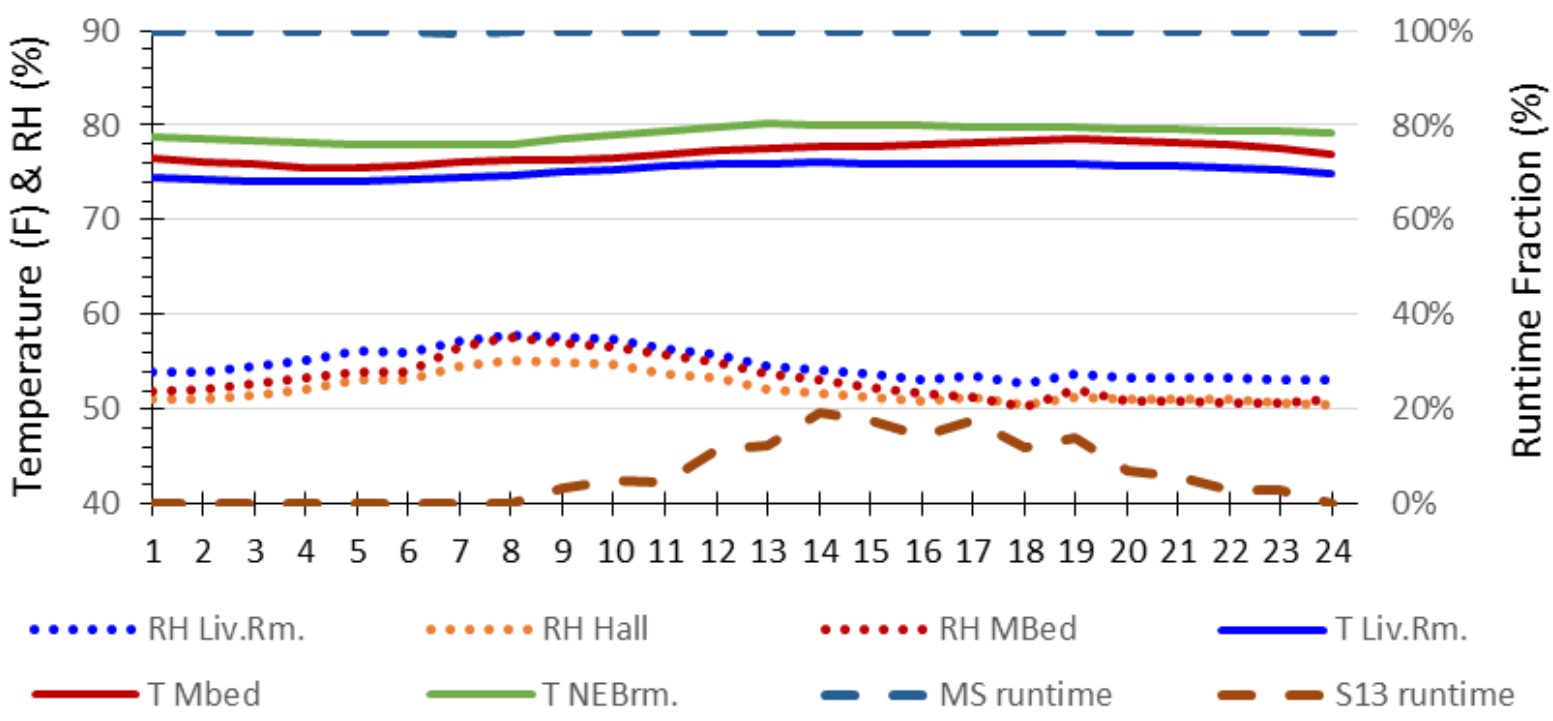

Figure 24. Indoor temperatures, RHs, and space-conditioning runtimes at hourly intervals with OA supplied to a MSHP in the living room and SEER 13 central secondary cooling

Patterns of higher indoor RH were associated with a lower delivered cooling capacity in Figure 25, which shows data with the MSHP and SEER 13 central system from September 4-11, 2014. Indoor RH exceeded $60 \%$ when the delivered cooling rate was at about 0.58 tons. The RH was lower at about $50 \%-55 \%$ when the cooling rate was about 1.2 tons. 


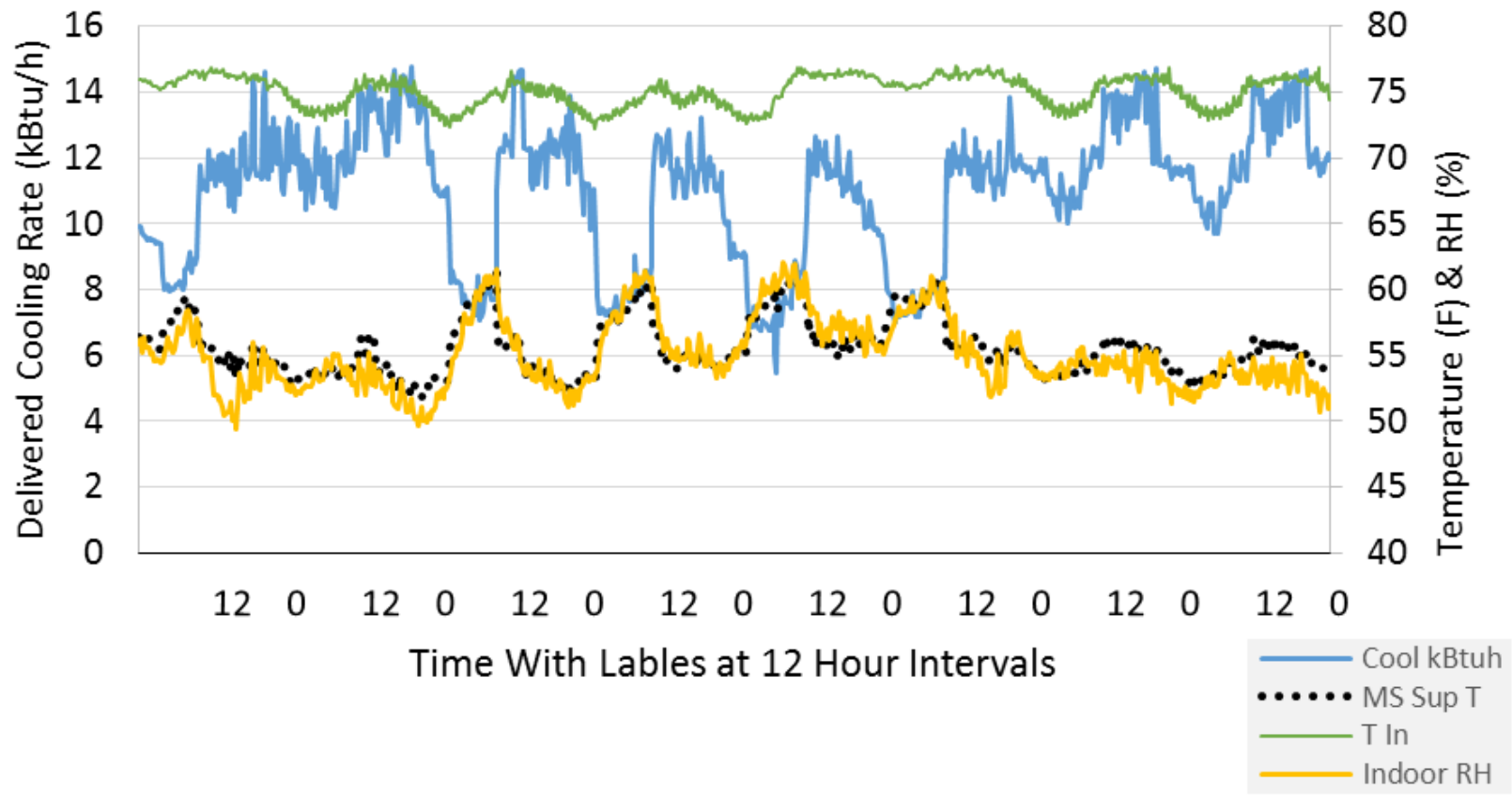

Figure 25. MSHP delivered cooling rates shown with indoor temperatures and RHs in the living room from September 4-11, 2014, with SEER 13 central secondary cooling

Also shown in Figure 25 is the MSHP supply air temperature (black dots), which trended very similarly to the indoor RH in the living room (yellow line). A correlation between the two is shown in Figure 26. The data in Figure 26 are at 15-min average intervals; although the MSHP was the primary cooling system, it was not the only one that operated and removed moisture. Figure 24 shows that the centrally ducted SEER 13 system provided some cooling and dehumidification mainly in the afternoons that removed some moisture and impacted the indoor RH. 


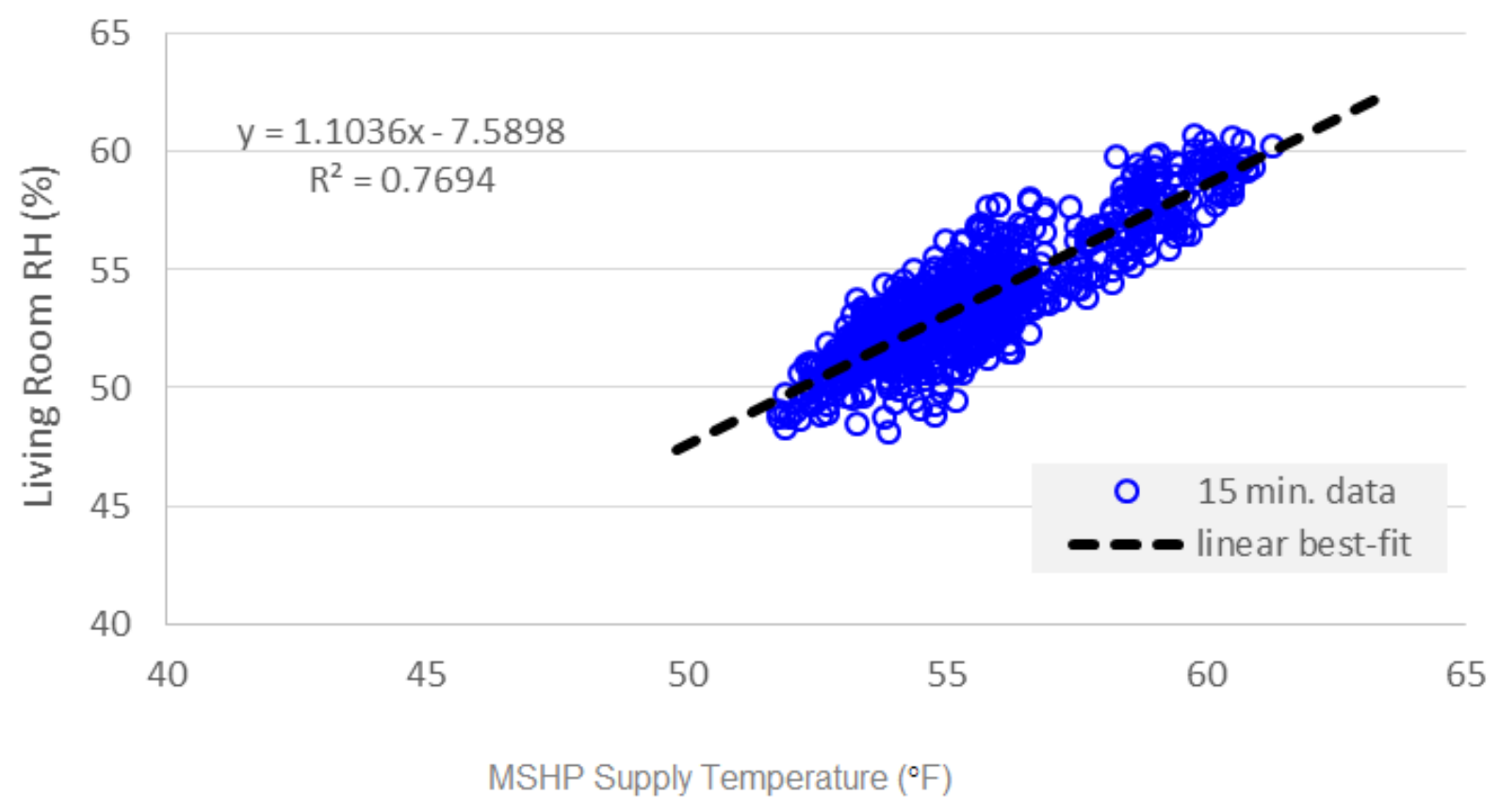

Figure 26. MSHP supply air temperatures plotted against the living room RHs with data at 15-min average intervals from September 4-11, 2014

Refrigeration engineers understand that humidity control in split direct expansion cooling systems decreases as the SHR increases, and SHR increases as CFM/ton rates increase. Shirey (2008) recognized the issue of low cooling load homes, mechanical ventilation, and higher indoor RH potential. His paper provided guidance for improved RH control without supplemental dehumidification and suggested better RH control in fixed- and two-stage-capacity systems could be obtained by lowering the CFM/ton. Conventional fixed-capacity cooling systems have been rated at about $400 \mathrm{CFM} /$ ton. Under normal operating conditions variablecapacity systems vary the cooling output and the CFM/ton depending upon the control design. Shirey et al. (2006) indicated the importance of maintaining a cold coil at varying stages of cooling by properly varying the flow rate. Some of the increased efficiency in SEER 20+ variable-capacity systems is achieved through periods of operation at high CFM/ton. These systems require a balance between higher-efficiency cooling operation and acceptable humidity control. The MSHP CFM/ton can vary significantly.

The MSHP system airflow rate per delivered cooling in tons is shown in Figure 27. The MSHP $\mathrm{CFM} /$ ton rates increased during the lowest cooling capacity output for the MSHP in economy control mode. 


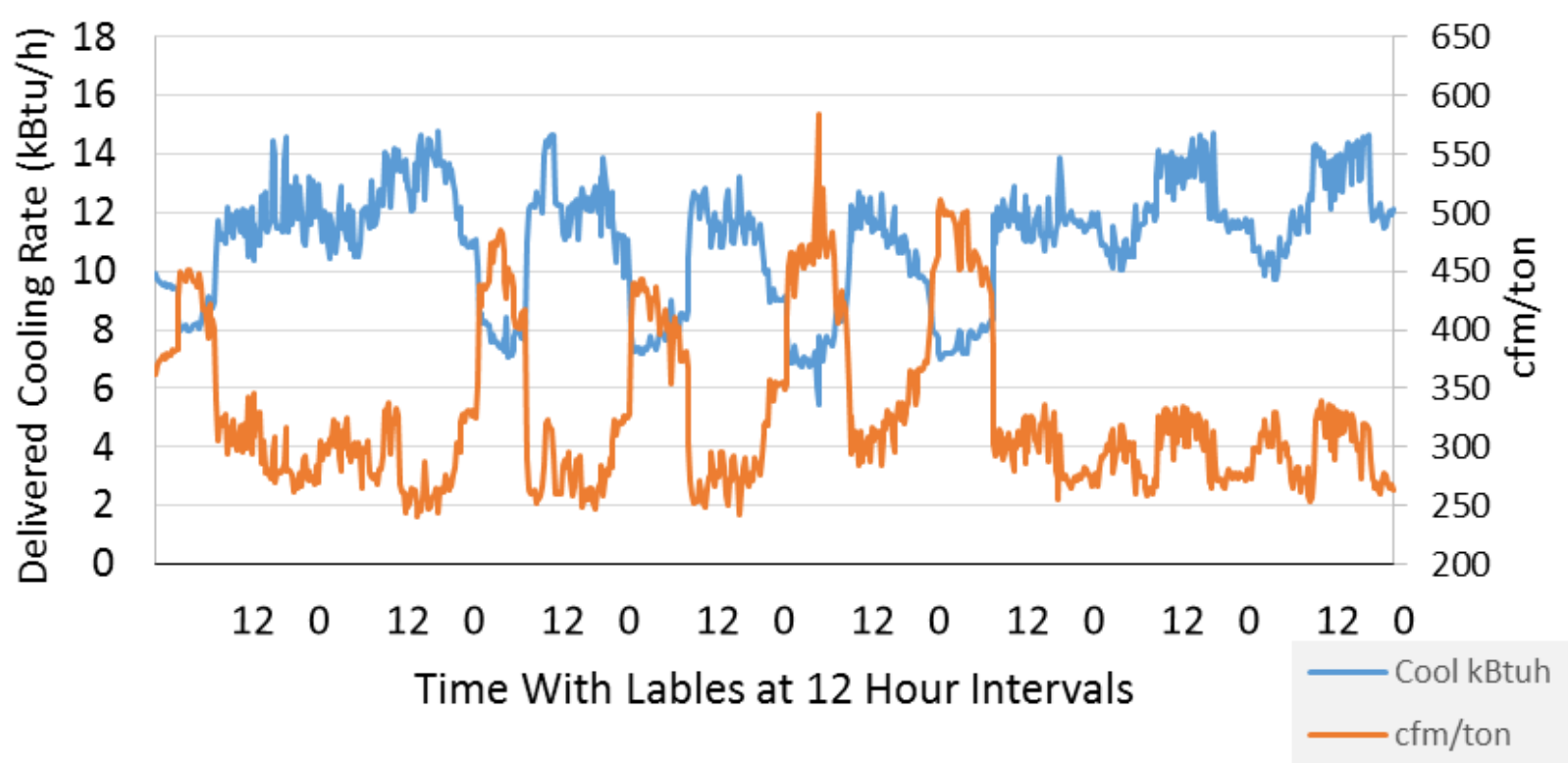

Figure 27. MSHP delivered cooling shown with the airflow rates per cooling (CFM/ton) from September 4-11, 2014, with SEER 13 central secondary cooling

The MSHP tended to stay at fixed flow rates for several hours, and the refrigerant flow varied to adjust cooling output as needed. Figure 28 shows the delivered cooling output versus the CFM/ton. The distinct linear patterns are based upon measured system flow rates of 266-385 CFM.

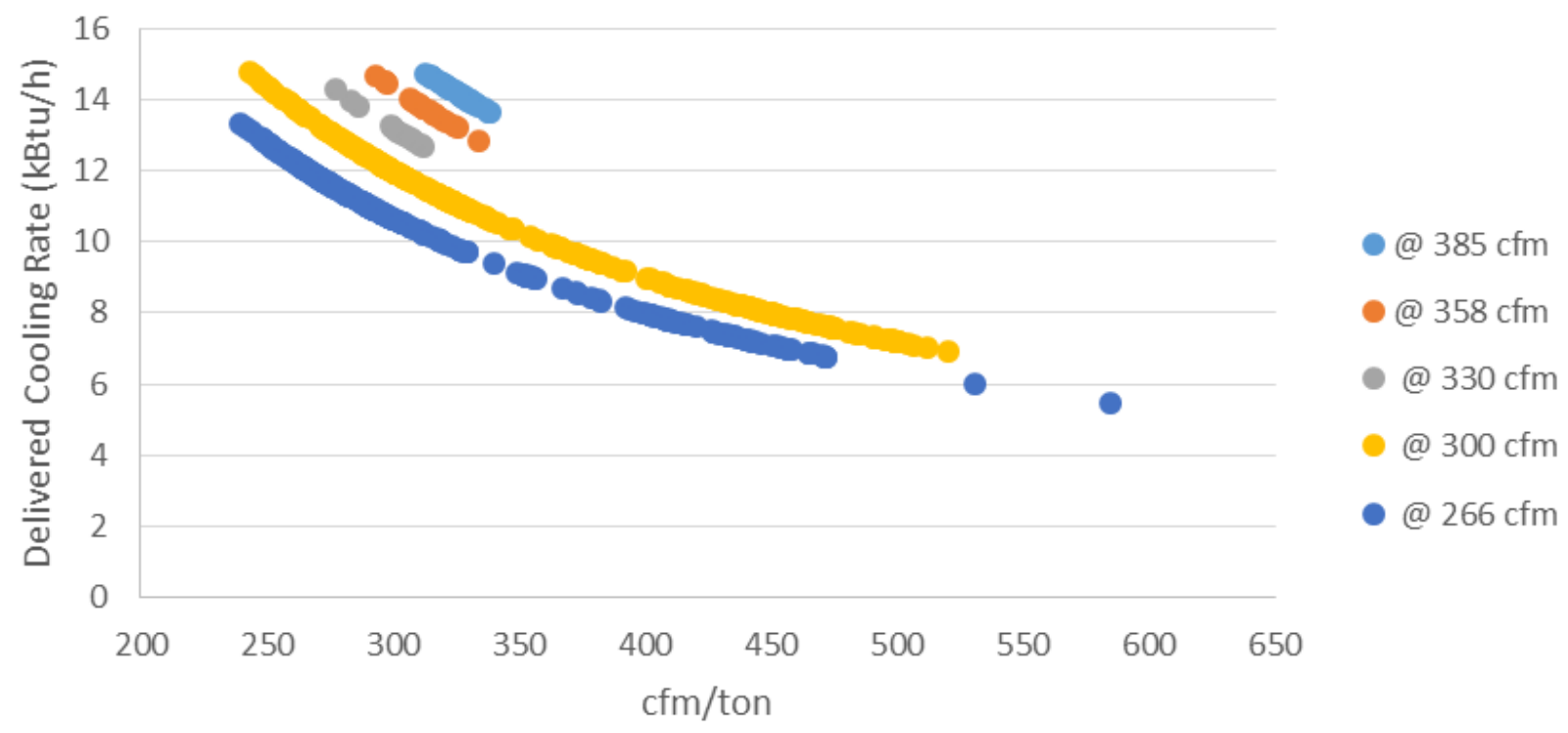

Figure 28. MSHP delivered cooling rates (kBtu/h) versus CFM/ton at five flow rates show distinct linear patterns depending upon the airflow rate

Figure 29 shows a relationship between the indoor living room RH and the MSHP CFM/ton with adjusted time averaging. At first, a straightforward plot of 15-min data average indoor $\mathrm{RH}$ versus 
the 15-min average CFM/ton was made, and a moderate degree of correlation was observed. However, the indoor RH is significantly impacted by cooling performance, load, and internal thermal and moisture capacitance that occurred hours before. A very simple approach to accommodate some of this time delay in impact was taken with the following steps:

1. The 15-min interval data were averaged into a running 2-h previous period average that was calculated at each 15-min interval.

2. The indoor $\mathrm{RH}$ was correlated with the $\mathrm{CFM} /$ ton occurring at earlier periods.

3. A least-squares best-fit regression was done several times using different hours of separation until the best correlation was found.

4. The best coefficient of determination, $\mathrm{R}^{2}$, was found by matching indoor $\mathrm{RH}$ occurring 2 $\mathrm{h}$ and $15 \mathrm{~min}$ later than each CFM/ton period.

Some interesting patterns are imbedded within Figure 29 that indicate various factors were influencing indoor RH. These data include periods when the central system cooling cycled on and off. So some periods represented when the MSHP would transition from one capacity to another and from one airflow speed to another. The lower linear pattern was further investigated and identified to be a continuous period from 12 a.m. to 5:15 p.m. on September 4, when the airflow rate remained constant at $300 \mathrm{CFM}$. The pattern changed as soon as the airflow rate changed (Figure 30). The MSHP airflow rate appeared to be one variable that accounted for improved correlation as $\mathrm{R}^{2}$ improved from 0.73 to 0.94 , when data were used at $300 \mathrm{CFM}$ only instead of at the five rates included in Figure 28. These limited data suggest limiting the steady state CFM/ton to less than $450 \mathrm{CFM} /$ ton for better RH control when improved RH control is desired. This is generally not a concern for cooling in more arid regions outside the hot-humid climate zone. In fact, arid regions benefit from improved efficiency from high CFM/ton without indoor humidity control problems under normal circumstances.

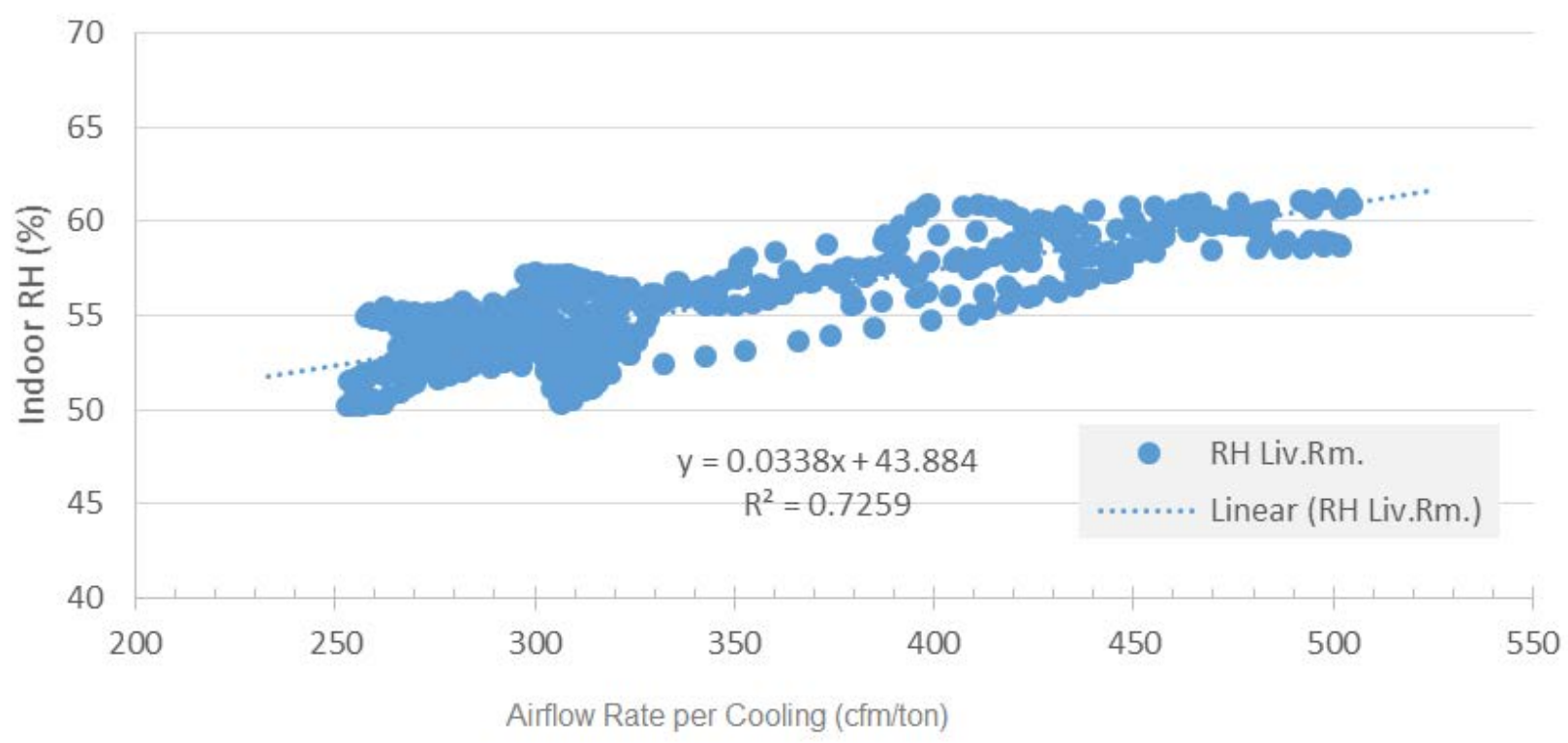

Figure 29. Indoor RH (living room) versus MSHP CFM/ton for September 4-11, 2014 


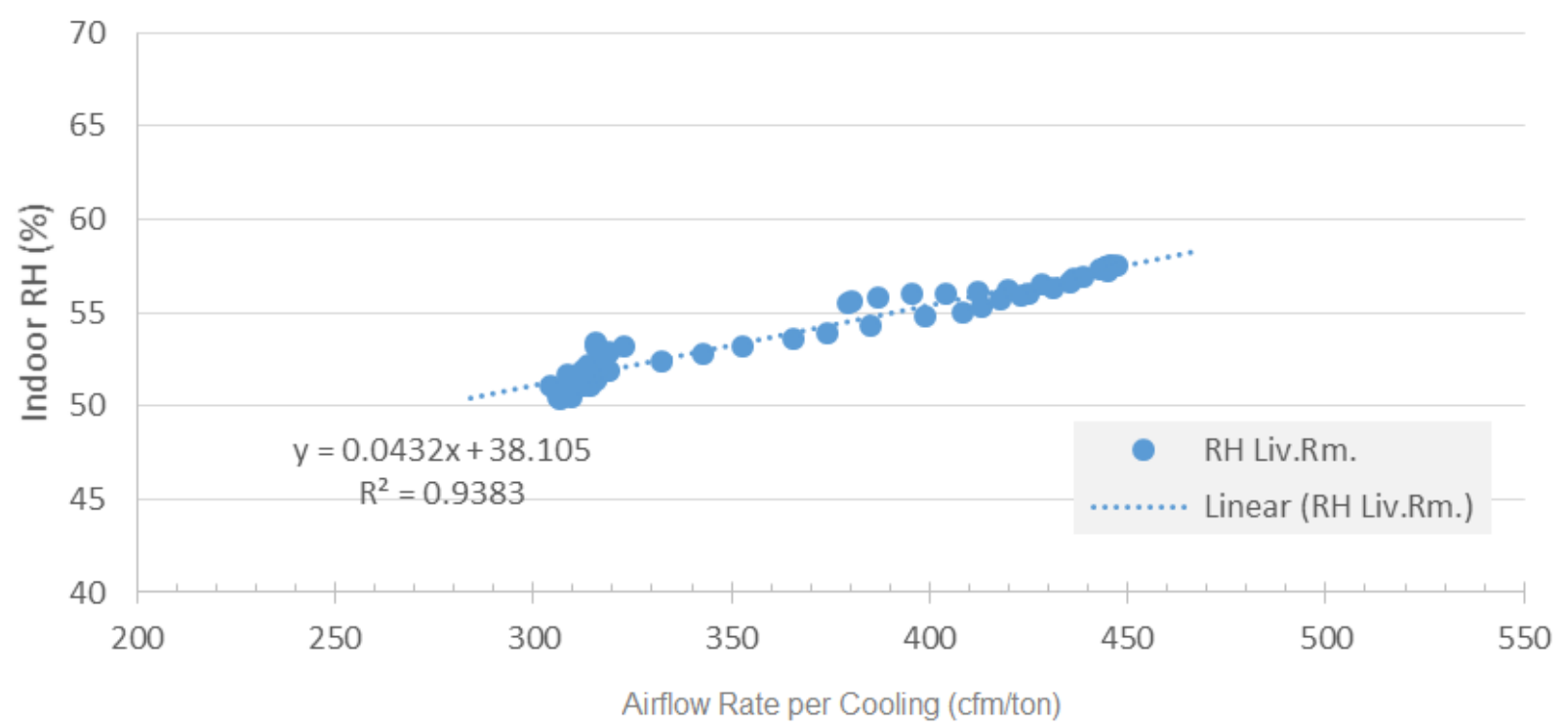

Figure 30. Indoor RH (living room) versus MSHP CFM/ton during $17 \mathrm{~h}$ in September at a constant airflow rate of $300 \mathrm{CFM}$

The MSHP configuration was also run with the SEER 22 central system. Just as with the MSHP/SEER 13 configuration, the indoor RH rose during the late morning hours and fell at midday during the longest cooling runtime and higher cooling load shown in Figure 31, a composite of 8 days from September 25-October 1, 2014. Indoor RH peaks were higher in this test configuration.

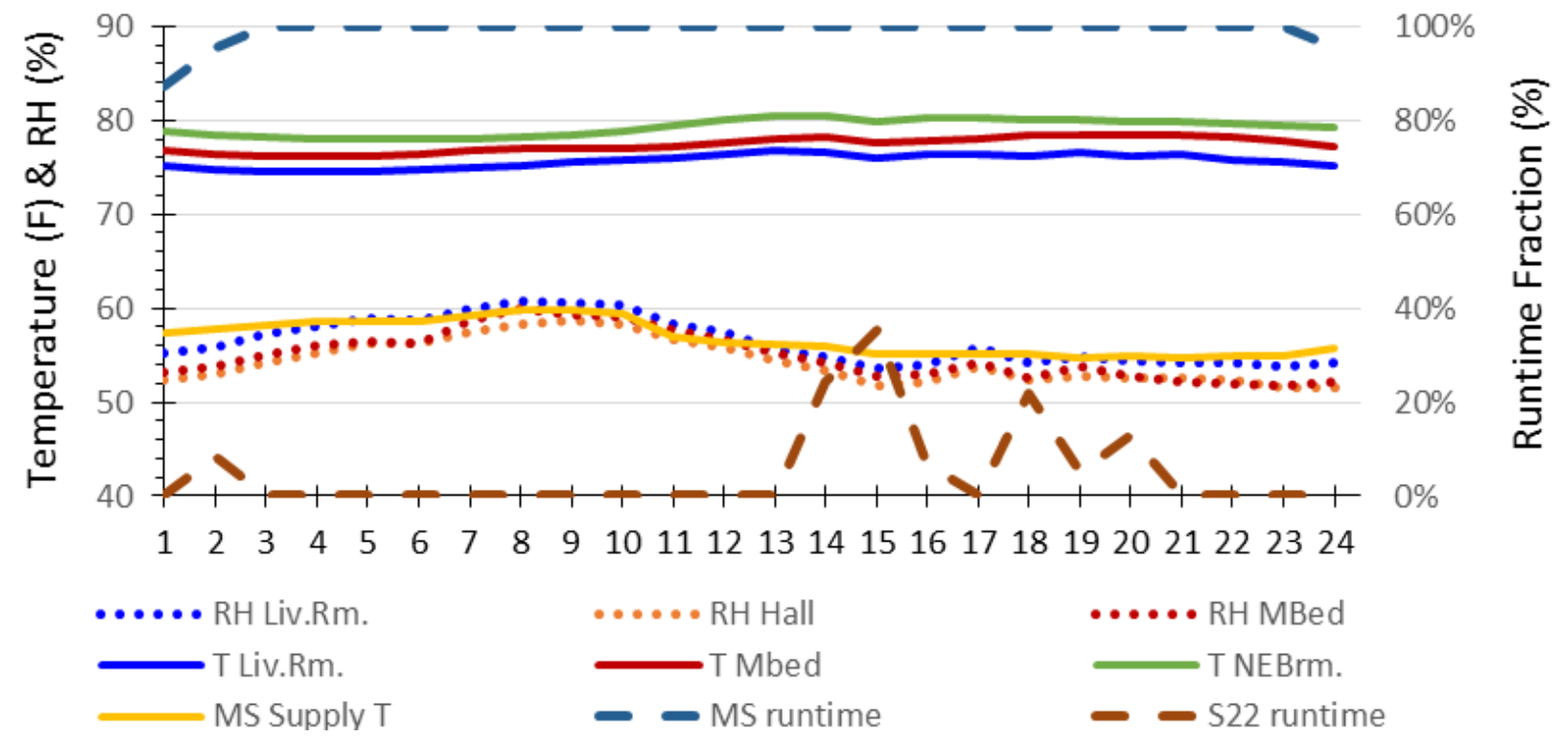

Figure 31. Indoor temperatures, RHs, and space-conditioning runtimes at hourly intervals with OA supplied to an MSHP in the living room and SEER 22 central cooling 
The interior living room RH just exceeded $60 \%$ around 8 a.m. and then dropped as the MSHP cooling output increased and central SEER 22 system cycled on, which resulted in additional moisture removal. Humidity this high was surprising, because the MSHP cooling never cycled off. The delivered supply air temperature (yellow line Figure 31) was a clue that perhaps the system operated at a higher SHR during low-load periods in the economy and standard cooling modes. A closer evaluation of the MSHP performance data revealed that the high SHR provided an inadequate explanation.

MSHP performance data during one of the days that made up the composite shown in Figure 31 were examined in detail to see what occurred during the high humidity and lower humidity period when the central system did not operate. Data from September 27, 2014, are shown in Table 9 for a period when indoor RH exceeded $60 \%$ and the afternoon had lower humidity. The high RH period data were an average from 6:15 a.m. to 8 a.m. and the lower RH period was an average from 12 p.m. to 1:15 p.m. The SHR, surprisingly, was not lower during the high RH period. Standard fixed-capacity centrally ducted cooling systems have an SHR around 0.75 under specific rated conditions. A higher SHR means that more cooling goes toward the sensible load, which would tend to result in higher RH with less latent removed. The SHR of 0.60 is lower than 0.75, which may suggest lower RH. However, the MSHP was a variable-capacity system, which meant that a low SHR would not result in low RH if the total delivered cooling was low. Stated another way, a high percentage of latent removal during very low cooling capacity would result in a low total moisture removed (compared to high latent removal at higher cooling capacity). This was also demonstrated in Table 9. The delivered cooling SHR can be compared to the water removal rate for both periods. The average SHR during the low RH period is $0.63,5 \%$ higher than the high RH period, but the total cooling output is $112 \%$ greater. The net result in moisture removal rate is $88 \%$ greater during the lower $\mathrm{RH}$ period $([4.74 \mathrm{pints} / \mathrm{h}-2.52] / 2.52)$.

Table 9. Indoor RH and MSHP Performance Data during High and Lower Indoor RH Periods

\begin{tabular}{c|c|c|c|c|c|c|c|c|c}
\hline & $\begin{array}{c}\text { Living } \\
\text { Room } \\
\text { RH }\end{array}$ & $\begin{array}{c}\text { Hall } \\
\text { RH }\end{array}$ & $\begin{array}{c}\text { MBR } \\
\text { RH }\end{array}$ & $\begin{array}{c}\text { Delivered } \\
\text { Cooling } \\
\text { (kBtu/h) }\end{array}$ & $\begin{array}{c}\text { EER } \\
\text { (Nonrated) }\end{array}$ & SHR & CFM/ton & $\begin{array}{c}\text { Water } \\
\text { Removal } \\
\text { Rate } \\
\text { (pints/h) }\end{array}$ & $\begin{array}{c}\text { Outdoor } \\
\text { Temp. } \\
\left({ }^{\circ} \mathbf{F}\right)\end{array}$ \\
\hline $\begin{array}{c}\text { High } \\
\text { RH } \\
\text { Period }\end{array}$ & $60.9 \%$ & $58.5 \%$ & $60.2 \%$ & 6.634 & 32.59 & 0.60 & 466 & 2.52 & 75.4 \\
$\begin{array}{c}\text { Lower } \\
\text { RH } \\
\text { Period }\end{array}$ & $55.3 \%$ & $54 \%$ & $54.9 \%$ & 14.053 & 16.97 & 0.63 & 328 & 4.74 & 86.4 \\
\hline
\end{tabular}

High RH period when RH >60\% September 27, 2014 6:15 a.m. 8 a.m. during MSHP cool only; no central cool occurred.

Lower RH period September 27, 201412 p.m. to 1:15 p.m. during MSHP cool only; no central cool occurred. EER is at the conditions indicated and does not indicate efficiency under rated conditions.

The matter of SHR or CFM/ton impact upon indoor RH is more complicated than Table 9 can indicate, because events that occur hours before the indoor $\mathrm{RH}$ have a bearing on the indoor $\mathrm{RH}$ at any given time. A house is in a continual process of varying rates of sensible and latent heat addition and removal. About 5 hours before the high RH period in Table 9 the SHR was as high as 0.69 , and several hours before the low RH period the SHR was as low as 0.53. 
The very high EER of 32.6 occurred under low-load conditions at which the variable-capacity MSHP operated at its lower end capacity (where it is most efficient) with mild outdoor conditions. The EER shown here does not represent the conditions at which the system is rated and is not intended to suggest this.

\subsection{Indoor Impacts with Mini-Split Heat Pump during a Low Load Period}

Low cooling loads increase the challenge of controlling indoor humidity with space-cooling equipment. Figure 32 shows the impact during a low cooling load period of MSHP operation in the standard cooling control mode. The standard mode has a colder cooling coil on average that results in better humidity control than the economy mode. The outdoor dew point average was only $61.3^{\circ} \mathrm{F} \mathrm{dp}$ on this day, but conditions were cloudy and somewhat rainy, which resulted in very low solar radiation (the daily total was only $1,269 \mathrm{Wh} / \mathrm{m}^{2}$ on December 8,2014 ). The test configuration at this time was with $\mathrm{OA}$ to the MSHP set to $70^{\circ} \mathrm{F}$ cooling set point and in standard mode. The SEER 22 central system was enabled to cool at this time but had no cooling cycles. The MSHP cooling set point could be lowered to $70^{\circ} \mathrm{F}$ by November to increase cooling runtime without making the space feel overcooled. This worked because the MSHP operated at the lowest cooling output that its control called for without fully reaching the set point. This resulted in daily average room temperatures that were a few degrees warmer than the actual set point.

The MSHP operation time averaged $15.7 \mathrm{~h}$ (65\% daily runtime) for the low-load day on December 8 , including the manufacturer's designed periodic short fan cycles that occur between cooling cycles. Figure 32 shows a continuous period from 2 a.m. to 4 a.m. with no cooling and only MSHP fan cycles. The fan cycles lasted only about $15 \mathrm{~s}$ each at about 170 CFM of flow and consumed only about $8 \mathrm{~W}$ of power. The manufacturer's purpose for these cycles was probably to circulate air across the room air sensor located at the return air intake to determine the room air temperature. The fan air sample was taken after no cooling or air sample was taken for $45 \mathrm{~s}$. If no MSHP cooling had occurred all day, the total MSHP fan recirculation runtime would be $25 \%$ of the whole day and consumed 48 Wh of electricity.

The indoor RH dropped slowly through midday. From 1 p.m. to 3 p.m. the MSHP had 100\% runtime and was delivered about 0.52 tons cooling with an SHR around 0.68 , and average $\mathrm{CFM} /$ ton of 510. Because the MSHP is specified as being able to deliver cooling as low as 3,100 $\mathrm{Btu} / \mathrm{h}$ ( 0.26 tons $)$ it would have been better if the system would allow longer cooling operation at the lower capacity overnight to improve humidity control. 


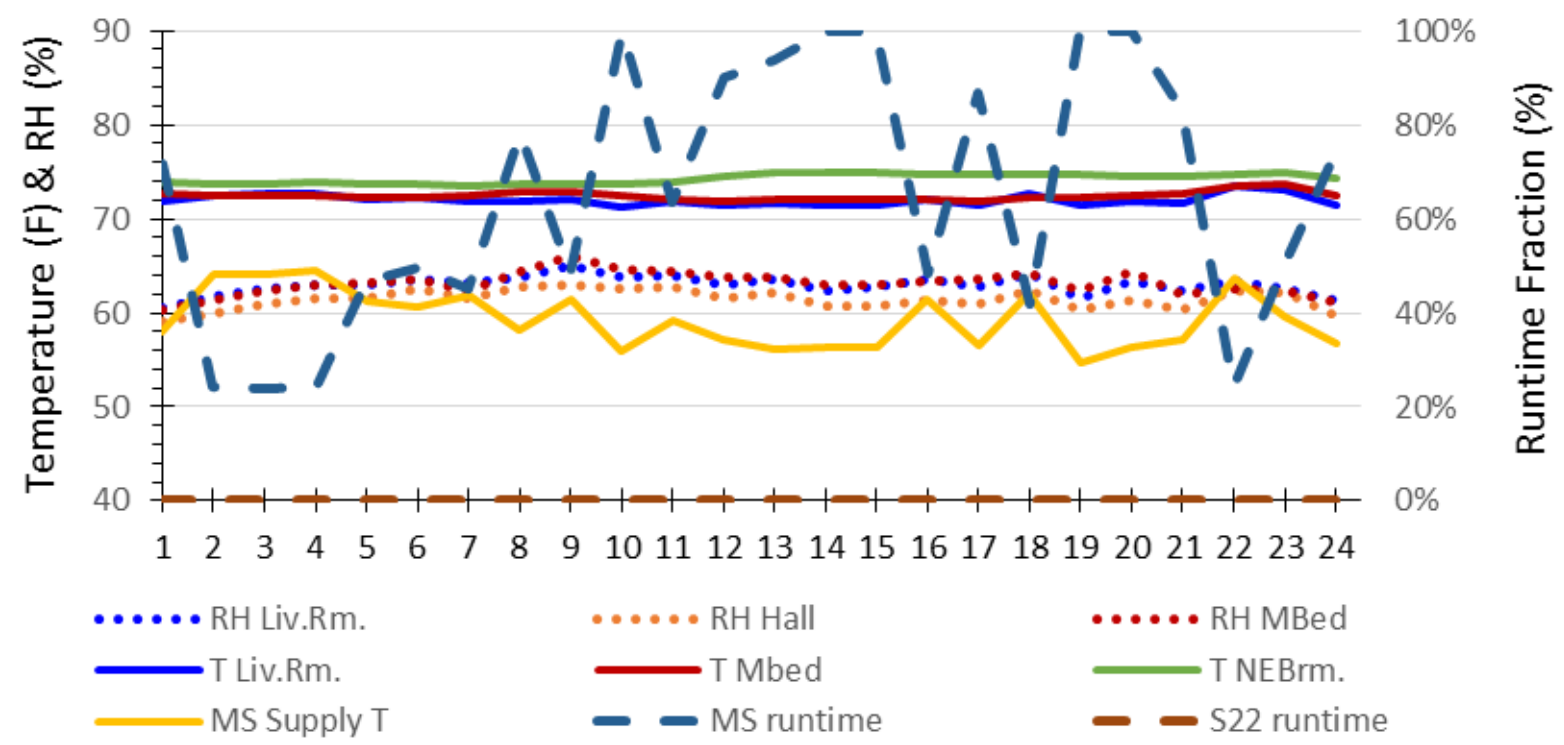

Figure 32. Indoor temperatures, RHs, and space-conditioning runtimes at hourly intervals with $\mathrm{OA}$ supplied to a MSHP in the living room with a very low cooling load on December 8, 2014

Figure 33 shows the MSHP cooling output and supply air temperature and the indoor living room temperature and RH. The data shown here were collected over 2 consecutive low cooling load days (December 7-8, 2014). The indoor RH did not trend closely to MSHP supply air in this case as it did in Figure 25 because of very big differences in the outdoor conditions. Figure 25 data were collected during hot-humid weather with outdoor conditions of at least $70^{\circ} \mathrm{F}$ dp and $100 \%$ MSHP runtime. Conditions in Figure 33 had a much lower cooling load with an average outdoor temperature of $64^{\circ} \mathrm{F}$ and only $60^{\circ} \mathrm{F}$ dp to $61^{\circ} \mathrm{F}$ dp as well as several periods during which the MSHP cooling cycled off instead of staying on full time.

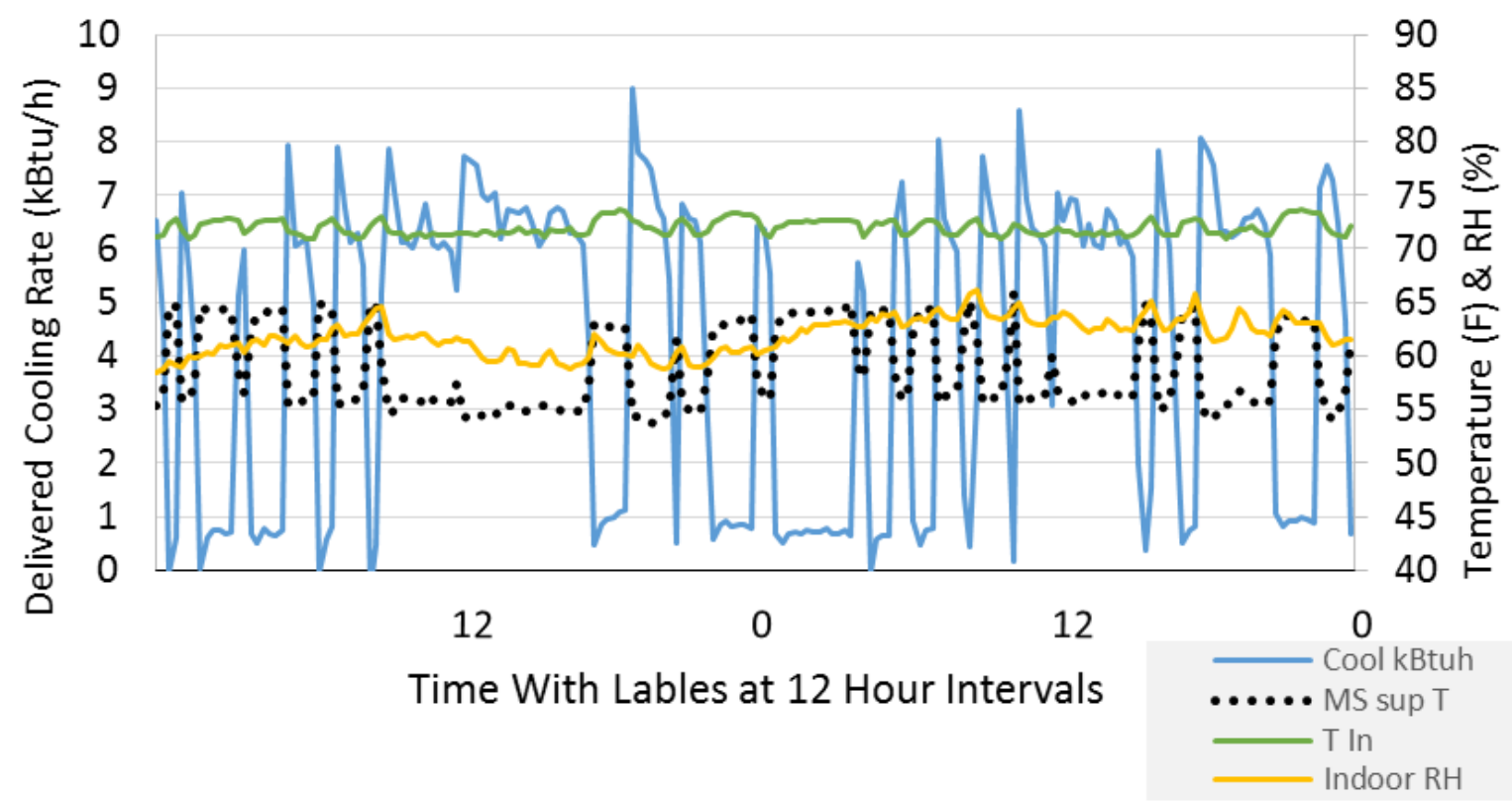

Figure 33. MSHP delivered cooling rates and supply air temperatures shown with the living room temperatures and RHs on 2 very low cooling load days December 7-8, 2014 
Figure 34 shows the cooling rate along with the CFM/ton. The flow rate per delivered cooling was about $500 \mathrm{CFM} /$ ton during periods with condenser cooling operation. The $\mathrm{CFM} /$ ton spikes higher than 600 were for periods when a cooling cycle ended and the airflow was maintained as the condenser reduced refrigerant flow, then the refrigeration cycle ended. Based on the data shown in Figure 29, 500 CFM/ton was higher than what was needed to maintain indoor RH lower than $60 \%$ during low cooling load periods. Figure 29 indicates that the MSHP in this mode should have stayed lower than $450 \mathrm{CFM}$ /ton to keep indoor RH lower than $60 \%$.

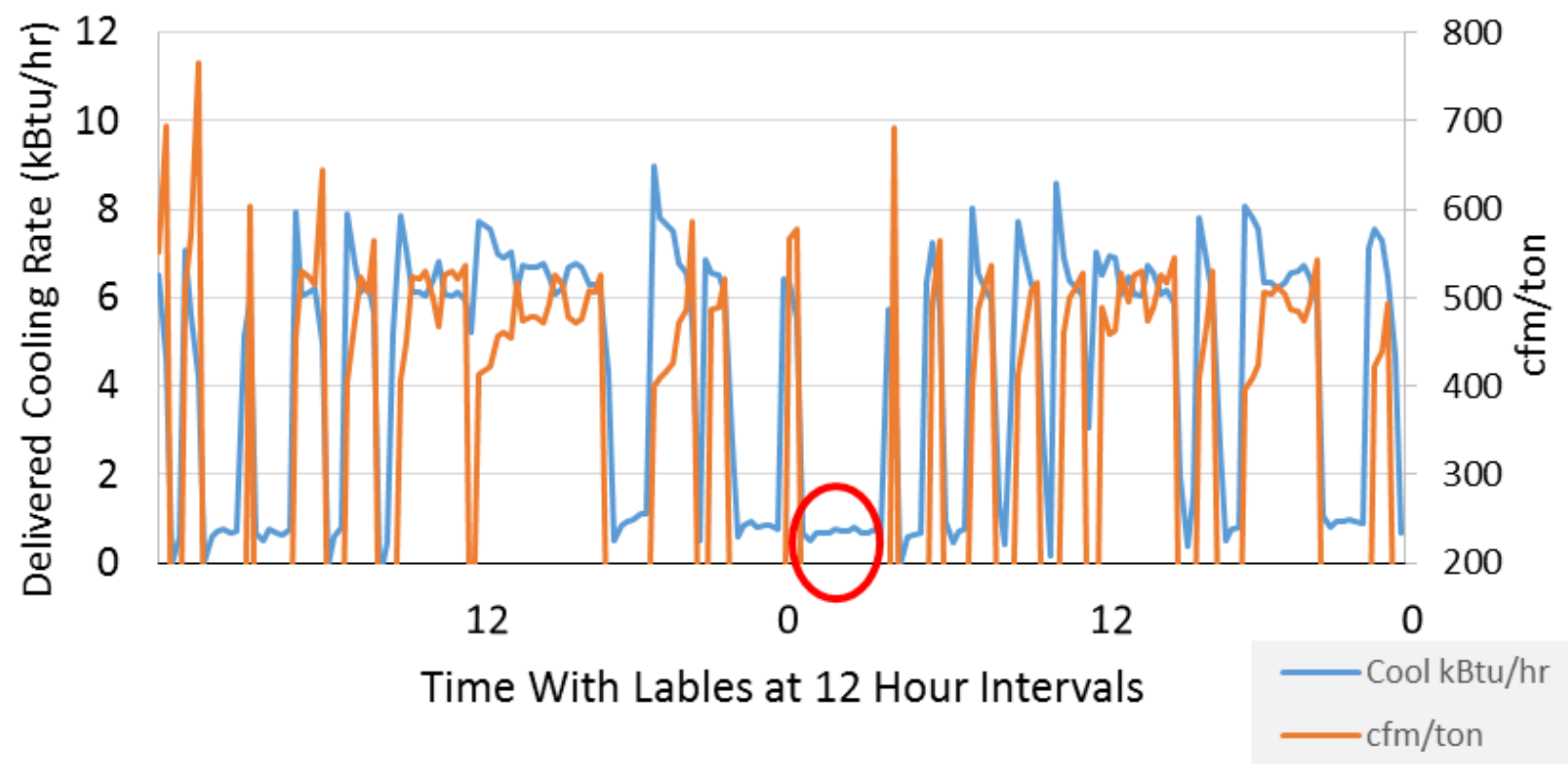

Figure 34. MSHP delivered cooling shown with the airflow rates per delivered cooling (CFM/ton) during very low cooling loads from December 7-8, 2014.

The periods of cooling rates lower than 1,000 Btu/h occurred without any cooling refrigeration cycle and during the short air circulation fan cycles at $128 \mathrm{CFM}$. The CFM/ton are not shown for these periods, because they were not part of the designed cooling operation. The CFM/ton calculation would be around 2,195 CFM/ton for these periods. These periods of fan circulation were detrimental to good indoor moisture management as space cooling was provided, because condensate water remained on the coil and in the pan and evaporated back into the space as latent heat added. This issue has been known for some time and prominently identified (Henderson 1990; Shirey et al. 2006). The period on December 8 circled in red on Figure 34 had a psychrometric analysis completed to determine how much water may be added back into the space during one such cycle. The period circled began at 1 a.m. after a cooling cycle and concluded at 4 a.m. just before a short cooling cycle began again. Results of the calculated latent heat added back into the living room (evaporated water from cooling coil) from the MSHP air circulation period circled in Figure 34 are shown in Figure 35. 


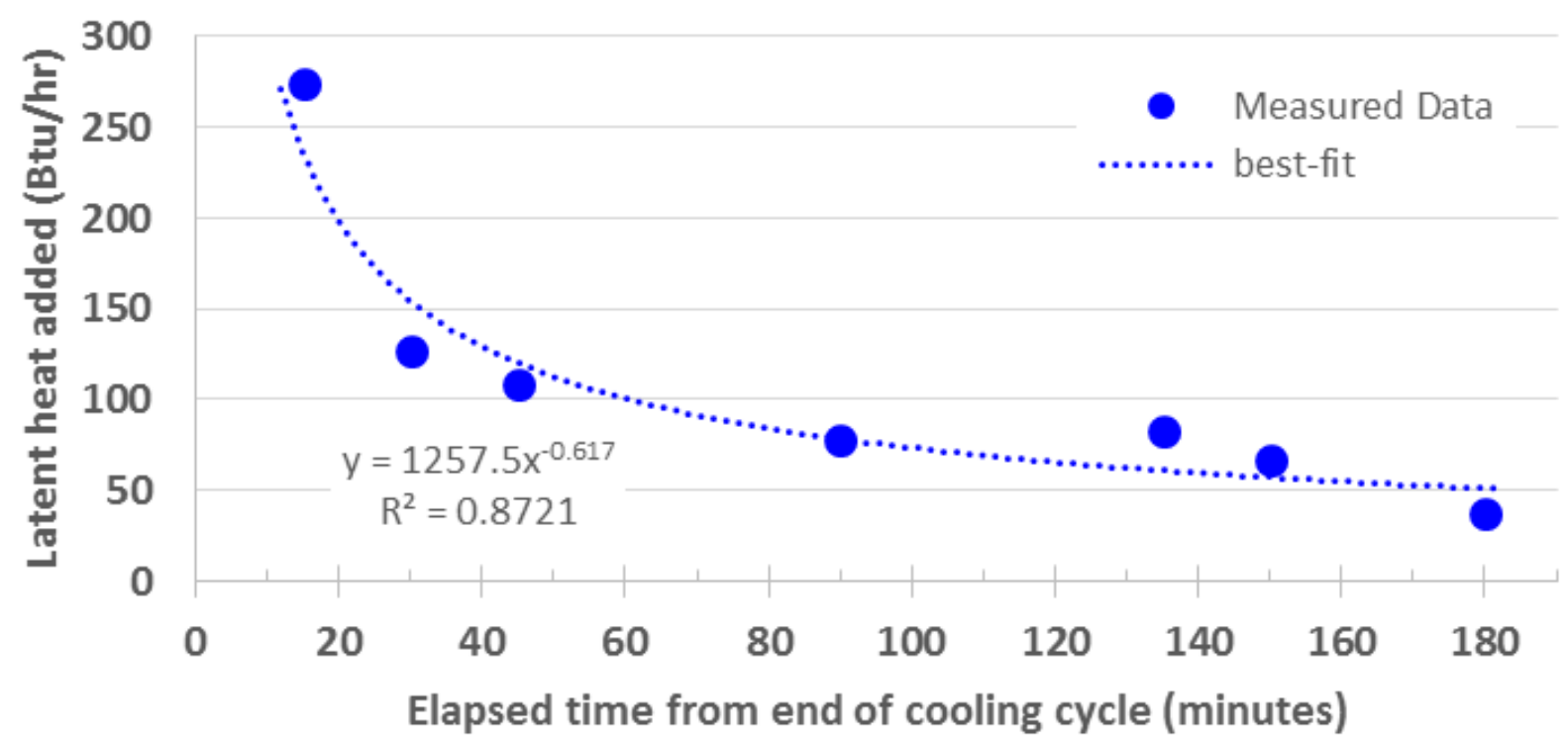

Figure 35. Condensate latent heat rates evaporated from the MSHP cooling coil shown with elapsed times from the end of the previous cooling cycle

The rate of water evaporated into the space over time dropped quickly. Using the best-fit line in Figure 35, the latent heat rates were calculated at 15-min intervals for the 3 -h period. The latent heat rate was then used to calculate the pints of water evaporated over this 3 -h period. After 15 min from the end of the cooling cycle, about 0.05 pints were evaporated into the space, and the cumulative amount evaporated after $3 \mathrm{~h}$ was only 0.26 pints. Although this may be considered a relatively small amount of moisture for one period, these periods recurred several times in a day and during periods when no moisture was being removed. The total amount added per day would no doubt be higher than this and would depend upon how wet the coil became and the frequency and duration of fan circulation cycles.

Other studies and observations of coil moisture evaporation in centrally ducted cooling systems resulting from setting the fan to operate continuously indicate a much greater impact than exhibited by the MSHP periodic fan cycling, because the airflow rates of central systems were much higher and continuous. The MSHP flow was only $128 \mathrm{CFM}$ and cycled at $25 \%$ runtime when not interrupted by cooling cycles.

\subsection{Mini-Split Heat Pump Results in Dry Control Mode under Low Cooling Load}

The MSHP unit used in this research had a dry control mode that was designed for better humidity control and operated within a much more limited cooling capacity. Because the manufacturer data stated this mode operated at low speed but did not specify the cooling capacity operating range, this control mode was not used in the main test configurations during the hottest summer weather. The benefits of a MSHP are that it provides as much cooling as possible (instead of a lower-efficiency ducted central system) and can operate at the lowest possible cooling capacity during low-load periods.

By December cooling loads were much lower and provided an opportunity to evaluate the dry mode. The MSHP cooling set point was set at $70^{\circ} \mathrm{F}$ in the dry mode. A continuous 9-day period 
from December 27, 2014, to January 4, 2015, had warm weather with moderately high outdoor dew points for this time of year. The average outdoor temperature was $70.3^{\circ} \mathrm{F}$ with a range of $61.1-84^{\circ} \mathrm{F}$. The average outdoor dew point was $65^{\circ} \mathrm{F} \mathrm{dp}$ with a range of $59^{\circ}-69^{\circ} \mathrm{F} \mathrm{dp}$. Figure 36 shows a daily composite of select data from these 9 days. These data show the runtime of the central SEER 13 system and MSHP and the indoor temperatures and RHs in different areas of the lab house.

On average indoor $\mathrm{RH}$ rose during the late morning hours and fell slowly through midday during the longest cooling runtime (Figure 36). The centrally ducted system operated very little and only during short midafternoon periods on warm days.

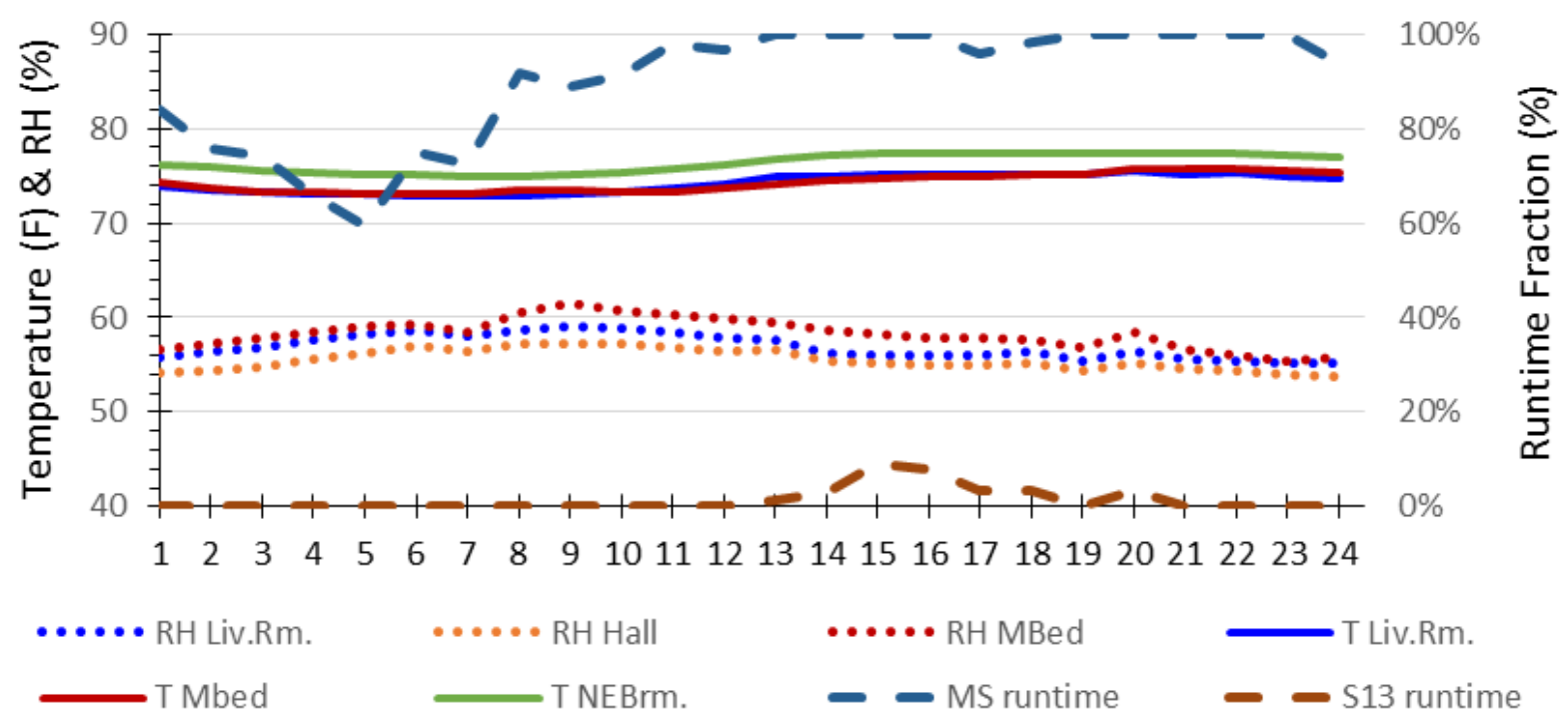

Figure 36. Indoor temperatures, RHs, and space-conditioning runtimes at hourly intervals with OA supplied to an MSHP operated in dry mode and SEER 13 central cooling

A pattern of higher indoor RH was associated with lower delivered cooling capacity in the dry control mode (Figure 37), just as in previous configurations. This figure shows the same data that made up the composite shown in Figure 36. Data in Figure 37 are shown at 15-min intervals from December 27, 2014 through January 4, 2015 and include periods of MSHP start-up and cycle-off operation. The indoor RH exceeded $60 \%$ when the delivered MSHP cooling rate was lower than about $8,000 \mathrm{Btu} / \mathrm{h}$ for prolonged periods if the previous day had few off-cycles. Warmer days had few to no MSHP off periods. The lowest capacity sustained during 15-min periods for the MSHP unit in dry mode was about $6,900 \mathrm{Btu} / \mathrm{h}(0.58 \mathrm{tons})$, even though this system was specified as being able to cool to as low as 3,100 Btu/h. The highest output capacity in dry mode was about $10,300 \mathrm{Btu} / \mathrm{h}$ (0.86 tons). The indoor temperature reached about $76^{\circ} \mathrm{F}$ ( $4^{\circ} \mathrm{F}$ above the MSHP dry mode set point), at which point the central cooling system tended to cycle on to assist cooling on the warmer days.

The period with the highest indoor RH occurred January 1-2 (identified by a red rectangle in Figure 37 and Figure 38). Data from this period are discussed later in this section to help explain why humidity was not maintained lower than $60 \%$ with the MSHP in dry control mode. 


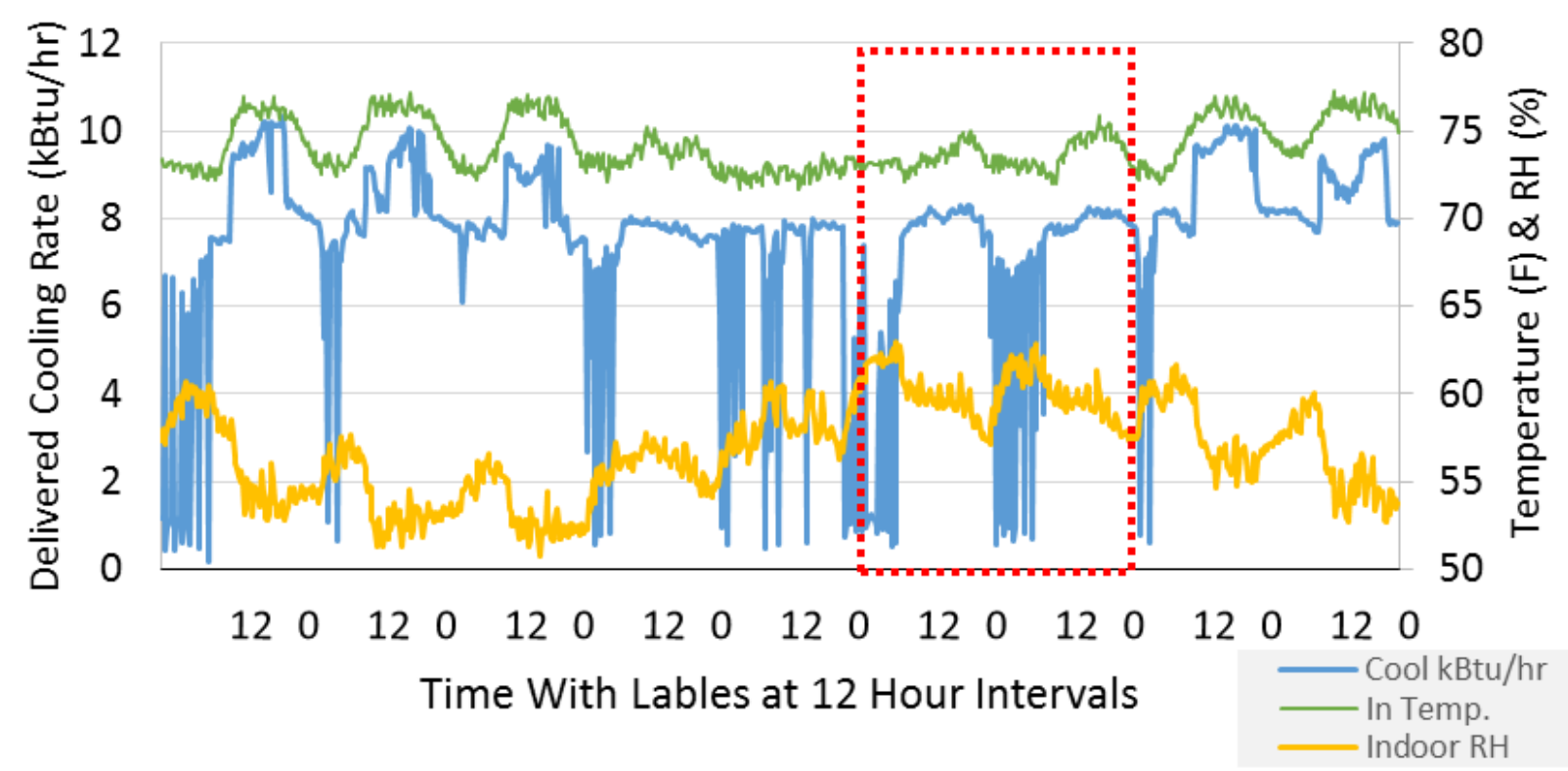

Figure 37. MSHP in dry mode showing delivered cooling rate with indoor temperatures and RHs in the living room from December 27-January 4

Figure 38 shows the cooling rate in thousands Btu/h and the flow rate per cooling rate $(\mathrm{CFM} /$ ton $)$ for 9 continuous days December 27-January 4 with the MSHP in dry mode. The CFM/ton calculation is shown for 15 -min periods only with at least $78 \%$ runtime to avoid odd values associated with short periods that comprised start-up or end-of-cycle operation. The average flow was $271 \mathrm{CFM} /$ ton with a high of $359 \mathrm{CFM} /$ ton and low of $214 \mathrm{CFM} /$ ton.

In comparison, when the MSHP was operated in the economy mode (with SEER 13 system backup), it had an average of $329 \mathrm{CFM}$ /ton over the 8-day period (Figure 27) with a range of 240-585 CFM/ton. The upper CFM/ton range tended to most frequently operate at 450-500 $\mathrm{CFM} /$ ton. 


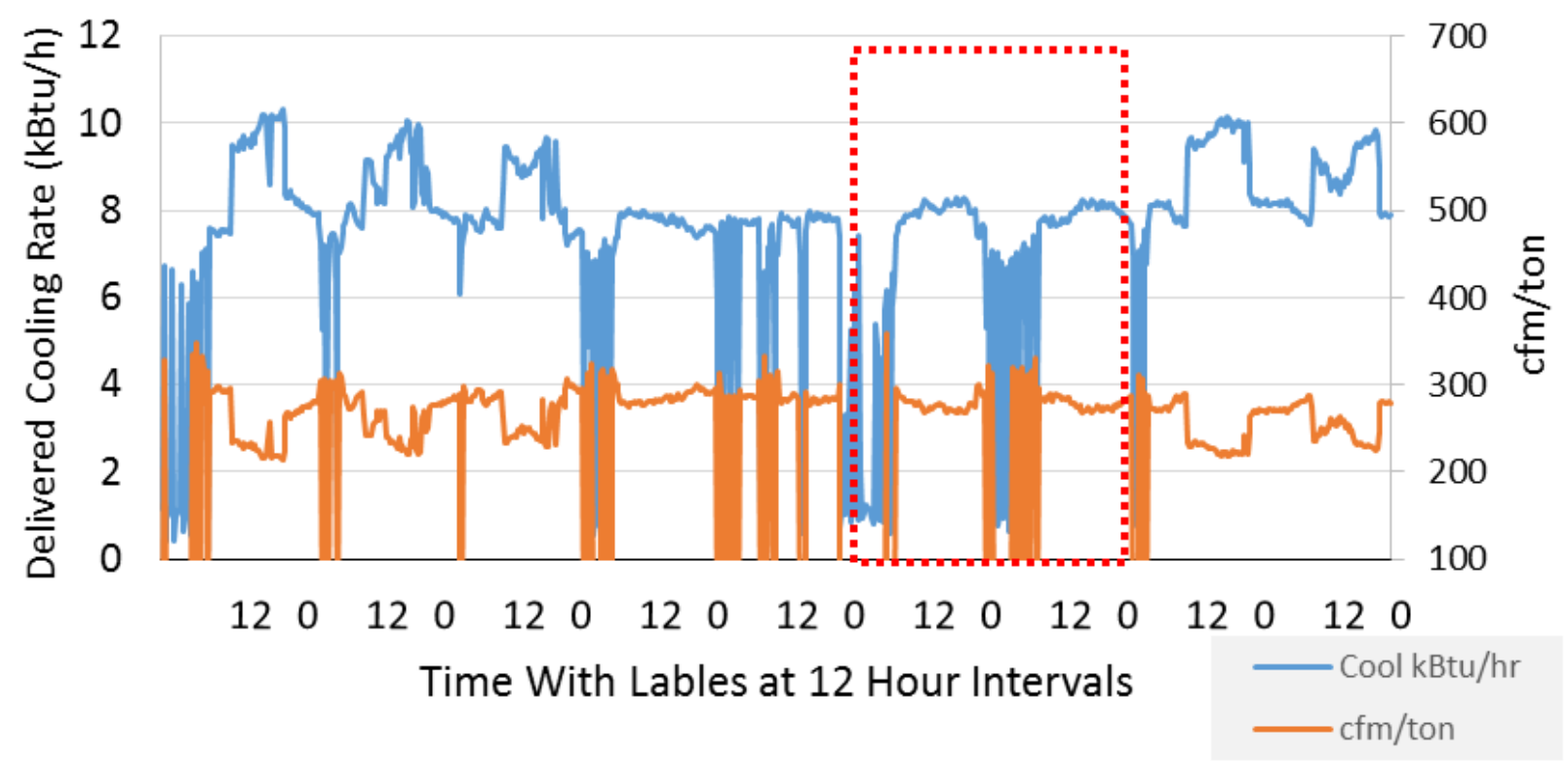

Figure 38. MSHP in dry mode showing delivered cooling and the airflow rate per cooling (CFM/ton) from December 27-January 4

Surprisingly, with much lower CFM/ton in the dry mode some periods had elevated indoor humidity. The problem was that when the system cycled off, no moisture was removed from the space, and another issue arose in which moisture on the coil was evaporated back into the space during the short and frequent fan circulation periods.

To better illustrate this, 2 days (January 1-2, 2015) with very low cooling loads were selected while the MSHP was in the dry mode (see the red rectangle in Figures 37 and 38). These were very cloudy days. January 1 had an average outdoor dew point of $64.1^{\circ} \mathrm{F}$ dp and total solar insolation of $1,855 \mathrm{Wh} / \mathrm{m}^{2}$. January 2 had an average outdoor dew point of $64.5^{\circ} \mathrm{F}$ dp and total solar insolation of $1,920 \mathrm{Wh} / \mathrm{m}^{2}$. December 31,2014 , the day before this period, was also a very cloudy day that resulted in decreased moisture removal and began the trend of increasing indoor RH (Figure 37).

Figure 39 shows the MSHP cooling output, supply air temperature, indoor temperature, and RH in the living room during this 2-day low cooling load period. By about 9 a.m. the MSHP began a long cooling cycle that lasted about $16 \mathrm{~h}$. The indoor RH (yellow line) averaged about $60 \%$ much of the time and gradually dropped lower toward the end of the long cycle. The intermittent cycles that occurred from around 12 a.m. to 9 a.m. resulted in an increase of living room RH from about $57 \%$ to $63 \%$. Indoor RH in other locations followed a similar trend, except the master bedroom RH, which peaked at about $65 \%$ at $8: 30$ a.m. This followed two of the automated internal load bathing and shower periods.

Also evident in Figure 39 was that the MSHP was not overcooling the space, because it limited output in the dry mode and tolerated a slow rise in indoor temperature before going into a higher cooling output. The MSHP set point was at $70^{\circ} \mathrm{F}$ and room temperature reached $75^{\circ} \mathrm{F}$ without the cooling output increasing. 


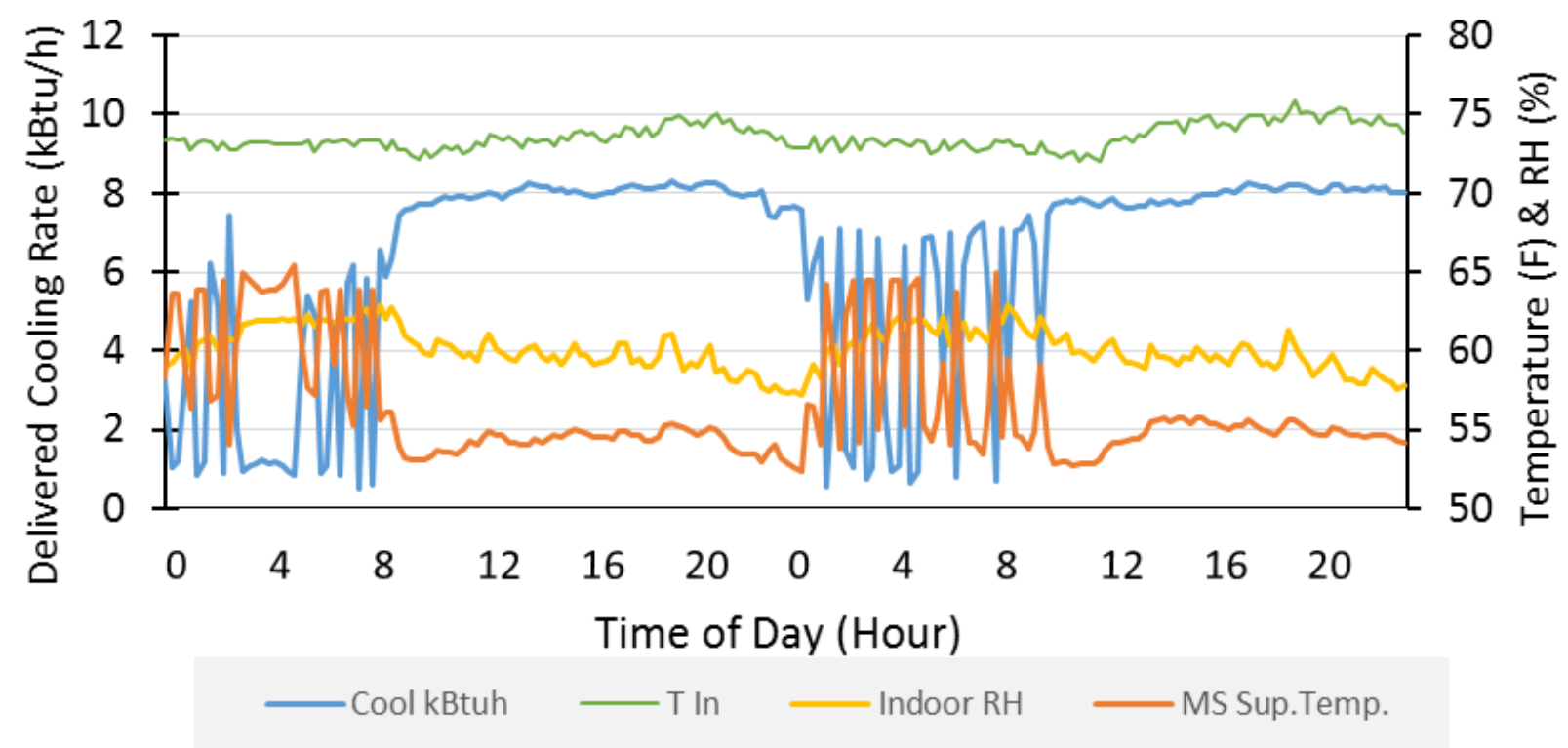

Figure 39. Two days (January 1 and 2, 2015) showing cooling output, supply temperature, indoor temperature, and RH with low cooling load while the MSHP operated in dry control mode

The CFM/ton was fairly stable around $280 \mathrm{CFM} /$ ton during the long runtime period (Figure 40).

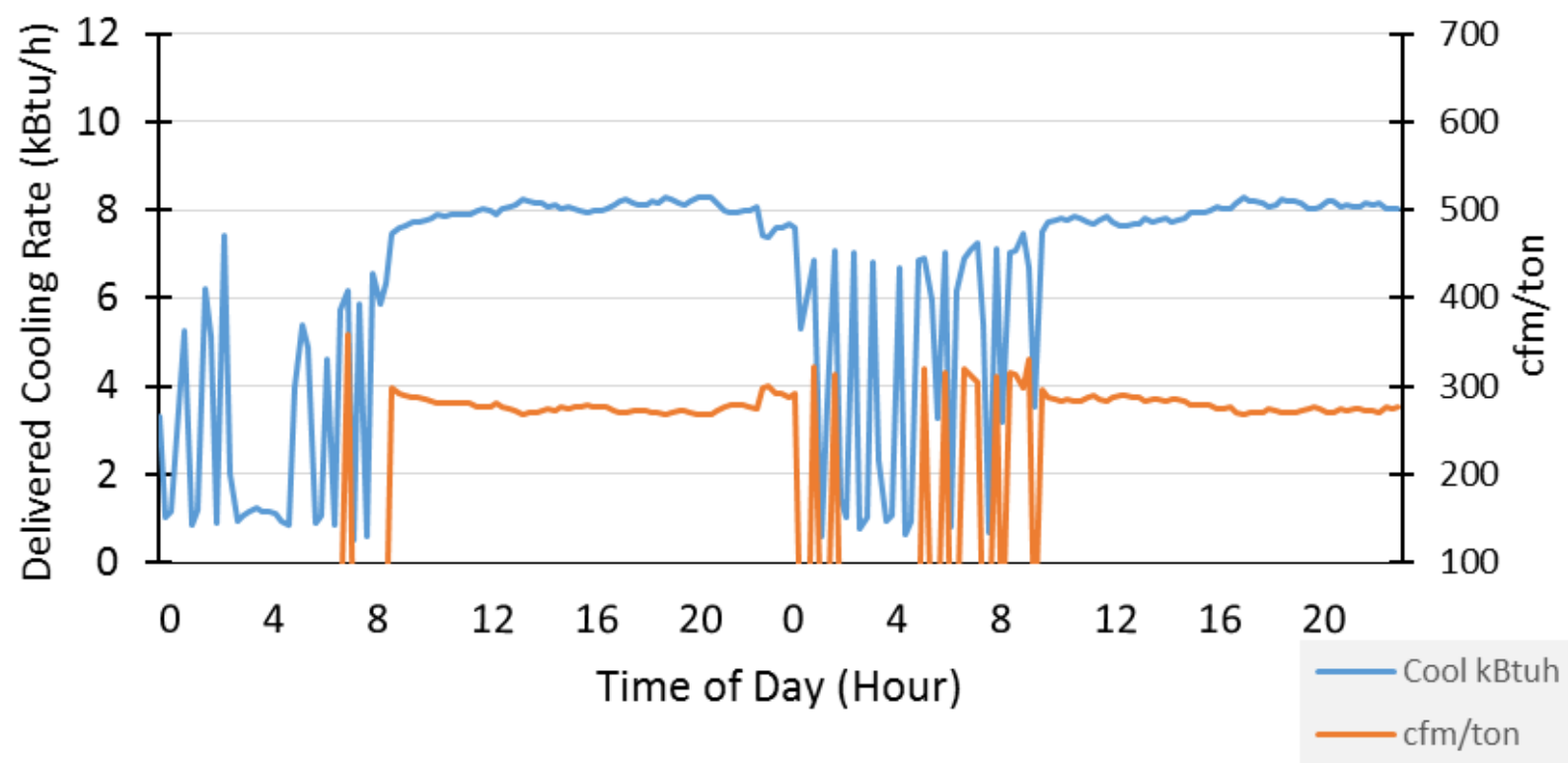

Figure 40. Two days (January 1 and 2, 2015) showing MSHP cooling output and CFM/ton with low cooling load while the MSHP operated in dry control mode

Figure 41 through Figure 43 show the SHR with cooling output, latent heat removal, and indoor RH during the 2-day low cooling load period while the MSHP was in the dry control mode. 


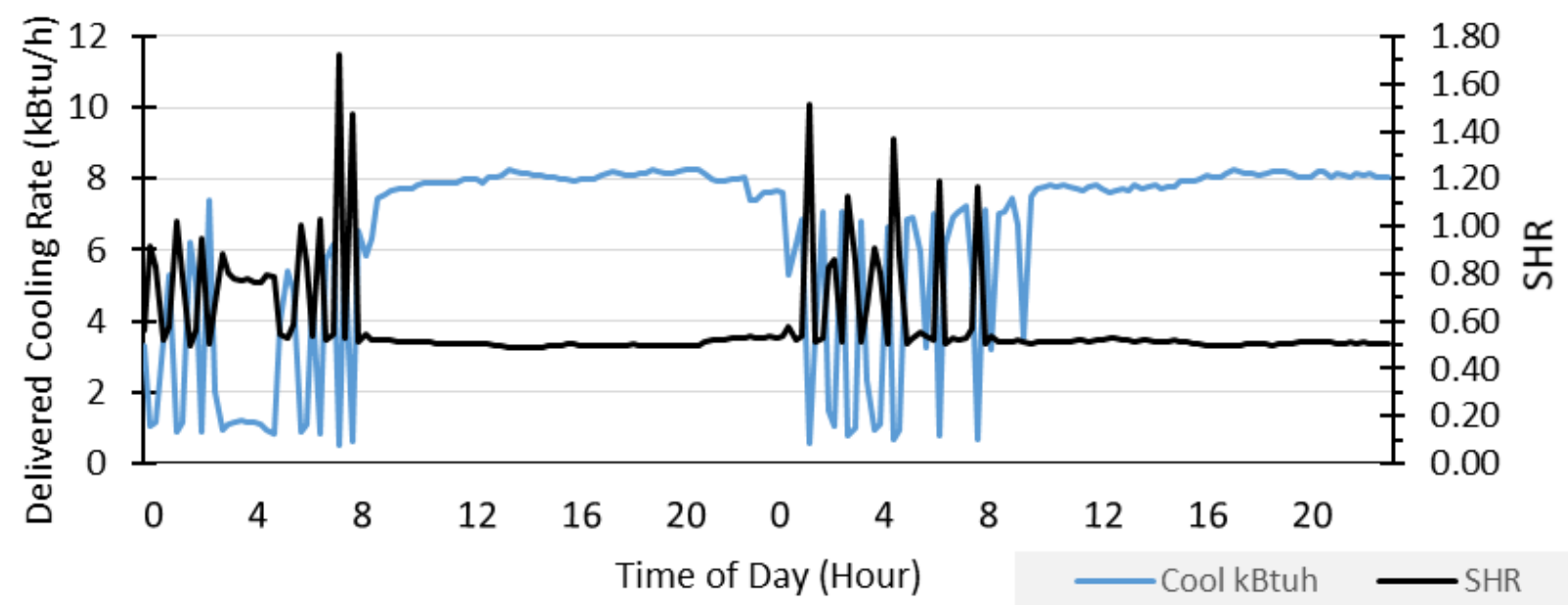

Figure 41. MSHP dry mode cooling output and SHR on January 1 and 2, 2015

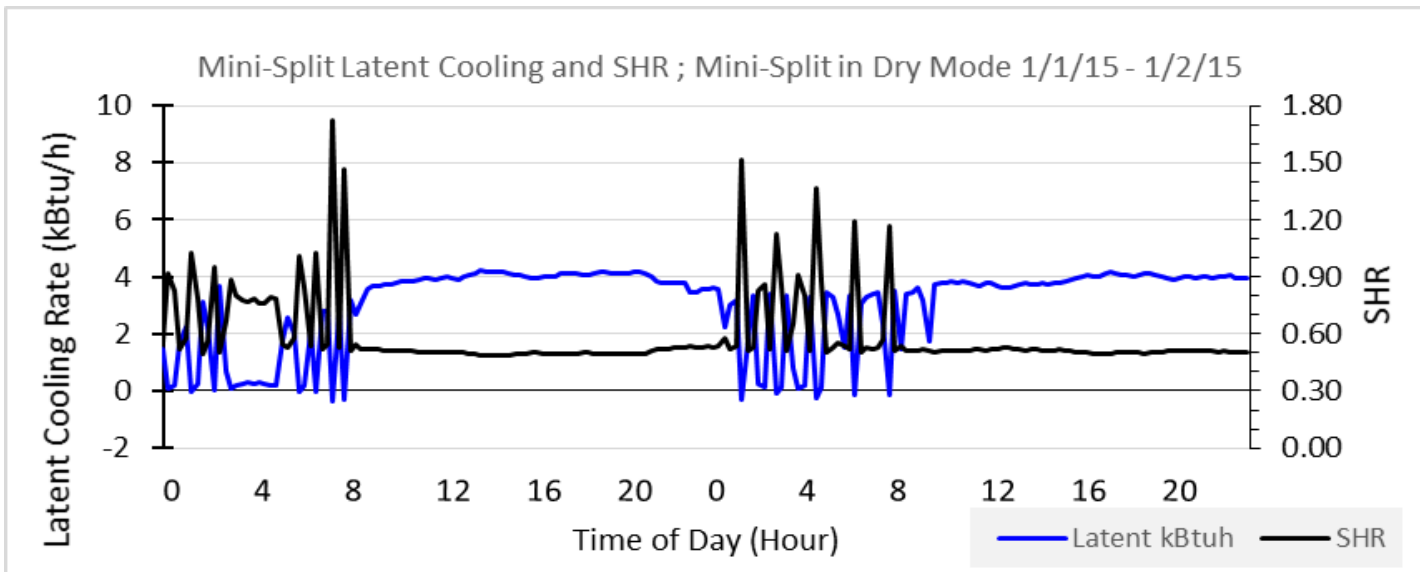

Figure 42. MSHP dry mode latent heat removal from air and SHR

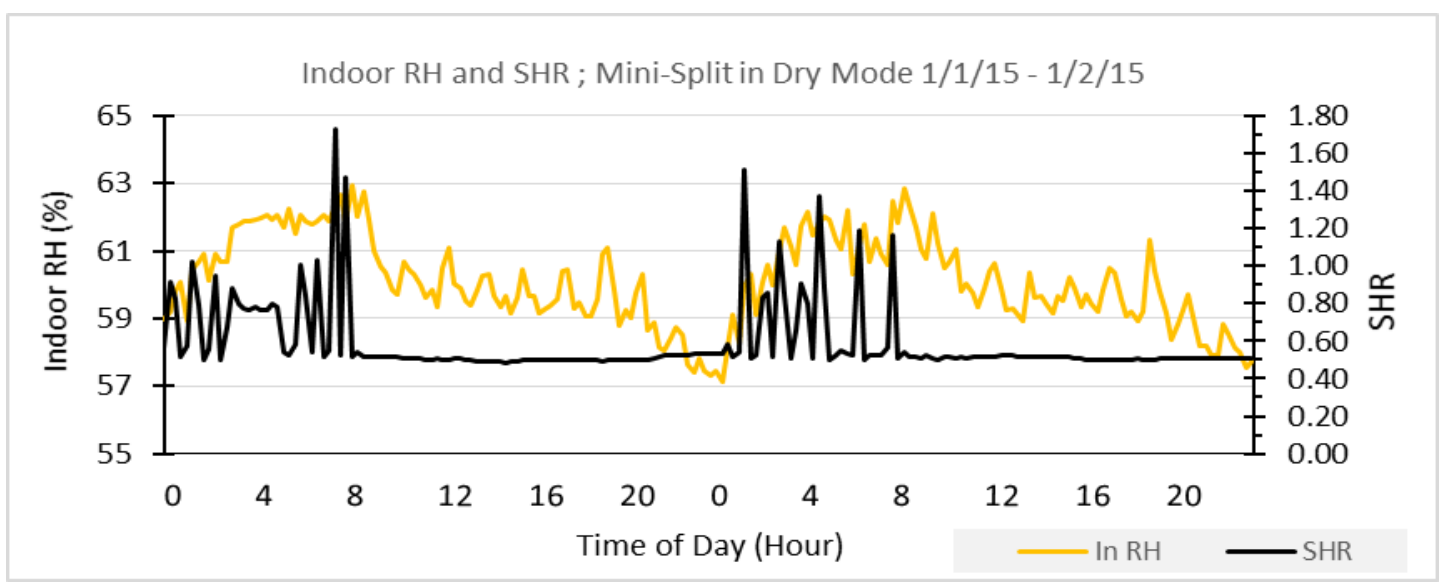

Figure 43. MSHP dry mode SHR and resulting indoor living room RH 
The data in Figure 41 through Figure 43 are shown at 15-min intervals. These figures show:

- SHR was relatively low and stable around 0.50 during the long cooling cycle period.

- SHR was very high during the early morning hours from midnight to 8 a.m. because of short and frequent noncooling MSHP fan recirculation cycles.

- The noncooling fan recirculation cycles added moisture back into the space at the same time there were internal latent loads and the latent load of OA was added to the space.

- Indoor RH was reasonably controlled during the long cooling period, during low cooling load days; it would remain lower than $60 \%$ except that it performed poorly during the early morning hours from 12 a.m. to 8 a.m.

$\mathrm{RH}$ control could be improved in dry mode operation by:

- Eliminating the fan recirculation operation, at least when set to the dry RH control mode

- Allowing the unit to operate at the lowest cooling capacity (around 3,100 Btu/h for sustained periods of time), particularly during overnight low cooling load periods, at the lowest possible SHR (low CFM/ton)

- Operating at the lowest possible SHR (low CFM/ton) at the lower-capacity stage that will avoid indoor coil frosting.

The energy use of the MSHP in dry mode was also evaluated with the SEER 13 ducted system serving as back-up cooling and indoor air circulation. The results were limited to the DecemberJanuary time frame, so how much total cooling energy would result during typical and peak summertime conditions is unknown. The combined daily total cooling energies of the MSHP and SEER 13 systems are shown plotted against the daily average dT in Figure 44.

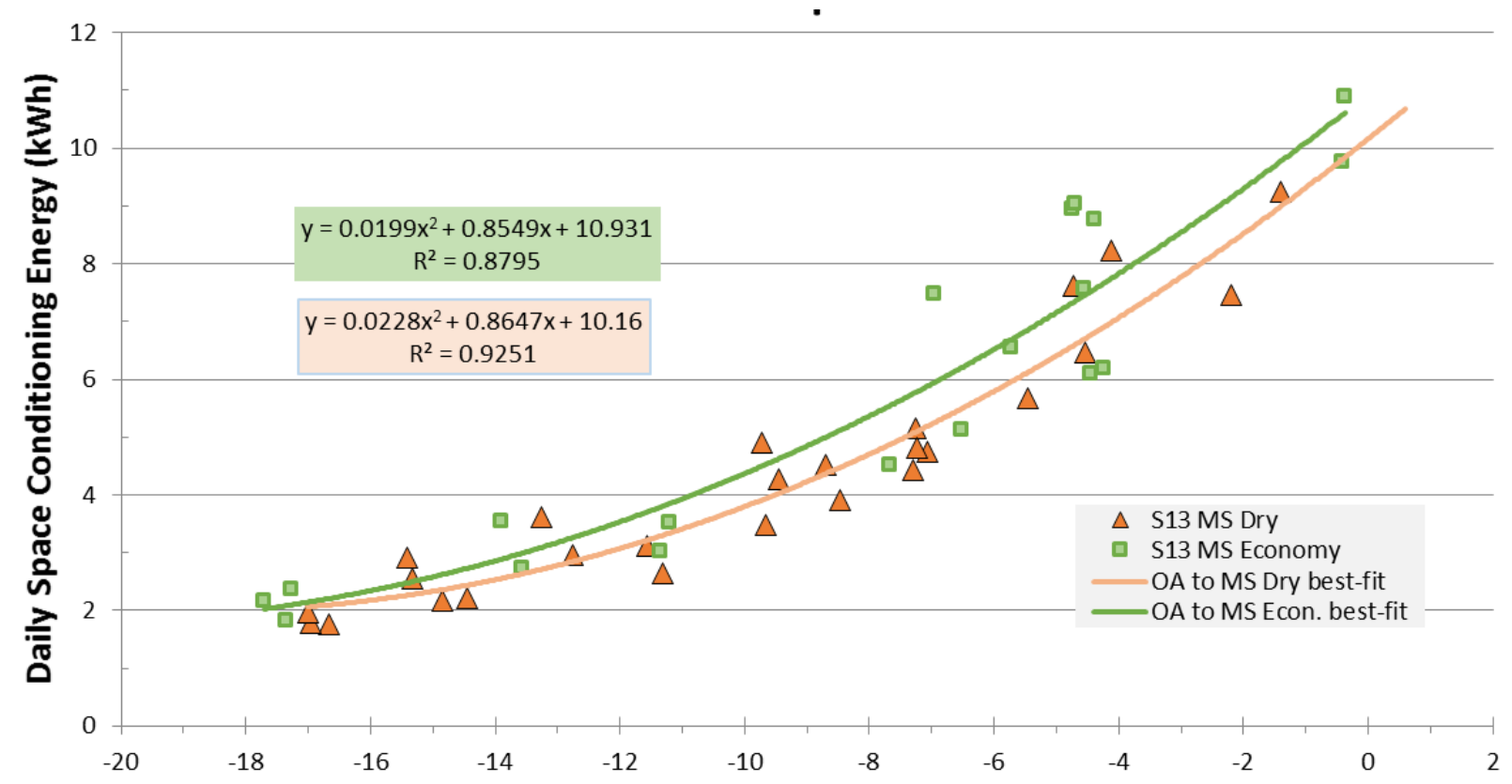

Figure 44. Daily SEER 13 plus MSHP cooling energies versus daily average dT when OA was supplied to the MSHP return intake 
The SEER 13/MSHP in economy mode was compared with the SEER 13/MSHP in dry mode. Because the available dT data were limited for the dry mode testing, the comparison was based on limiting the SEER 13/MSHP economy mode data used in Figure 17 to dT less than zero.

Based on the limited range in dT up to 0 , the MSHP dry mode used less energy during periods of lower cooling loads. Using the best-fit lines at $\mathrm{dT}=0^{\circ} \mathrm{F}$, the MSHP dry mode used about 0.77 $\mathrm{kWh}$ /day less (7.1\%). Because the maximum output of the MSHP in dry mode was limited to around 10,000 Btu/h instead of its maximum $18,400 \mathrm{Btu} / \mathrm{h}$, the less-efficient centrally ducted SEER 13 system would have to operate more and the resulting energy consumption would rise. Therefore, using this limited data range to predict savings for a typical summer day with $\mathrm{dT}=$ $5^{\circ} \mathrm{F}$ does not seem appropriate. 


\section{Conclusions}

This research project focused on energy-efficient management of mechanical ventilation and RH during the cooling season. It was guided by the research questions posed below and consisted of eight test configurations. Evaluating how well a ductless SEER 21.5 MSHP could perform as the primary cooling system without a dehumidifier for supplemental dehumidification in a continuously mechanically ventilated house was of particular interest. The following research questions to be answered as part of this project were:

1. What space RH and measured cooling season energy use/demand result from operation of centrally ducted and fixed-capacity SEER 13 systems and centrally ducted variablecapacity SEER 22 systems with supplemental dehumidification when ASHRAE Standard 62.2-2013 ventilation is introduced?

2. What energy and demand savings and RH outcomes result from operating a ductless MSHP as the primary cooling system with ducted central SEER 13 and central SEER 22 as secondary systems and with ventilation introduced near the MSHP return intake?

3. What is the impact on space RH and energy/demand when ventilation air is introduced directly into the central living room space versus delivery near the centrally ducted system's return intake?

Specific answers to the research questions were provided in Section 4.

The conclusion is that the MSHP configurations used the least seasonal and peak demand energy and usually provided reasonable thermal distribution and adequate RH control. However, exactly what constitutes acceptable RH levels is subjective and bears some consideration when RH control is evaluated. RH control effectiveness was evaluated based on maintaining indoor conditions lower than $60 \%$. No consensus has been established about the appropriate period of time for RH evaluation. This makes judging RH levels more difficult, because they can vary significantly throughout the day. RH data were evaluated in hourly intervals to allow readers an opportunity to draw their own conclusions about RH control effectiveness.

Based on daily average $\mathrm{RH}$, all configurations had acceptable RH control. When hourly average RH was considered, all configurations had at least some hours that exceeded $60 \%$ in some parts of the home. Indoor RH was higher in areas where OA was delivered compared to other parts of the home.

During most summer days the MSHP maintained acceptable humidity levels; however, $\mathrm{RH}$ tended to drift up toward $60 \%$ during the early morning hours. Then the $\mathrm{RH}$ was maintained in the mid-50\% range from 12 p.m. to 12 a.m. On days with low cooling load and outdoor dew points higher than $60^{\circ} \mathrm{F}$ dp, the average indoor RH exceeded $60 \% \mathrm{RH}$ at a frequency of $65 \%$ of all hours during a 2-day period with the MSHP in standard control mode. Operating the MSHP in its "dry" mode significantly reduced the frequency of RH higher than $60 \%$ to $15 \%$ of all hours during a 9-day low cooling load period. Based on measured data, the MSHP control design could be improved to enhance the humidity control mode. Further details about suggested improvements are discussed in Section 6. 
Salient findings include:

- When using a minimum-efficiency SEER 13 central system, the cost increase for replacing a quiet ENERGY STAR ${ }^{\circledR}$ dehumidifier controlled by a remote dehumidistat with a SEER 21.5 MSHP is less than $\$ 2,400$. The cost difference could be less if special construction is required to accommodate the dehumidifier configuration. In comparison, other options for controlling RH more efficiently than standard dehumidifiers cost around $\$ 2,000$ and would use more energy than the MSHP option. These other options include subcooling reheat, full-condensing reheat, or desiccant dehumidifiers.

- The SEER 13 and SEER 22 systems showed very little energy use difference with MSHP operation. This small difference makes a strong financial case for staying with a lessexpensive fixed-capacity ducted system. The SEER 22 ducted system installed cost was about $\$ 3,250$ more than the installed cost for the SEER 13 ducted system.

- The dehumidifier needed very little supplemental dehumidification with a remote dehumidistat located in the central living room. In tests with the dehumidifier enabled, the average dehumidifier runtime was shorter than $0.1 \%$ on average summer days for SEER 13 configurations $2.5 \%$ dehumidifier runtime for SEER 22 configurations. The tested dehumidifier configurations were estimated to use about 12 times less energy annually than other control designs. Appendix $\mathrm{C}$ provides further details about inefficient dehumidifier control issues.

- The dehumidifier did not operate during peak summer hours for any of the test configurations; therefore, the peak summer power impacts were due to cooling energy use.

- Operating the MSHP as the primary cooling system with a ducted central system as backup resulted in the most significant reduction in summer peak power use. The SEER 13 with OA-to-MSHP configuration used $0.55 \mathrm{~kW}(27 \%)$ less energy than the SEER 13 with OA-to-dehumidifier configuration.

Because codes and building programs require continuous mechanical ventilation in homes, challenges to effectively control indoor RH energy efficiently during low cooling load periods will arise. The industry needs improvements in optimizing RH control and energy efficiency outside the scope of this project; such improvements should be feasible through improved "ventilation mode" HVAC sensors, controls, and improved airflow and refrigerant flow operations of variable-capacity systems.

An optimal design for a variable-capacity cooling system RH control should be able to maximize moisture removal performance by maintaining a cold coil for as long as possible without significantly overcooling the space. It should also be able to prioritize to a maximum cooling efficiency performance when indoor $\mathrm{RH}$ is relatively low. 


\section{Recommendations}

The MSHP test configurations usually demonstrated the lowest space-conditioning energy use and acceptable RH control; however, during low cooling load periods RH slightly exceeded $60 \%$. Variable-capacity systems with humidity control options can apparently provide very good humidity control with some modification in mechanically ventilated homes. Dehumidifiers effectively control humidity in most areas of the home depending upon how and where OA is delivered; however, they have the potential to use a substantial amount of energy. Based on findings from this project, the following recommendations are made:

- High SEER 21.5 variable-capacity ductless MSHPs with OA ducted near the return intake can be used as the primary cooling system to significantly reduce space-cooling and dehumidification energy provided that it is used to displace the cooling load of a minimum-efficiency centrally ducted cooling system. The MSHP has long runtimes that increase the OA mixing and conditioning. The MSHP tested could not maintain indoor RH below $60 \%$ during all hours but can probably do so with some control modifications by the manufacturer.

- Variable-capacity heat pump manufacturers should improve humidity control by modifying the control design to eliminate periods of CFM/ton rates higher than 450 $\mathrm{CFM} /$ ton during dry or RH control modes. Increasing periods of low CFM/ton will further improve RH control. This approach is not recommended for the standard cooling modes, because it will lower system efficiency.

- MSHP and other variable-capacity cooling systems operated in an RH control mode can significantly improve RH control by allowing the lowest stage of cooling to be used for sustained periods of 15 min or longer-particularly during low-load periods. RH control can be further improved by increasing the periods of time of low CFM/ton during lowstage cooling. This tactic will maintain a very cold coil, remove more moisture, and help limit overcooling.

- Short-cycle fan air circulation operation between cooling cycles of MSHP units should be eliminated for improved RH control— particularly for the dry control mode. If fan circulation is required to pass air over the room temperature sensor inside the return air stream of the unit, the first fan cycle after the end of a cooling cycle should be delayed for at least $15 \mathrm{~min}$.

- A centrally ducted system that uses a fan cycler control or other mechanical fan circulation may be needed to maintain acceptable thermal distribution during the hottest months of the year when a ductless MSHP is used as the primary cooling system.

- During the cooling season when using a central fan cycle control, the central system should remain off for at least $20 \mathrm{~min}$ before a fan circulation cycle of about $20 \mathrm{~min}$ is activated. This measure minimizes evaporation of water off the cooling coil and will cause an increase in indoor RH.

- Continuous supply mechanical ventilation should be allowed to mix with dry indoor air before it comes in contact with indoor surfaces to minimize high surface $\mathrm{RH}$ potential on 
cool surfaces. The OA should not be allowed to blow directly upon thermostats or dehumidistats.

- The typical building materials of the MH Lab were not damaged by moisture; however, using moisture-durable building materials and finishes wherever they are likely to be in direct contact with the OA stream is prudent.

- When using a design with unconditioned OA delivered to a cooling system, deliver OA close to and toward the return intakes at velocities lower than those of the cooling system return intake. This will allow OA to mix with some dry indoor air and then be effectively captured, cooled, dehumidified, and distributed by the cooling system when it is on.

- Stand-alone dehumidifiers placed in isolated indoor locations should be controlled by a remote dehumidistat in a central open location and have dehumidified air from the unit ducted to a place where it can be distributed most effectively.

- Dehumidifiers (or dehumidistats) should not be placed inside small isolated closets with OA ducted into the closet and in which only OA enters the closet and all dehumidified air is ducted outside the closet to other indoor spaces. Using this design with the on-board dehumidifier control will result in excessively high energy use and may cause moisture problems inside the closet.

- New mechanically ventilated homes in hot-humid climates should be dehumidification ready. If supplemental dehumidification is not added during construction, builders of mechanically ventilated homes in hot-humid climates should build in the capability for supplemental dehumidification that occupants can add later. This approach requires forethought about siting the electricity service, condensate line, drain pan, and structural support in reasonably accessible locations that allow supplemental dehumidifier installation, service, and maintenance.

Further research is needed to evaluate energy efficiency and RH control effectiveness of other available variable-capacity products. Also of interest are field evaluations of other available OA/dehumidifier systems and controls (besides the simple stand-alone indoor dehumidifier test of this project). Other types of evaluation needed for homes ventilated to ASHRAE 62.2 standards are:

- Field studies of single- versus multiple-OA supply drop locations to determine if singleOA supply ventilation results in acceptable ventilation distribution within various residential designs

- Evaluation of residential-scale dedicated OA systems that use variable-capacity systems that can handle OA in hot-humid climates

- Studies of the impact and effectiveness of runtime vent operation performance on managing $\mathrm{RH}$ in homes

- Evaluation of energy and indoor RH impacts of advanced OA vent controls. 


\section{References}

ASHRAE. 2013. ANSI/ASHRAE Standard 62.2-2013. "Ventilation and Acceptable Indoor Air Quality in Low-Rise Residential Buildings.” Atlanta, GA: American Society of Heating, Refrigerating and Air-Conditioning Engineers, Inc. http://ashrae.org.

Cummings, J., and Withers, C. 2011. Energy Savings and Peak Demand Reduction of a SEER 21 Heat Pump vs. a SEER 13 Heat Pump with Attic and Indoor Duct Systems (Subcontract Report). Golden, CO: National Renewable Energy Laboratory, NREL/SR-5500-53355. www.nrel.gov/docs/fy14osti/53355.pdf.

Cummings, J.; Withers, C. and Kono, J. (2013). Energy and Peak Demand Savings from "Right Sizing" of Fixed Capacity (SEER 13) and Variable Capacity (SEER 22 and 21) Heat Pumps with Attic and Indoor Ductwork for the FPL Service Territory. Cocoa, FL: Florida Solar Energy Center, FSEC-CR-1969-13.

Henderson, H.I. 1990. “An Experimental Investigation of the Effects of Wet and Dry Coil Conditions on Cyclic Performance in the SEER Procedure." Proceedings of USNC/IIR Refrigeration Conference at Purdue University, July 1990, West Lafayette, IN.

Hendron, R. 2008. Building America Research Benchmark Definition (Technical Report). Golden, CO: National Renewable Energy Laboratory, NREL/TP-550-44816.

ICC. 2012a. “International Energy Conservation Code.” International Code Council. Accessed June 2014: http://publicecodes.cyberregs.com/icod/iecc/2012/index.htm?bu=IC-P-2012$\underline{000014 \& b u 2=I C-P-2012-000019 .}$

ICC. 2012b. "International Mechanical Code." International Code Council. Accessed June 2014: http://publicecodes.cyberregs.com/icod/imc/2012/index.htm?bu=IC-P-2012-000005\&bu2=IC-P2012-000019.

Martin, E., Amos, B., Mcilvaine, J., Widder, S., Fonorow, K. 2014. "Measured Cooling Season Results Relating the Impact of Mechanical Ventilation on Energy, Comfort, and Indoor Air Quality in Humid Climates.” American Council for an Energy-Efficient Economy ACEEE Summer Study Proceedings August 19, 2014.

Rudd, A., and Henderson, H. 2007. "Monitored Indoor Moisture and Temperature Conditions in Humid-Climate US Residences.” DA-07-046. ASHRAE Transactions, 113 (1).

Rudd, A., Henderson, H., Bergey, D., and Shirey, D. 2013. “ASHRAE 1449-RP: Energy Efficiency and Cost Assessment of Humidity Control Options for Residential Buildings." Research Project Final Report submitted to American Society of Heating, Refrigerating and AirConditioning Engineers, Atlanta, GA. "Driven Air Infiltration Calculations." ASHRAE HVAC\&R Research Journal 4(2):119-140.

Rudd, A., Lstiburek, J., Eng, P., and Ueno, K. 2005. Residential Dehumidification Systems Research for Hot-Humid Climates (Subcontract Report). Golden, CO: National Renewable Energy Laboratory, NREL/SR-550-36643. www.nrel.gov/docs/fy05osti/36643.pdf. 
Shirey, D., Henderson, H., and Raustad, R. 2006. Understanding the Dehumidification Performance of Air-Conditioning Equipment at Part-Load Conditions. Cocoa Lake, FL: Florida Solar Energy Center, FSEC-CR-1537-05: www.fsec.ucf.edu/en/publications/pdf/FSEC-CR1537-05.pdf.

Shirey III, D. 2008. AC System Equipment Specification, Installation and Operational Options for Improved Indoor Humidity Control. Cocoa Lake, FL: Florida Solar Energy Center, FSECPF-443-08: www.fsec.ucf.edu/en/publications/pdf/FSEC-PF-443-08.pdf .

Walker, I., and Sherman, M. 2007. Humidity Implications for Meeting Residential Ventilation Requirements. Berkeley, CA: Earnest Orlando Lawrence Berkeley National Laboratory, LBNL621822007.

Winkler, J., Christensen, D., and Tomerlin, J. 2014. Measured Performance of Residential Dehumidifiers Under Cyclic Operation (Technical Report). Golden, CO: National Renewable Energy Laboratory, NREL/TP-5500-61076.

Withers, C., and Sonne, J. 2014. Assessment of Energy Efficient Methods of Indoor Humidity Control for Florida Building Commission Research. Cocoa Lake, FL: Florida Solar Energy Center, FSEC-CR-1976-14.

Withers, C., Cummings, J., and Nigusse, B. (2014). Cooling and Heating Seasonal Energy and Peak Demand Impacts of Improved Duct Insulation on Fixed Capacity (SEER 13) and Variable Capacity (SEER 22) Heat Pumps. NREL Draft Final Report May 2014. 


\section{Appendix A: Leaky Nonvented versus Tighter Mechanically Vented Home}

The material presented here is outside the primary focus of the project goals; however, it may be of interest to some who want to learn about the measured energy impacts of making homes more airtight and adding continuous mechanical ventilation. The MH Lab has also been used in previous research projects. This raised an opportunity to share results that compare the leaky lab home with no mechanical ventilation to the same lab home that was made tighter with continuous mechanical ventilation in accordance with ASHRAE 62.2-2013.

The energy impact of adding mechanical ventilation to the tighter house compared to the same building that was much leakier without mechanical ventilation is shown in Figure A-1. The data without mechanical ventilation, "No OA," come from work (Withers et al. 2014) that was performed shortly before this ventilation project began. The "No OA" building represents the same building characteristics except it was not mechanically ventilated to any standard and was much leakier. (It had a measured air leakage of 10.2 ACH50.) The "OA liv.rm." building was tightened to $4.5 \mathrm{ACH} 50$ and had $55 \mathrm{CFM}$ of continuous supply OA provided into the living room. This level of airtightness was chosen because it complies with the upcoming Florida code and International Energy Conservation Code (ICC 2012a) requirement for new home construction to have measured airtightness of 5 ACH50 or lower. The data shown in Figure A-1 noted as "OA liv. rm." denote a test configuration with OA brought into the living room. This configuration is represented with OA supplied directly into living room about $7 \mathrm{ft}$ above the floor and also with OA into the living room about $4 \mathrm{ft}$ above the floor captured at the dehumidifier.

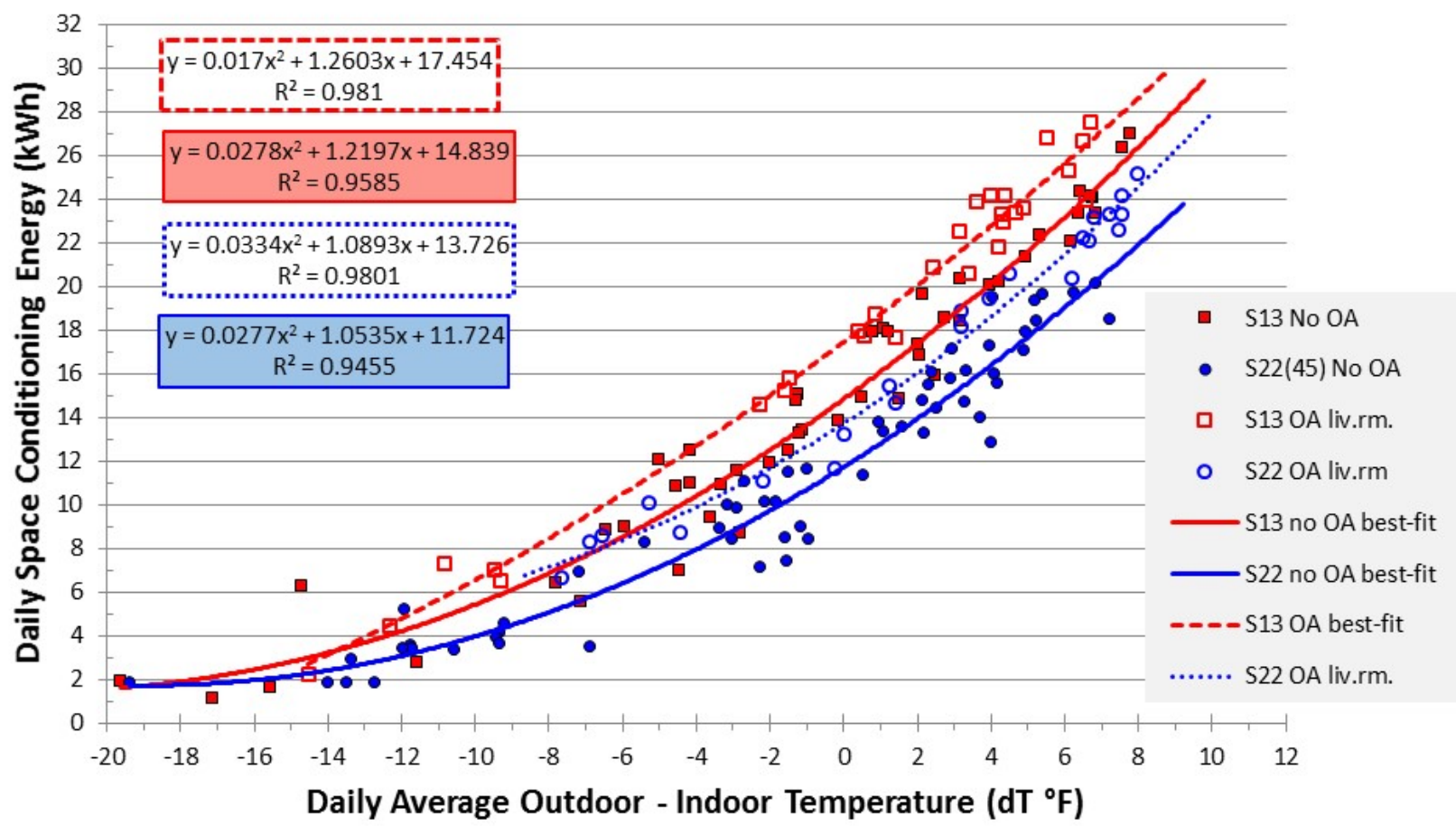

Figure A-1. Daily total cooling and dehumidifier energy plotted against the daily average dT between outdoors and indoors shown for the house lab with and without $O A$ 
Based on a typical hot summer day with average daily $\mathrm{dT}=5^{\circ} \mathrm{F}$ and the regression least-squares best-fit equations, the following energy impacts were calculated:

- Tightening the home and adding ventilation that meets ASHRAE 62.2-2013 increased SEER 13 system energy use $1.05 \mathrm{kWh} /$ day $(5.5 \%)$.

- Tightening the home and adding ventilation that meets ASHRAE 62.2-2013 increased SEER 22 system (with RH control active) energy use $2.90 \mathrm{kWh} /$ day $(18.9 \%)$. The greater impact on the SEER 22 system can be expected, because the added load causes this variable-capacity system to operate at higher capacity. The impact of the delivered capacity as a percentage of its total possible capacity on this variable-capacity system efficiency was demonstrated by Cummings and Withers (2011). These authors showed that although the variable-capacity system is still very efficient, its efficiency decreases as the delivered capacity increases (without the impact of increased OA temperature entering a condenser).

- The SEER 22 system saves cooling energy by about $3.71 \mathrm{kWh} /$ day (19.4\%) compared to the SEER 13 system in the leaky 10.2 ACH50 house without mechanical ventilation.

- The SEER 22 system saves about $1.86 \mathrm{kWh} /$ day (12.1\%) compared to the SEER 13 system in the tighter home (4.5 ACH50) with ASHRAE 62.2-2013 ventilation.

By comparing energy impacts in other occupied mechanically ventilated homes, Martin et al. (2014) found a 9\% increase in cooling energy when continuous exhaust ventilation was used averaging $61 \mathrm{CFM}$ in six homes compared to operating a runtime vent strategy, which averaged only 34 CFM in the same six homes. These energy-efficient high-performance homes had a Home Energy Rating System Index lower than 65 and were located in Gainesville, Florida. They all used fixed-capacity cooling systems. Ventilation strategies were alternated from late June through mid-October 2013. Because the runtime vent delivered an average of only 34 CFM when the central system operated, the daily average rate would be lower than 34 CFM. If the average runtime were $60 \%$, the average runtime ventilation could be 20 CFM. Assuming a runtime of $60 \%$ in the Martin study, the average ventilation differential between continuous exhaust and runtime vent could be about 40 CFM. Thus, an approximately 40 CFM increase resulted in an average 9\% increase in space cooling energy. The continuous exhaust ventilation method is very different than the supply method, because the OA's entry point and conditions are unknown. 


\section{Appendix B: Utility Room Relative Humidity with Outdoor Air at Central Return}

\section{Utility Room Relative Humidity with Outdoor at Centrally ducted Seasonal Energy-Efficiency Ratio 13 Fixed-Capacity Return}

Information in this appendix is provided as supportive material to Section 4.3.2.1. It provides details about humidity levels in the utility room when OA was delivered into it. Indoor RH was controlled well in other sections of the MH Lab with the test configurations where OA was delivered near the central return in the utility room. However, the utility room had periods when the RH exceeded $60 \%$. Observation of the patterns and conditions at which this occurs may be of interest to those who are considering a similar OA delivery method.

Data with the fixed-capacity system operating over several early summer days are shown in Figure B-1. The top plot shows the utility room temperature, $\mathrm{RH}$, and dew point at 1-min intervals. The normal trend of lower $\mathrm{RH}$ occurs during the midday when sensible load is highest and results in a longer cooling runtime. The utility room $\mathrm{RH}$ exceeded $60 \%$ (hourly average) $24 / 156$ hours shown ( $15.4 \%$ of total time). The period average RH was $56.6 \%$. The average utility room dew point was $57.5^{\circ} \mathrm{F}$ dp. The cool surfaces of the AHU and supply ducts showed no notable condensation during this period.

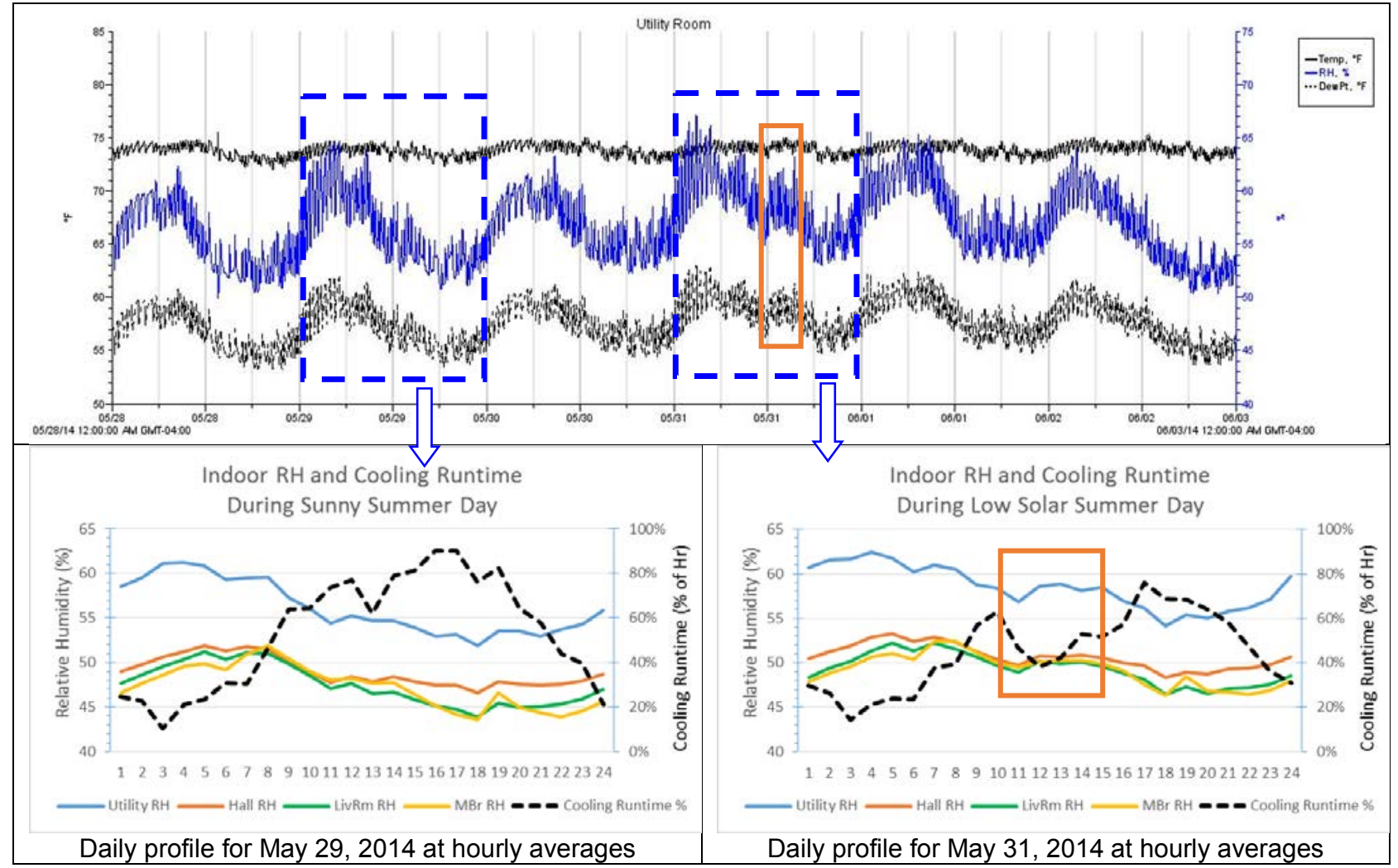

Figure B-1. Indoor conditions comparing a sunny summer to a low solar summer day with OA delivered at SEER 13 central return in the utility room

Two days are highlighted in Figure B-1 with blue dashed rectangles: a summer day with sunny conditions and a cloudy summer day. Both days had average outdoor dew points around $69^{\circ} \mathrm{F} \mathrm{dp}$. 
The orange rectangle notes the low solar daytime period. Directly below the top plot of several days are two plots that show a single daily period during the highlighted sections of the top plot. The lower left plot shows the hourly average indoor $\mathrm{RH}$ and cooling runtime as a percentage of each hour of the day during a sunny summer day. The plot to the right shows the same for a cloudy summer day.

The most notable indoor RH impact is on the utility room where the OA is delivered. During the sunny day, with total horizontal insolation of $7,416 \mathrm{Wh} / \mathrm{m}^{2}$, the utility room $\mathrm{RH}$ exceeded $60 \%$ for 3 of $24 \mathrm{~h}(12.5 \%)$. On the cloudy day, with only $3,719 \mathrm{Wh} / \mathrm{m}^{2}$ of daily total solar, utility room $\mathrm{RH}$ exceeded $60 \%$ for 8 of $24 \mathrm{~h}(33.3 \%)$. Although room RH increased slightly during the low solar daytime period, the hours that exceeded $60 \%$ occurred overnight only and appeared to have nothing to do with the amount of daytime solar radiation on warm summer days. The increase from $3 \mathrm{~h}$ to 8 may seem significant, but upon close inspection, the RH levels from 1 a.m. to 8 a.m. averaged about $60 \%$ for the sunny day and the longer-term average from 1 a.m. to 8 a.m. during the low solar day averaged about $61.2 \%$. Therefore, these levels show little difference, and the hours at $60 \%$ or higher are due to a shorter cooling runtime during low sensible load occurring overnight.

\section{Utility Room Relative Humidity with Outdoor Air at Centrally ducted Seasonal Energy-Efficiency Ratio 22 Variable-Capacity Return}

Data with the variable-capacity system operating over several early summer days are shown in Figure B-2. The top plot shows the utility room temperature, $\mathrm{RH}$, and dew point at 1-min intervals. The normal trend of lower RH occurs during the midday period when the sensible load is highest and results in a longer cooling runtime, just as it did for the fixed-capacity system. The utility room RH exceeded $60 \%$ (hourly averaged) $37 / 217 \mathrm{~h}$ shown (17.1\% of total time). The period average $\mathrm{RH}$ was $56 \%$. The average utility room dew point was $57.2^{\circ} \mathrm{F} \mathrm{dp}$. The cool surfaces of the AHU showed no condensation during this period. 


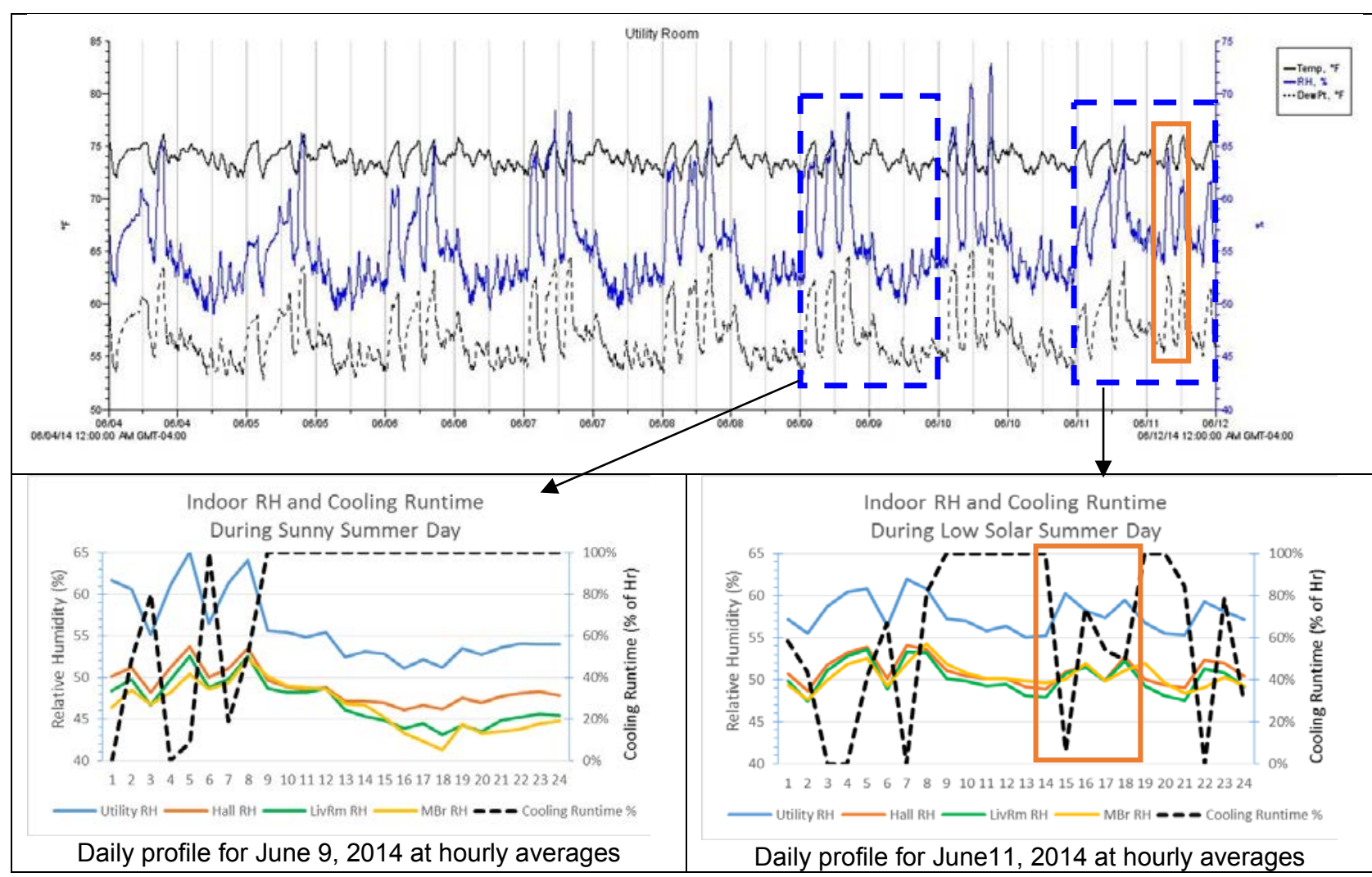

Figure B-2. Indoor conditions comparing a sunny summer day to a low solar summer day with OA delivered at SEER 22 central return in the utility room

Two days are highlighted in Figure B-2 with blue dashed rectangles: a summer day with sunny conditions and a cloudy summer day. Both days had average outdoor dew points around $68^{\circ} \mathrm{F}$ dp. The orange rectangle notes the low solar daytime period. Directly below the top plot of several days are two plots that show a single daily period during the highlighted sections of the top plot. The lower left plot shows the hourly average indoor $\mathrm{RH}$ and cooling runtime as a percentage of each hour of the day during sunny summer day. The plot to the right shows the same for a cloudy summer day.

Again just as with the fixed-capacity system, the most notable indoor RH impact is on the utility room where the OA is delivered. During the sunny day, with total horizontal insolation of 8,131 $\mathrm{Wh} / \mathrm{m}^{2}$, the utility room RH exceeded $60 \%$ for 6 of 24 hours (25\%). The cloudy day, with only $3,056 \mathrm{Wh} / \mathrm{m}^{2}$ of daily total solar, the utility room RH exceeded $60 \%$ for 5 of 24 hours (20.8\%). Although room RH increased slightly during the low solar daytime period, the hours that exceeded $60 \%$ occurred overnight. During two daytime hourly periods (at about 3 p.m. and 6 p.m.) on the low solar day the utility room was at or very near $60 \% \mathrm{RH}$. Both cases occurred when the variable-capacity system had cycled off for 40 min or longer.

On November 23, 2014, weather patterns resulted in a late autumn day with high outdoor moisture (average $69.1{ }^{\circ} \mathrm{F} \mathrm{dp}$ ) and very cloudy conditions (total daily solar energy $2,393 \mathrm{Wh} / \mathrm{m}^{2}$ ). This type of day represents the most challenging for controlling moisture when the outdoor moisture content is high and the exterior cooling load to drive air-conditioning runtime is very 
low. These types of days occur in Florida periodically, generally from late August through February.

On this particular day, the daily average indoor RH was $61.2 \%$ in the utility room and $54 \%-55 \%$ elsewhere in the house. The hourly indoor RH data for this day are shown in Figure B-3. Only in the utility room did the indoor RH exceed $60 \%$ on this day. Twelve of $24 \mathrm{~h}(50 \%)$ had utility room $\mathrm{RH}$ higher than $60 \%$. Eight of $24 \mathrm{~h}(33.3 \%)$ had indoor RH of $65 \%-70 \%$. The indoor utility room RH did not exceed 70\%. The dehumidifier (located in the living room) had four operational cycles that can be observed by the brown dashed line representing the percentage of hourly runtime shown in Figure B-3. The dehumidifier runtimes were 19-24 min long and consumed $0.859 \mathrm{kWh}$ for the day.

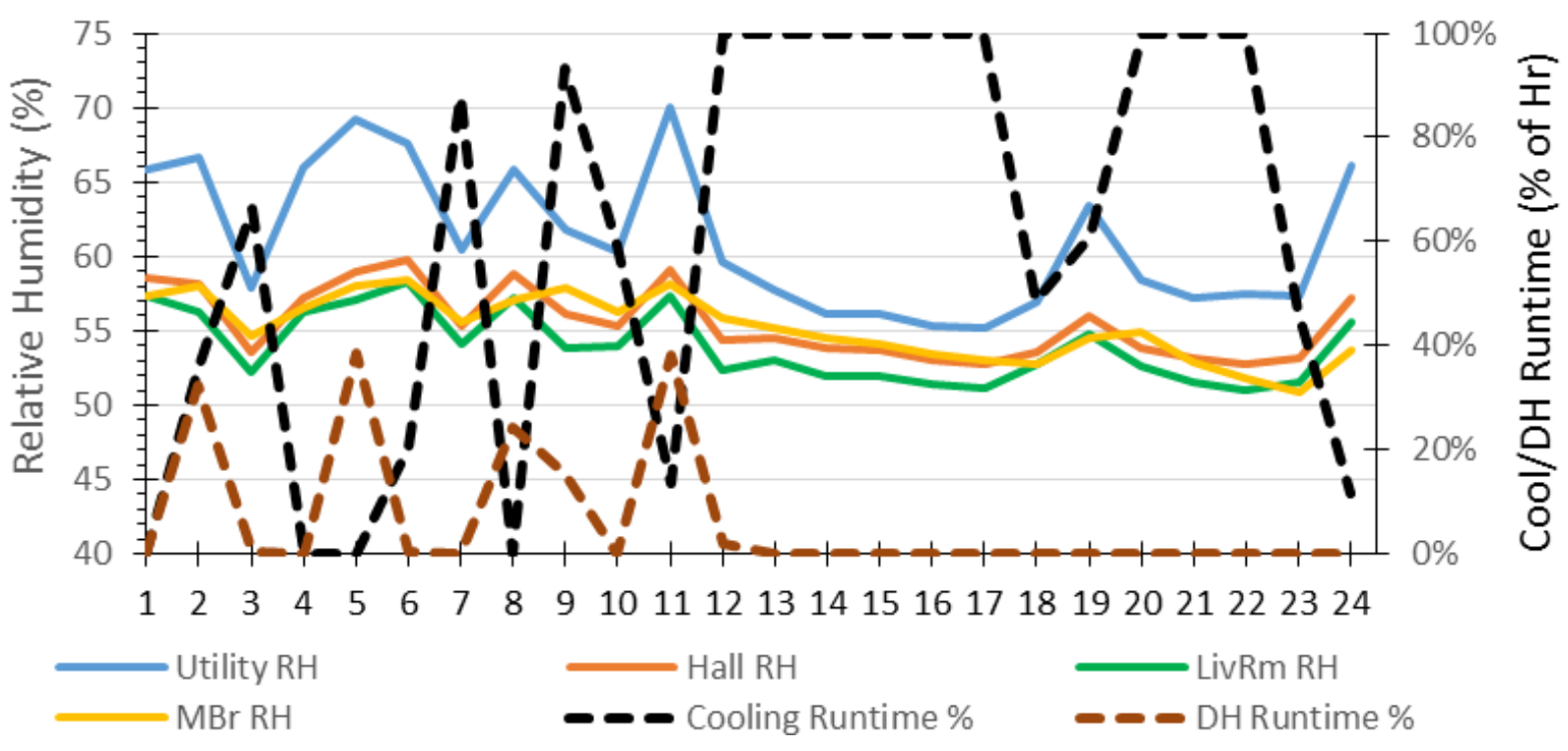

Figure B-3. Indoor RHs and space-conditioning runtimes with OA supplied at SEER 22 central return in utility room when outdoor dew point was $69^{\circ} \mathrm{F} \mathrm{dp}$ and with low solar radiation on November 23, 2014 


\section{Appendix C: Challenges of Supplying Outdoor Air to Small Rooms or Closets}

Ventilation air may be supplied to a small utility room near a central return intake, as was done in this project or even to small mechanical closets or directly into the central return plenum. However, moisture problems - and even increased energy use - may result under certain conditions. This section addresses potential causes for wasteful dehumidifier operation and moisture issues related to OA delivery into small spaces.

The potential for excessive dehumidifier energy will be discussed first. The key to optimal dehumidifier energy use is to have an RH sensor control location that is reasonably representative of indoor RH conditions and not directly impacted by high RH sources such as OA. Dehumidifier energy use is directly impacted by the RH level at the RH control sensor. Consider an example of a dehumidifier placed within a small interior closet, where the OA passes through the closet and out to another terminal location. A quick review of TMY data from hot-humid climate areas shows that outdoor RH will exceed $60 \%$ during $80 \%$ of the annual hours in hot-humid climates. In a worst-case design, the dehumidifier could run $80 \%$ of the year. Much of this operation is not necessary during moderate to high cooling load periods and causes the interior RH to drop lower than necessary during such periods, because the space-cooling equipment provides adequate dehumidification.

An estimate of the potential worst-case annual energy use is offered here. Based on TMY data and an assumed dehumidifier runtime of about $80 \%$, the 70 pint/day rated ENERGY STAR dehumidifier used in this study had a measured power consumption of $564 \mathrm{~W}$. This could consume an average of $10.8 \mathrm{kWh}$ /day instead of the occasional $0.5-0.9 \mathrm{kWh} /$ day observed in the design used in this project. A conservative estimate based on this comparison indicates a poor mechanical ventilation/dehumidifier design could use 12 times more energy than necessary. Another comparison can be made to results from Rudd et al. (2005), who found that using a stand-alone dehumidifier located inside a ducted closet with only $1 / 3$ OA and 2/3 indoor air mixture passed over on-board humidity control resulted in average dehumidifier energy use around $9 \mathrm{kWh}$ /day. An even higher energy use would be expected if the OA were not mixed with drier house air. A conservative comparison between the Rudd et al. study and the remote living space RH control design indicates the enclosed RH control influenced by high RH OA could use at least 10 times the dehumidifier energy.

Now consider an example similar to this project in which a remote $\mathrm{RH}$ control is used in a central living room location away from the direct impact of the OA. The OA was also able to mix with indoor air before reaching the dehumidifier RH control. In this particular case, the dehumidifier did not operate on hot days and ran very little during low cooling load periods. On days when the dehumidifier operated, the dehumidifier energy represented an average of only about $9 \%$ of the total space-conditioning energy use each day.

The challenge of greatest concern is avoiding moisture problems, particularly in spaces where $\mathrm{OA}$ enters the home. If remote $\mathrm{RH}$ control is used, energy is conserved, but long-term elevated $\mathrm{RH}$ within the closet/plenum presents a risk of moisture issues. Building this type of space like a bathroom shower space could be a way to make it more resilient to high $\mathrm{RH}$ exposure. No moisture-related problems were observed with the small capture plenum used with the 
dehumidifier in the lab experiments. The plenum was constructed of foil-faced insulation board sealed with foil tape. This material worked within the confines of the research project but is not suggested as a durable interior finish for dehumidifier closets. Moisture-related problems may vary from mild to severe. Mild issues related to elevated humidity may only result in occupant discomfort some of the time. An example of a moderate issue could be condensation on cold supply air equipment sources for short durations. Severe issues may arise from prolonged periods of high humidity that increase the potential for occupant health-related problems and building material degradation. Indoor moisture issues are most likely to arise during low cooling load periods with $\mathrm{OA}$ dew point higher than about $60^{\circ} \mathrm{F} \mathrm{dp}$. This appendix further discusses observed impacts of supplying OA to a utility room and considerations about the potential for moisture problems in doing so.

The hourly average RH in the OA air stream brought into the test home exceeded $60 \%$ for 3,636 hours from June 1 to December 1, 2014 (85.1\% of the 6-month period). By comparison, TMY data indicate that outdoor RH exceeds $60 \%$ about $82 \%$ of the year. The RH of the OA varies depending upon the absolute moisture content and the dry bulb temperature of the air. The OA was not ducted through the attic, which would have increased the temperature and lowered the average RH during cooling periods. Allowing OA to mix with dry indoor air helps the OA RH to decrease. In fact, Rudd et al. (2005) used a ratio of three parts indoor air mixed with one part OA to avoid condensation. The drying potential of mixing indoor air with OA depends upon the ratio of room air used and the dryness of the room air. The RH in the OA will not decrease significantly if the indoor air is not reasonably dry.

The indoor RH was lower than $60 \%$ during all hours in primary habitable rooms (bedrooms, living room, and dining room) during warm humid summer periods, but not so in the utility room where OA was supplied. Table $\mathrm{C}-1$ shows a daily average indoor $\mathrm{RH}$ comparison between the utility room and average of three other indoor locations representing the days shown in Figure B1 through Figure B-3 of Appendix B. The three locations are in the hallway near two bedrooms, in the central living room, and in the master bedroom. The indoor RH is consistently higher in the utility room than in the other three locations, as expected. The average difference between the utility room RH and other indoor locations is $7.8 \%$. The difference appears to decrease with lower cooling load and increasing interior humidity.

Table C-1. Daily Average Indoor RH Comparison between Utility Room with OA Supply and Average of Three Other Indoor Locations during Different Types of Weather

\begin{tabular}{c|c|c|c}
\hline & $\begin{array}{c}\text { Utility Room RH } \\
(\mathbf{\%})\end{array}$ & $\begin{array}{c}\text { Average Indoor RH } \\
\mathbf{( \% )}\end{array}$ & $\begin{array}{c}\text { Delta } \\
(\mathbf{\%} \text { RH) }\end{array}$ \\
\hline SEER 13 Sunny Summer & 56.2 & 48 & $8.2 \%$ \\
SEER 22 Sunny Summer & 55.9 & 47.6 & $8.3 \%$ \\
SEER 13 Cloudy Summer & 58.5 & 49.7 & $8.8 \%$ \\
SEER 22 Cloudy Summer & 57.7 & 50.5 & $7.2 \%$ \\
\hline SEER 22 Cloudy Autumn & 61.2 & 54.8 & $6.4 \%$ \\
\hline Average & 57.9 & 50.1 & $7.8 \%$ \\
\hline
\end{tabular}

Utility room humidity was $60 \%-65 \%$ for approximately 6 of 24 hours of the day $(25 \%)$ during hot or warm humid weather. Because this elevated $\mathrm{RH}$ occurs during the early morning period from 12 a.m. to 8 a.m., the proportion of $\mathrm{RH}$ higher than $60 \%$ is much higher for about 6 of 8 
hours $(75 \%$ of the early morning period). These conditions occurred when outdoor dew points were $68^{\circ}-70^{\circ} \mathrm{F} \mathrm{dp}$. The utility room volume was about 9.4 times the OA volume $\left(517 \mathrm{ft}^{3}\right) /(55$ $\left.\mathrm{ft}^{3} / \mathrm{min}\right)$.

A word of caution is noted here about dropping high dew point OA into utility spaces. It is beneficial to allow as much mixing of OA with dry indoor air before capture at central returns, because this will lower the dew point and decrease condensation potential and other moisturerelated issues. Adequately insulated AHU and moisture-durable materials in wall, ceiling, and floor construction are also important. The MH Lab had a ceramic tile floor and typical drywall and paint finish on walls and ceiling. No moisture-related issues such as mold, mildew, or condensation were observed; however, conditions may occur in other homes that may result in moisture issues.

Assume the following conditions for $\mathrm{OA}$ at $75^{\circ} \mathrm{F}$ dp and an interior wall surface temperature at $76^{\circ} \mathrm{F}$. The $\mathrm{RH}$ at wall surface could potentially be as high as $97 \%$ without any dry indoor air mixing with OA at the wall surface. Such a case could be possible if unconditioned OA were blown directly onto the cool wall surface. Space-cooling equipment surfaces should be insulated well, but some parts of the AHU may easily have exterior surfaces of $70^{\circ} \mathrm{F}$ or cooler. Areas that are not adequately insulated may have parts of surfaces cooler than $60^{\circ} \mathrm{F}$ during cooling cycles. Such conditions have a high potential for moisture condensation.

If OA is dropped into utility rooms or closets, these spaces should be constructed of moisturedurable materials and finishes. The OA should be delivered in a way to enhance mixing of the dry indoor air with the OA to lower the dew point, which will help lower the potential for high surface RH and condensation. Table C-2 shows two hypothetical examples of the amount of indoor air needed to result in a mixture at a marginal $60 \% \mathrm{RH}$ and at 55\% $\mathrm{RH}$.

Table C-2. Indoor Airflow Rate Required To Produce a Mixture with OA at $60 \%$ RH and $55 \% \mathbf{R H}^{*}$

\begin{tabular}{c|c|c}
\hline & $\begin{array}{c}\text { OA/Indoor Air Mix at } \\
\mathbf{6 0 \%} \mathbf{R H}\end{array}$ & $\begin{array}{c}\text { OA/Indoor Air Mix at 55\% } \\
\text { RH }\end{array}$ \\
\hline $\begin{array}{c}\text { Indoor Airflow Rate } \\
\text { (CFM) }\end{array}$ & 57 & 130 \\
\hline
\end{tabular}

Indoor conditions at $77.2^{\circ} \mathrm{F}$ and $54.7^{\circ} \mathrm{F}$ dp mixed with $\mathrm{OA}$ at $55 \mathrm{CFM}$ at $84.8^{\circ} \mathrm{F}$ and $75^{\circ} \mathrm{F}$ dp.

If the indoor conditions are not dry enough, no reasonable amount of indoor air mixed with OA can keep the mixture lower than $60 \% \mathrm{RH}$. Consider the challenging conditions shown in the psychrometric chart in Figure $\mathrm{C}-1$ with $\mathrm{OA}$ at a high outdoor dew point of $75^{\circ} \mathrm{F} \mathrm{dp}\left(75^{\circ} \mathrm{F}, 100 \%\right.$ $\mathrm{RH})$ and the lowest point at indoor condition of $60.6^{\circ} \mathrm{F} \mathrm{dp}\left(75^{\circ} \mathrm{F}, 60.8 \% \mathrm{RH}\right)$. These conditions are examples of outdoor conditions that are known to occur overnight or during stormy conditions and of moist indoor conditions that are known to occur in the utility room for some hours when the cooling load is low and the central cooling has been cycled off for an hour or more. The process of converting the OA to the indoor air qualities would require $2,027 \mathrm{Btu} / \mathrm{h}$ latent removal and $0 \mathrm{Btu} / \mathrm{h}$ sensible $(\mathrm{SHR}$ load $=0.00)$ under these extreme conditions. Without substantial interior sensible loads, the space cooling would stay off for some time and moisture would continue to be added to the conditioned space. 
The point in Figure C-1, labeled "mixture," shows the conditions that could occur at the beginning of a cooling cycle in which 745 CFM of indoor air mixes with 55 CFM of OA and results in about $63.5 \% \mathrm{RH}$. This is a best-case scenario for this mixture assuming perfect mixing. This would not likely occur without a well-engineered design.

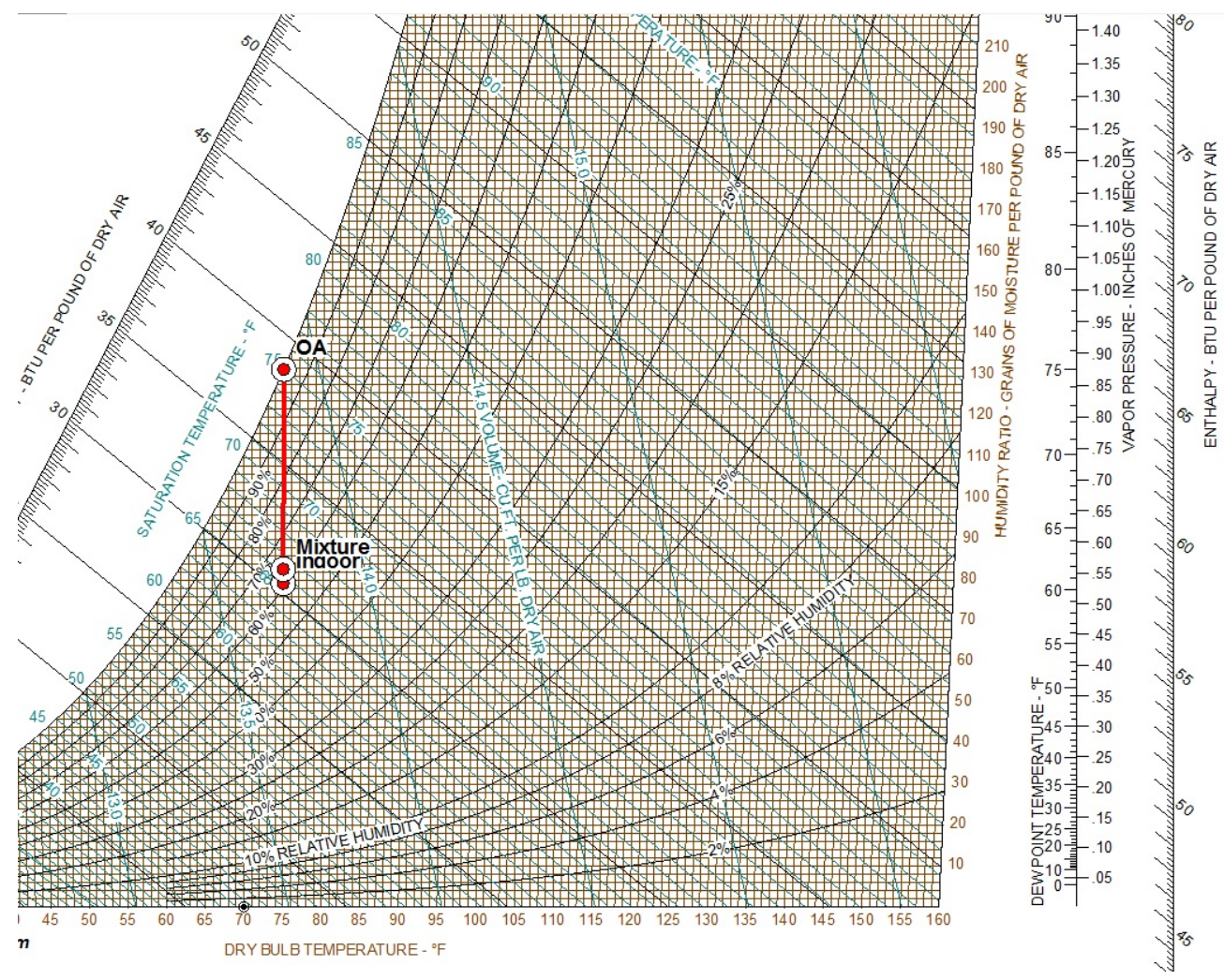

Figure C-1. Process of mixing $55 \mathrm{CFM}$ humid OA with moist $750 \mathrm{CFM}$ indoor air with both at $75^{\circ} \mathrm{F}$ dry bulb results in a mixture at about $63.5 \% \mathrm{RH}$

Under these extreme conditions, no amount of indoor air mixture can result in an RH mixture lower than $60 \%$. In practical effort, if the flow rate of the central system is relied upon to supply indoor air for mixing, it would not exceed about $93 \%$ of the system total airflow when OA makes up the other 7\%. In the case of the research lab home, the nominal $800 \mathrm{CFM}$ system flow comprised about 745 CFM indoor air mixed with 55 CFM OA. Table C-3 shows the resulting $\mathrm{RH}$ of the mixture at a best practical case scenario with indoor air mixture flow of $745 \mathrm{CFM}$. The resulting $\mathrm{RH}$ when the indoor mix rate is only 57 CFM is also shown for comparison to Table C2. Clearly, having dry indoor air to work with can be beneficial for periods of time when the cooling load is low and the outdoor moisture content is high.

Table C-3. Resulting RH for Two Moist Indoor Air Mix Rates at $75^{\circ} \mathrm{F}$ and $60.6^{\circ} \mathrm{F} \mathrm{dp}$ When Mixed with $\mathrm{OA}$ at $55 \mathrm{CFM}$ at $75^{\circ} \mathrm{F}$ and $75^{\circ} \mathrm{F}$ dp

$$
\begin{array}{cc}
\text { Indoor Air Mix Rate } & \text { Indoor Air Mix Rate } \\
\text { at } 750 \mathrm{CFM} & \text { at } 57 \mathrm{CFM}
\end{array}
$$

\section{Resulting \% RH of \\ $\mathrm{OA}$ and Indoor Air Mix}

$63.5 \%$

$79.8 \%$ 


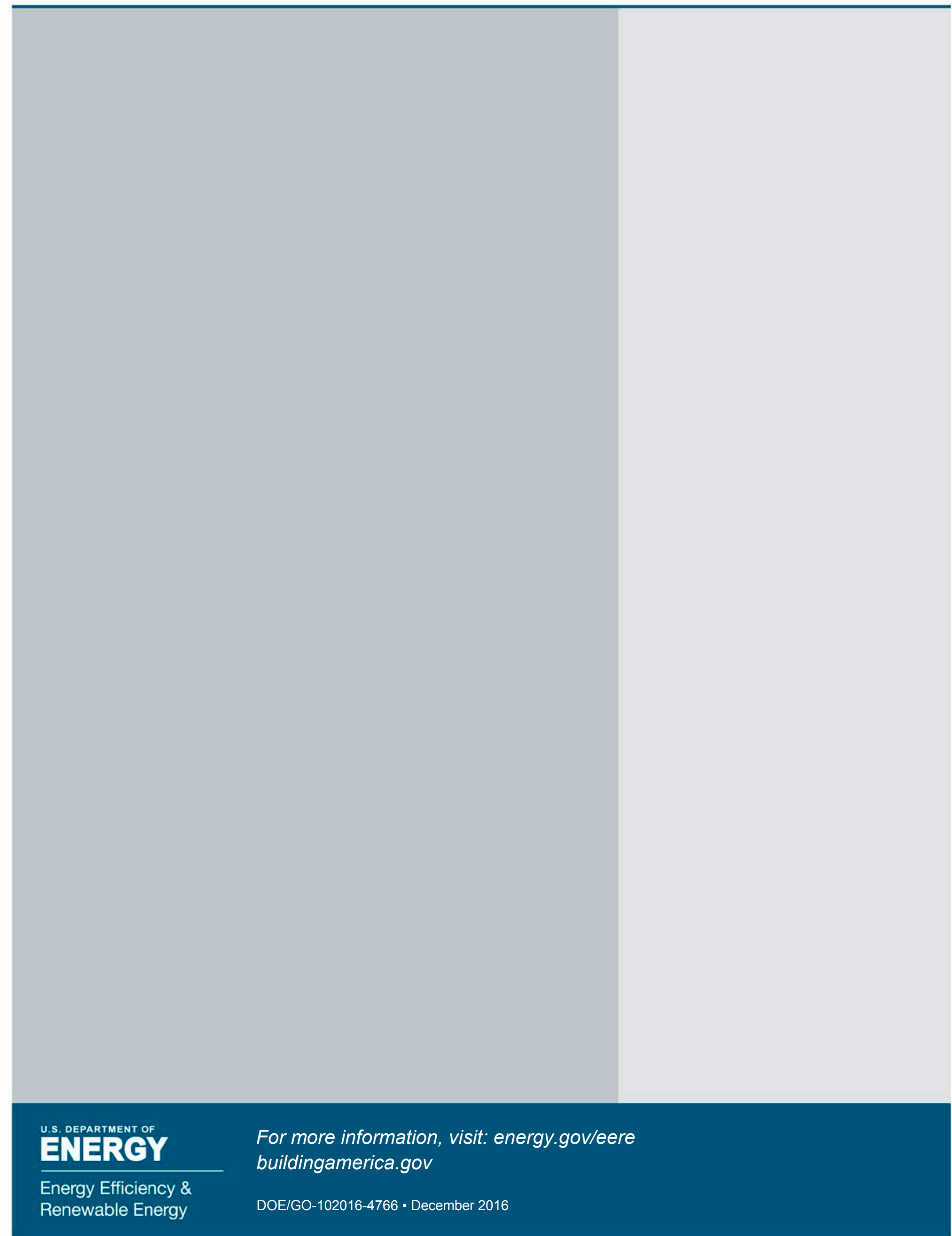

